\author{
Universidade de São Paulo \\ Faculdade de Medicina de Ribeirão Preto \\ Programa de Mestrado Profissional em Gestão de Organizações de Saúde
}

Gustavo Davoli

Análise das distorções entre os componentes da remuneração dos prestadores de saúde e os custos dos serviços em oncologia na saúde suplementar brasileira 


\section{Gustavo Davoli}

\section{Análise das distorções entre os componentes da remuneração dos prestadores de saúde e os custos dos serviços em oncologia na saúde suplementar brasileira}

Dissertação apresentada ao Programa de Mestrado Profissional em Gestão de Organizações de Saúde da Faculdade de Medicina de Ribeirão Preto da Universidade de São Paulo para a obtenção do título de Mestre em Ciências.

Orientador: Prof. Dr. Carlos Alberto Gabrielli Barreto Campello

Ribeirão Preto 


\section{AUTORIZO A REPRODUÇÃO E DIVULGAÇÃO TOTAL OU PARCIAL DESTE TRABALHO, POR QUALQUER MEIO CONVENCIONAL OU ELETRÔNICO, PARA FINS DE ESTUDO OU PESQUISA, DESDE QUE CITADA A FONTE.}

\section{FICHA CATALOGRÁFICA}

Davoli, Gustavo,

Análise das distorções entre os componentes da remuneração dos prestadores de saúde e os custos dos serviços em oncologia na saúde suplementar brasileira.

Ribeirão Preto, 2017.

86 p.: il. ; $30 \mathrm{~cm}$

Defesa de Mestrado Profissional em Gestão de Organizações de Saúde apresentada à Faculdade de Medicina de Ribeirão Preto, Universidade de São Paulo. Área de concentração: Ciências

Orientador: Prof. Dr. Carlos Alberto Gabrielli Barreto Campello

1. Remuneração na saúde. 2. Custos em saúde. 3. Oncologia. 4. Saúde suplementar. 


\section{FOLHA DE APROVAÇÃO}

\section{Nome: DAVOLI, Gustavo}

Título: Análise das distorções entre os componentes da remuneração dos prestadores de saúde e os custos dos serviços em oncologia na saúde suplementar brasileira.

Dissertação apresentada ao Programa de Mestrado Profissional em Gestão de Organizações de Saúde da Faculdade de Medicina de Ribeirão Preto da Universidade de São Paulo para a obtenção do título de Mestre em Ciências.

Aprovado em:

Banca examinadora

Prof. Dr.

Instituição: Assinatura:

Prof. Dr.

Instituição: Assinatura:

Prof. Dr.

Instituição: Assinatura: 


\section{Agradecimentos}

A minha amada esposa Elaine e aos meus amados filhos Luiza, Lucas e Léo, que me incentivaram e souberam compreender a importância de ter me dedicado a este estudo, sacrificando preciosos momentos de convívio.

Aos meus queridos pais João e Zélia e aos meus queridos irmãos Guerino e Silvia, que nunca mediram esforços para me oferecerem as bases para o meu crescimento pessoal e profissional que são a educação, os valores e a liberdade de escolha.

Aos professores André e Campello, pelo incentivo, direcionamento e inspiração.

Aos meus colegas e amigos conquistados na vida profissional, representados nas figuras do Albino e do Dr Julião do InORP, pela convivência e aprendizado constantes. As vitórias obtidas sempre foram consequências.

Acima de tudo, a Deus, motivo, origem e fim de todas as coisas. 
DAVOLI, Gustavo. Título: Análise das distorções entre os componentes da remuneração dos prestadores de saúde e os custos dos serviços em oncologia na saúde suplementar brasileira. 2017. 86f. Defesa (Mestrado Profissional em Gestão de Organizações de Saúde) Faculdade de Medicina de Ribeirão Preto, Universidade de São Paulo, Ribeirão Preto, 2017.

\section{Resumo}

A Saúde Suplementar atua como uma alternativa para aproximadamente $25 \%$ da população brasileira que buscam maior facilidade no acesso aos serviços de saúde e maior qualidade. Porém, os problemas enfrentados e a insatisfação dos principais atores do segmento (operadoras de planos de saúde, prestadores de serviços e usuários) assemelham-se às dificuldades amplamente vivenciadas no Sistema Único de Saúde - SUS.

O fator econômico é uma das principais causas dessa insatisfação: operadoras com baixas margens de lucro ou deficitárias afirmam pagar muito aos prestadores; prestadores com baixas margens de lucro ou deficitários afirmam receber pouco; e, o usuário pagando muito e insatisfeito com a oferta dos serviços.

Este trabalho analisou, durante todo o exercício de 2015, os componentes da remuneração de uma clínica oncológica e a participação de cada um desses componentes em relação ao total da remuneração e traçou um comparativo com a estrutura de custos desses mesmos itens, que também foram analisados em relação ao total dos custos. A remuneração pelos serviços médicos representou $2 \%$ do total de receitas, enquanto o desembolso com as equipes médicas representou $14 \%$ do total dos gastos. As taxas que remuneram a estrutura física, equipes de profissionais não médicos, todos os demais gastos e o capital investido representaram $2 \%$ do total de receitas, enquanto o custo com estes itens representou 44\%. Já a remuneração referente aos materiais e medicamentos utilizados no tratamento quimioterápico representou $96 \%$ do total das receitas, enquanto o custo desses materiais e medicamentos representou $42 \%$ do total. Com isso, verificou-se existência de distorções na participação de cada item em relação ao total, confrontando a estrutura de custo com a estrutura de remuneração. Além disso, analisando a média da remuneração paga pelas operadoras de saúde suplementar por uma consulta médica, encontrou-se a proporção de $19 \%$ de seu custo unitário e, no caso de um tratamento de quimioterapia, esta proporção fica em torno de $10 \%$ de seu custo unitário, excluindo o efeito do custo e da remuneração com os materiais e medicamentos utilizados.

Tal análise ganha importância, pois apesar da sistemática de remuneração dos prestadores na saúde suplementar possuir, há um bom tempo, um modelo estável e equilibrado, nos últimos anos as operadoras de planos de saúde vêm pressionando os prestadores de serviços, reduzindo as tabelas de remuneração dos materiais e medicamentos e provocando um potencial desequilíbrio nas relações comerciais e na sustentabilidade dos prestadores de serviços. Por isso, o entendimento real da relação entre os componentes da remuneração confrontando com seus respectivos custos, torna-se um subsídio importante para discussões de novos arranjos, sem que se gere um desequilíbrio no atual sistema.

Palavras-chave: remuneração na saúde, custos em saúde, oncologia, saúde suplementar 
DAVOLI, Gustavo. Título: Analysis of the distortions between the components of the remuneration of health care providers and the services costs in oncology in Brazilian supplementary health. 2017. 86f. Defesa (Mestrado Profissional em Gestão de Organizações de Saúde) - Faculdade de Medicina de Ribeirão Preto, Universidade de São Paulo, Ribeirão Preto, 2017.

\begin{abstract}
Supplementary Health acts as an alternative to approximately $25 \%$ of the Brazilian population that seek greater ease in accessing health and higher quality services. However, the problems faced and the dissatisfaction of the main actors in the segment (health plan operators, service providers and users) are similar to the difficulties that are widely experienced in the Unified Health System - SUS.

The economic factor is one of the main causes of this dissatisfaction: operators with deficit or low profit margins claim to pay the providers a lot; Providers with deficit or low profit margins claim to receive little; And the user who is paying a lot and is dissatisfied with the offer of the services.

This study analyzed the components of an oncology clinic's remuneration during the entire year of 2015 and the participation of each of these components in relation to the total remuneration, and outlined a comparison with the cost structure of the same items, which were also analyzed in relation to total costs. Medical services compensation accounted for $2 \%$ of total revenues, while medical team disbursement accounted for $14 \%$ of total expenditures. The rates which remunerate the physical structure, the non-medical professional teams, all other expenses and the invested capital represented $2 \%$ of total revenues, while the cost of these items represented 44\%. Material and drug remuneration used in chemotherapy treatment accounted for $96 \%$ of total revenues, while the cost of these materials and drugs accounted for $42 \%$ of the total. Hence, there was a distortion in the participation of each item in relation to the total, comparing the cost structure to the compensation structure. In addition, analyzing the remuneration median paid by supplementary health care providers for a medical consultation, the proportion of $19 \%$ of their unit cost was found and, in the case of a chemotherapy treatment, this proportion is around $10 \%$ of its unit cost.

Such analysis gains importance, because despite of the supplementary health providers have been having a stable and balanced remuneration systematic model, in recent years health plan operators have been pressing service providers, reducing the material and medicines remuneration tables and causing a potential imbalance in the trade relations and in the service provider's sustainability. Therefore, the real understanding of the relationship between the remuneration components compared to their respective costs becomes an important subsidy for new arrangement discussions, without generating an imbalance in the current system.
\end{abstract}

Keywords: health remuneration, health costs, oncology, supplementary health 


\section{Lista de Figuras}

Figura 1 - Equação de valor adaptada para a área da saúde...................................................15

Figura 2 - Relação Contratual entre os Agentes no Mercado de Saúde Suplementar.................18

Figura 3 - Proposta de nova sistemática de remuneração para hospitais....................................39

Figura 4 - Macro Fluxograma do paciente para uma consulta oncológica................................44

Figura 5 - Macro Fluxograma do paciente encaminhado para tratamento de quimioterapia......46 


\section{Lista de Gráficos}

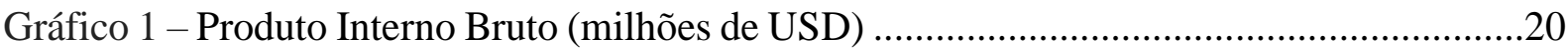

Gráfico 2 - Produto Interno Bruto per capita (USD) …...................................................21

Gráfico 3 - Gasto total per capita com saúde (milhões de USD) ….......................................22

Gráfico 4 - Número de Operadoras de Planos Médico-Hospitalares e Odontológicos..............26

Gráfico 5 - Número de Beneficiários de Planos Médico-Hospitalares e Odontológicos...........27

Gráfico 6 - Taxa de Crescimento de Beneficiários de Planos Médico-Hospitalares e

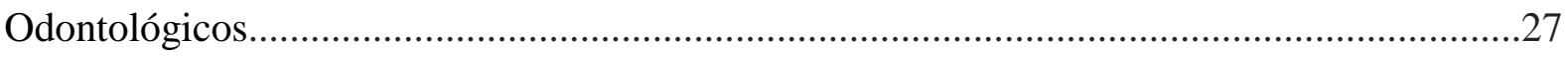

Gráfico 7 - Análise comparativa da participação de cada componente em relação ao total da

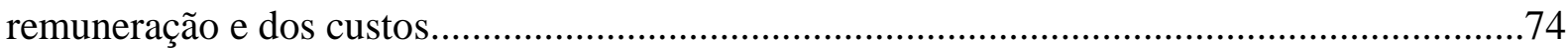

Gráfico 8 - Comparativo entre a remuneração unitária e o custo unitário..................................76 


\section{Lista de Quadros}

Quadro 1 - Relatório anual de receitas por fonte pagadora.................................................47

Quadro 2 - Estrutura de Remuneração X Custos.......................................................................48

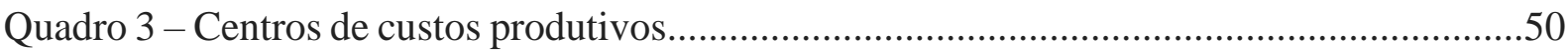

Quadro 4-Centros de custos produtivos objeto do estudo (resumidos) ..................................50

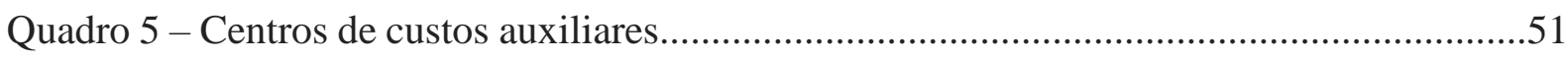

Quadro 6 - Centros de custos Administrativos...................................................................51

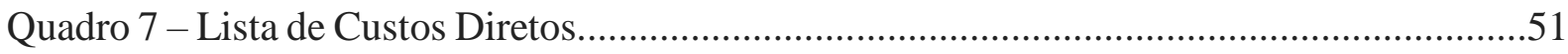

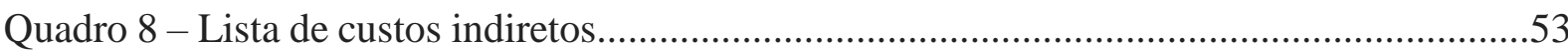

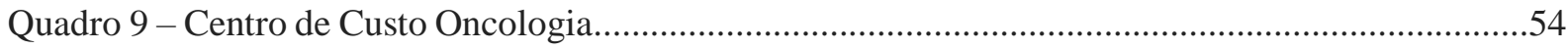

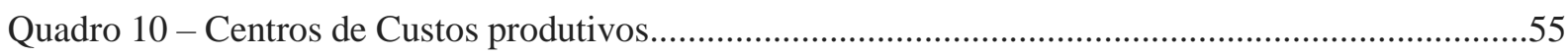

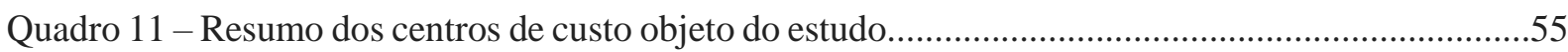

Quadro 12 - Comparativo entre a remuneração (mediana) e o respectivo custo do procedimento

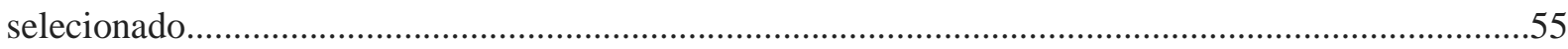




\section{Lista de Tabelas}

Tabela 1 - Apuração anual das receitas em 2015

Tabela 2 - Total das receitas, segmentada de acordo com os critérios desejados no estudo.......57

Tabela 3 - Comparativo com valores e percentuais confrontando as receitas com seus

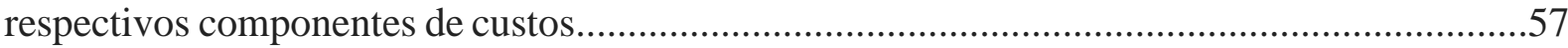

Tabela 4 - Cálculo do custo de pessoal próprio, terceirizado e equipe médica............................59

Tabela 5 - Rateio de aluguel e impostos, proporcional por área ocupada.................................60

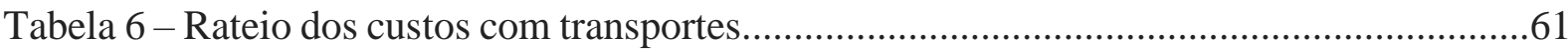

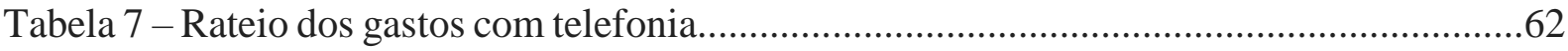

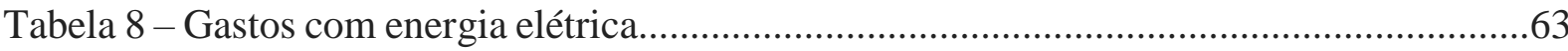

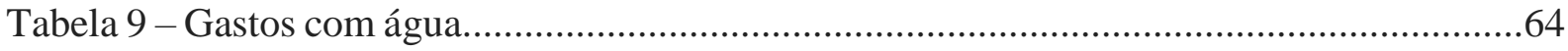

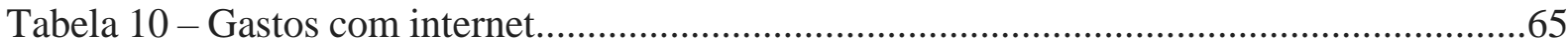

Tabela 11 - Gastos com materiais e medicamentos.............................................................66

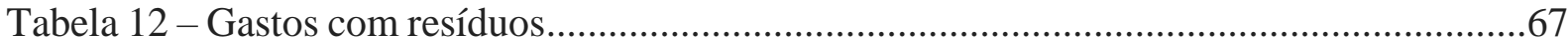

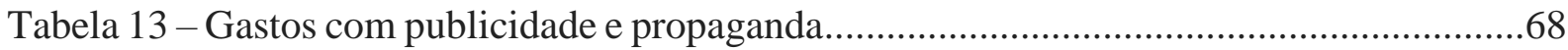

Tabela 14 - Custo total e unitário dos centros de custo produtivos......................................................69

Tabela 15 - Extrato individualizado do centro de custo oncologia (101) ................................70

Tabela 16 - Extrato individualizado do centro de custo quimioterapia (109) ..........................71

Tabela 17 - Valores da consulta médica e taxa de sala de infusão por Operadora de Plano de Saúde....72

Tabela 18 - Comparativo entre a remuneração e o custo unitário dos procedimentos.................73 


\section{Lista de Siglas e Abreviaturas}

AMB - Associação Médica Brasileira

ANS - Agência Nacional de Saúde Suplementar

ANVISA - Agência Nacional de Vigilância Sanitária

CADOP - Sistema de Cadastro de Operadoras

CBHPM - Classificação Brasileira Hierarquizada de Procedimentos Médicos

CFM - Conselho Federal de Medicina

$\mathrm{CH}$ - Coeficiente de Honorário

CID - Código Internacional de Doenças

$\mathrm{CL}-$ Consulta

CMED - Câmara de Regulação do Mercado de Medicamentos

CNES - Cadastro Nacional de Estabelecimentos de Saúde

CNPJ - Cadastro Nacional de Pessoa Jurídica

DRE - Demonstrativo de Resultado do Exercício

DRG - Diagnosis Related Groups

FENAM - Federação Nacional dos Médicos

FMI - Fundo Monetário Internacional

IBGE - Instituto Brasileiro de Geografia e Estatística

KM - Quilômetro

KW/H - Quilowatts/hora

LPM - Lista de Procedimentos Médicos

MAT/MED - Materiais e Medicamentos

MS - Ministério da Saúde

$\mathrm{M}^{2}$ - Metro Quadrado

OPME - Órteses, Próteses e Materiais Especiais

PIB - Produto Interno Bruto

PF - Preço Fábrica

PMC - Preço Máximo ao Consumidor

RDC - Resolução da Diretoria Colegiada

RN - Resolução Normativa

SADT - Serviço de Apoio Diagnóstico Terapêutico

SIB - Sistema de Informação de Beneficiários 
SUS - Sistema Único de Saúde

TUSS - Terminologia Unificada em Saúde Suplementar 


\section{Sumário}

1. Introdução

2. O universo das operadoras de planos de saúde e dos prestadores de serviços de saúde no Brasil - visão geral e específica na oncologia

2.1 Modelo vigente 18

2.2 O Universo das Operadoras de Planos de Saúde 23

2.3 O Universo dos Prestadores de Serviços Privados de Assistência à Saúde 29

3. Sistemas e formas de remuneração: Hospitais e médicos 31

3.1 Remuneração por Procedimento - "fee for service" 32

\subsection{Capitation} 33

3.3 Trabalho assalariado 34

3.4 Pagamento por Pacotes 35

3.5 "Diagnosis Related Groups" 37

4. Metodologia: análise da composição de remuneração versus custos num prestador da oncologia

5. Resultados 56

6. Conclusões 74

Anexos 83 


\section{Introdução}

A Constituição Federal de 1988 apresenta em seu capítulo II, "um conjunto de ações de iniciativa dos Poderes Públicos e da sociedade, destinadas a assegurar os direitos relativos à saúde, à previdência e à assistência social”. E, nos artigos 197 e 199, a responsabilidade depositada sobre os Poderes Públicos é compartilhada com a iniciativa privada, permitindo-a participar de forma complementar, seguindo as diretrizes do SUS (Brasil, 1988).

Os dados consolidados de 2015 da Agência Nacional de Saúde Suplementar - ANS demonstram que quase 50 milhões de beneficiários possuem planos privados de assistência médica com ou sem odontologia e quase 22 milhões de beneficiários possuem planos privados exclusivamente odontológicos (ANVISA, 2016), numa população que totaliza no Brasil mais de 205 milhões de habitantes, segundo projeção estimada do Instituto Brasileiro de Geografia e Estatística - IBGE (IBGE, 2016).

Representando cerca de 1/4 da população e, em tese, oferecendo diferenciais como qualidade (PINTO, 2003) e acesso adicionais ao que a população possui no atendimento público do SUS (MÉDICI; PIOLA; VIANNA, 2002), o segmento da saúde suplementar vem encontrando dificuldades semelhantes como desequilíbrio entre a oferta e a demanda gerando a mesma dificuldade de acesso, questionamentos sobre a qualidade dos serviços prestados, críticas em relação à remuneração dos serviços e dos profissionais contratados, problemas financeiros no setor com constantes intervenções da ANS e até mesmo liquidação de operadoras e uma crescente intervenção da justiça visando proteger os usuários contra aumentos abusivos, ausência de cobertura e demais descumprimentos em relação às regras reguladoras (ABELHA; GONÇALVES; PITASSI, 2014).

O tema remuneração, tão enfatizado pelos diversos atores na área da saúde e constantemente noticiado pela grande mídia no que se refere a tabela SUS, precisa também ser analisado na ótica da saúde suplementar, que adota predominantemente um sistema diferente de remuneração conhecido como pagamento por procedimento ou "fee for service", mas que, segundo Médici, Piola e Vianna (2002), gera distorções claras, podendo ser um dos grandes vilões da crise vivenciada no modelo de negócio da saúde suplementar no Brasil.

Não se pode resumir essas distorções ao simples fato de que o prestador estimula a geração de procedimentos para elevar ganhos (ANDREAZZI, 2003; STEFANI, 2005; KOYAMA, 2006; GOMES, 2010; BESSA, 2011; SOARES, 2012; BICHUETTI e MERE Jr, 
2016), mas outras causas precisam ser analisadas como a lucratividade não adequada do setor e a subvalorização do trabalho médico e dos serviços de saúde prestados por profissionais da saúde versus a supervalorização na utilização de medicamentos e materiais, órteses e próteses ou realização de exames com alta tecnologia incorporada, sendo que esta última causa se torna o principal foco de análise com este trabalho.

O que, de fato, o mundo todo vem buscando é uma transformação na sistemática de remuneração dos serviços de saúde, passando de um modelo baseado em volume para um novo modelo baseado em valor (HFMA, 2011). Esta equação é representada de forma simplificada na figura 1, onde o conceito de qualidade carrega as dimensões das entregas feitas ao consumidor, a segurança envolvida em todas as etapas do processo pelo qual ele esteve e todas as experiências vividas durante este processo. Por outro lado, o fator custo compreende todos os investimentos feitos por todos os atores envolvidos na cadeia da saúde: clientes, prestadores de serviços, operadoras de saúde suplementar e governo (HFMA, 2011).

Figura 1 - Equação de valor adaptada para a área da saúde

\section{Qualidade}

\section{Valor $=$}

\section{Custo}

Fonte: adaptado de HFMA, 2011.

A implantação deste novo modelo depende do desenvolvimento de 4 competências organizacionais: cultura organizacional e pessoas voltadas para a oferta de serviços baseados em valor; obtenção de dados através de sistema de "business intelligence" que forneçam informações para a tomada de decisões; foco na melhoria contínua dos processos, buscando melhores resultados na entrega dos serviços de saúde e melhor custo-efetividade; e, 
previsibilidade de custos e compartilhamento de riscos com os financiadores do sistema (HFMA, 2011).

Outro fator importante que impede a evolução nas relações entre prestadores e operadoras de saúde suplementar, defendido por Porter e Teisberg (2007), é que a competição no setor acontece em nível equivocado. Ao invés de se buscar uma competição positiva (conceito defendido no livro: Repensando a Saúde), adota-se a competição de soma zero, na qual os ganhos de um, significa prejuízo para o outro.

Visando obter dados práticos para ilustrar a realidade destas distorções existentes nos diversos modelos discutidos, este trabalho objetivou analisar a existência de distorções na estrutura de remuneração de uma clínica oncológica, que tem como principais atividades o atendimento da consulta médica e a infusão de medicamentos quimioterápicos.

Analisando os componentes da remuneração de uma clínica oncológica (honorários médicos, taxas que remuneram a estrutura física + serviços profissionais não médicos + capital investido, e remuneração pela utilização de materiais e medicamentos na prestação dos serviços) e a participação de cada um desses componentes em relação ao total da remuneração traçou-se um comparativo com a estrutura de custos desses mesmos itens, que também são analisados em relação ao total dos custos. Com isso, verificou-se a existência de distorções na participação percentual de cada item em relação ao total, confrontando a estrutura de custo com a sua respectiva estrutura de remuneração.

Utilizando-se dos dados obtidos para o alcance do objetivo deste trabalho, foi possível aprofundar o detalhamento e eleger dois itens dentre os serviços mais importantes no negócio analisado para o confronto do custo unitário desses serviços com suas respectivas remunerações médias.

A relevância deste estudo se justifica, pois, apesar de se encontrar alguns estudos internacionais e também nacionais, abordando exclusivamente o SUS (KOS et al, 2011), não se encontram referenciais acadêmicos demonstrando esta relação na saúde suplementar no Brasil.

Outro ponto que reforça a relevância deste trabalho é que, com a crise econômica que as operadoras de saúde suplementar vêm enfrentando, a pressão passa a ser exercida sobre os prestadores de serviços focando no item que representa o maior fator de custo para as operadoras que é a remuneração paga sobre os materiais e medicamentos utilizados. Como a sustentação do modelo de remuneração está apoiada neste item e, por consequência, a saúde 
financeira dos prestadores, a alteração deste componente, sem a devida compensação nos demais componentes da remuneração, pode estender a crise econômica aos demais atores da cadeia, que são os prestadores. Este cenário real está em andamento e vem se concretizando rapidamente devido ao poder que a fonte pagadora (operadoras de saúde suplementar) exerce no mercado.

Com a identificação das distorções em ambos os casos, pode-se sugerir novos arranjos que apresentem maior coerência e favoreçam a manutenção do equilíbrio na relação comercial no longo prazo, que poderão ser objeto de estudos futuros, visando assegurar a viabilidade deste setor.

Ao escolher a área de oncologia, que em termos do modelo de remuneração pode ser considerado um segmento relativamente simples dentro do universo do setor de serviços de saúde, espera-se obter uma amostra que poderá servir de base para estudos e conclusões dentro deste segmento específico, mas que também poderá auxiliar em novos estudos e conclusões em outras áreas e especialidades do setor da saúde. 


\section{O universo das operadoras de planos de saúde e dos prestadores de serviços de saúde no Brasil - visão geral e específica na oncologia}

\subsection{Modelo vigente}

Olhando para o mercado da saúde suplementar, pode-se perceber que ele é constituído por três grupos de atores: as operadoras de planos de saúde, os usuários e os prestadores de serviço em saúde. Segundo Campos (2004), o modelo abaixo representa, de forma simplificada, a relação econômica existente entre esses grupos, sendo que os usuários demandam e os prestadores de serviços ou provedores, ofertam. Completando o modelo, a operadora de planos de saúde intermedia esta relação.

Figura 2 - Relação Contratual entre os Agentes no Mercado de Saúde Suplementar

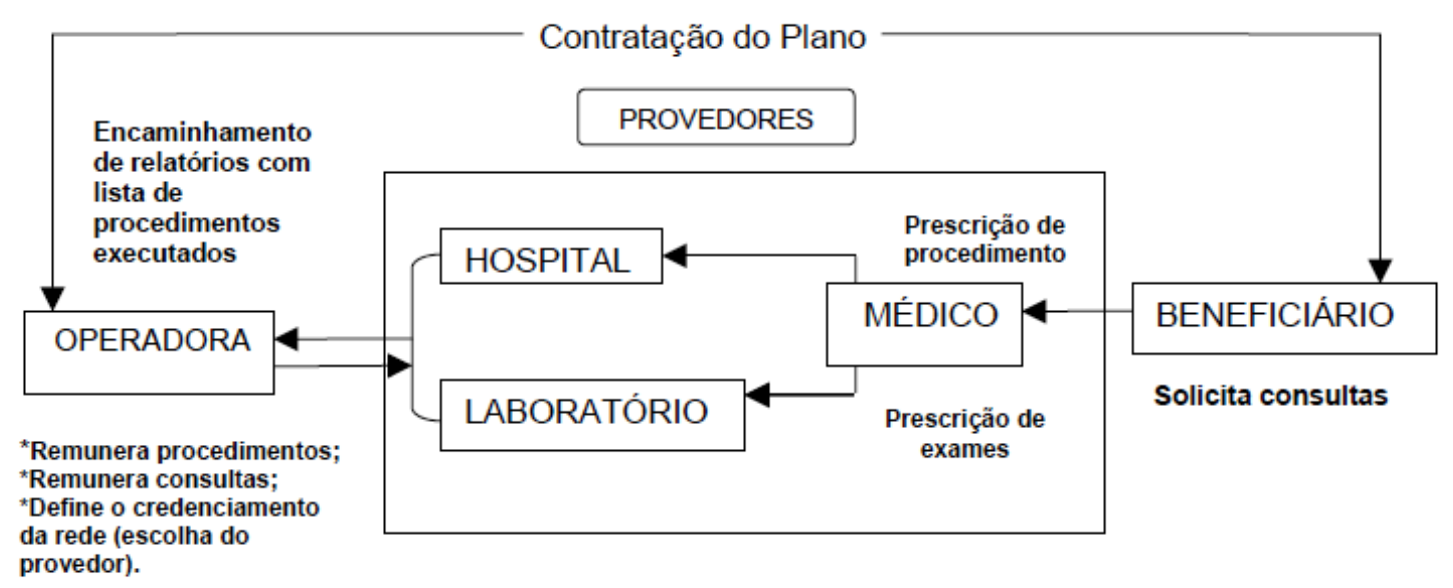

Fonte: Campos, 2004

Nesta intermediação, que consiste em comercializar e gerenciar a utilização por parte dos usuários, está a principal atividade da operadora de planos de saúde. Porém, apesar de todas essas relações serem regulamentadas por contratos, conflitos podem surgir uma vez que “eventos que representam custos para as operadoras, também representam receita para os prestadores de serviços de saúde e o que representa custo para o usuário, também representa receita para as operadoras de planos de saúde”, afirma Campos (2004).

Apesar de ser claro e bem definido o papel de cada grupo representado na figura 2, notase um movimento chamado de verticalização na prestação dos serviços pelas operadoras de planos de saúde, ou seja, quando ela se coloca também como prestadora de serviços de saúde. 
Conforme define Campos (2004), “as operadoras apresentam duas formatações de estrutura no mercado: empresas de caráter híbrido, no sentido de atuarem simultaneamente como organização gerenciadora e como prestadora de serviços de assistência à saúde e empresas que atuam exclusivamente como organizações gerenciadoras, não possuindo rede própria, sendo de maior generalidade.

Segundo Ribeiro, Montone e Castro (2003), pode-se resumir os problemas de regulação e governança do setor em 3 pontos: restrição de informações, custos de transação e problemas de caráter administrativo e político. A restrição de informações envolve o risco moral e a seleção adversa, uma vez que os prestadores são autônomos para decidir preço e qualidade e normalmente detém maior acesso ao conhecimento médico e tecnologias do setor. Os custos de transação são avaliados pelas operadoras através de comparativos obtidos na própria base de dados dos prestadores que é enviada mensalmente com a produção e por dados externos dos custos de execução coletados com pares ou em banco de dados mundiais.

Já os problemas de caráter administrativo e político compõem-se de uma infinidade de possibilidades movidas normalmente por interesses individuais, que escancaram os problemas de gestão e de governança, tão comuns no Brasil, mas que sobressaltam quando refletidos em organizações que têm a missão de cuidar da saúde da população.

Segundo Médici, Piola e Vianna (2002), é importante gerar incentivos para a racionalização dos gastos com saúde, já que os gastos e custos com os sistemas de saúde crescem mais do que os índices de preços. Porém, a adoção desses incentivos não é uma tarefa simples já que o crescimento dos gastos e custos com a saúde está relacionado com o comportamento dos médicos e comportamento dos usuários e é importante adotar medidas que racionalizem os custos sem prejudicar a assistência.

“O crescimento dos gastos em saúde depende do mercado, ou seja, do encontro entre os que querem adquirir os bens e serviços de saúde e aqueles que os oferecem", afirmam Zucchi, Del Nero e Malik (2000). Complementam, demonstrando os fatores que agem na oferta (progresso técnico-médico, difusão da inovação e multiplicação dos centros de assistência à saúde) e os fatores que agem na demanda (necessidade sentida, fatores psicossociais, seguridade social, demografia, epidemiologia, experiência na utilização, regulação e fatores culturais (ZUCCHI; DEL NERO; MALIK, 2000).

Os gastos com saúde tiveram seu nível de crescimento intensificado na maioria dos países após a $2^{\mathrm{a}}$ Guerra Mundial, dentro do conceito do Welfare State, com subsídios 
provenientes de fundos fiscais e sociais. Com estruturas universalistas, este enfoque elevou o gasto com saúde em economias desenvolvidas, de $2 \%$ a 5\% do PIB no final dos anos 40 para $6 \%$ a 12\%, no final dos anos 80 (MEDICI; PIOLA; VIANNA, 2002). Como principais causas para esta elevação apontam: a extensão horizontal (inclusão da população) e vertical de cobertura (complexidade e diversidade); o envelhecimento da estrutura etária; transformação na estrutura de morbi-mortalidade; mudanças na tecnologia médica; interesses da indústria farmacêutica, de equipamentos e insumos médicos; fatores sócio-econômicos e culturais; e, as estruturas securitárias (MEDICI; PIOLA; VIANNA, 2002).

De acordo com os dados do Fundo Monetário Internacional - FMI (2013), o Brasil estava posicionado como o sétimo maior PIB mundial, conforme apresentado no gráfico 1.

Gráfico 1 - Produto Interno Bruto (milhões de USD)

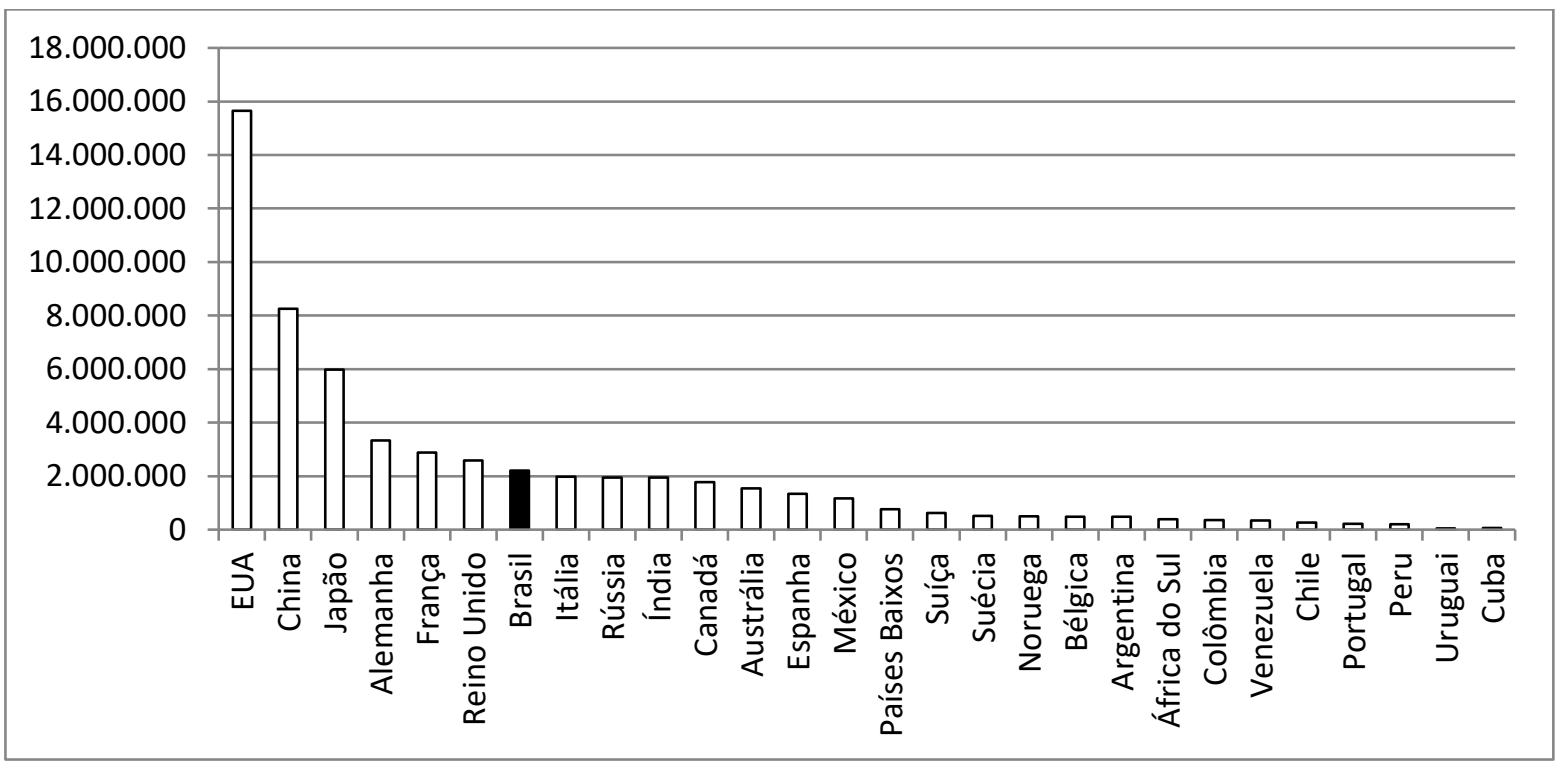

Fonte: Fundo Monetário Internacional, 2013.

Porém, é importante analisar também este dado dividido pela população do país o que derruba consideravelmente a posição do Brasil colocando-o abaixo de alguns países sulamericanos como Chile, Uruguai, Venezuela e Argentina, conforme demonstrado no gráfico 2. 
Gráfico 2 - Produto Interno Bruto per capita (USD)

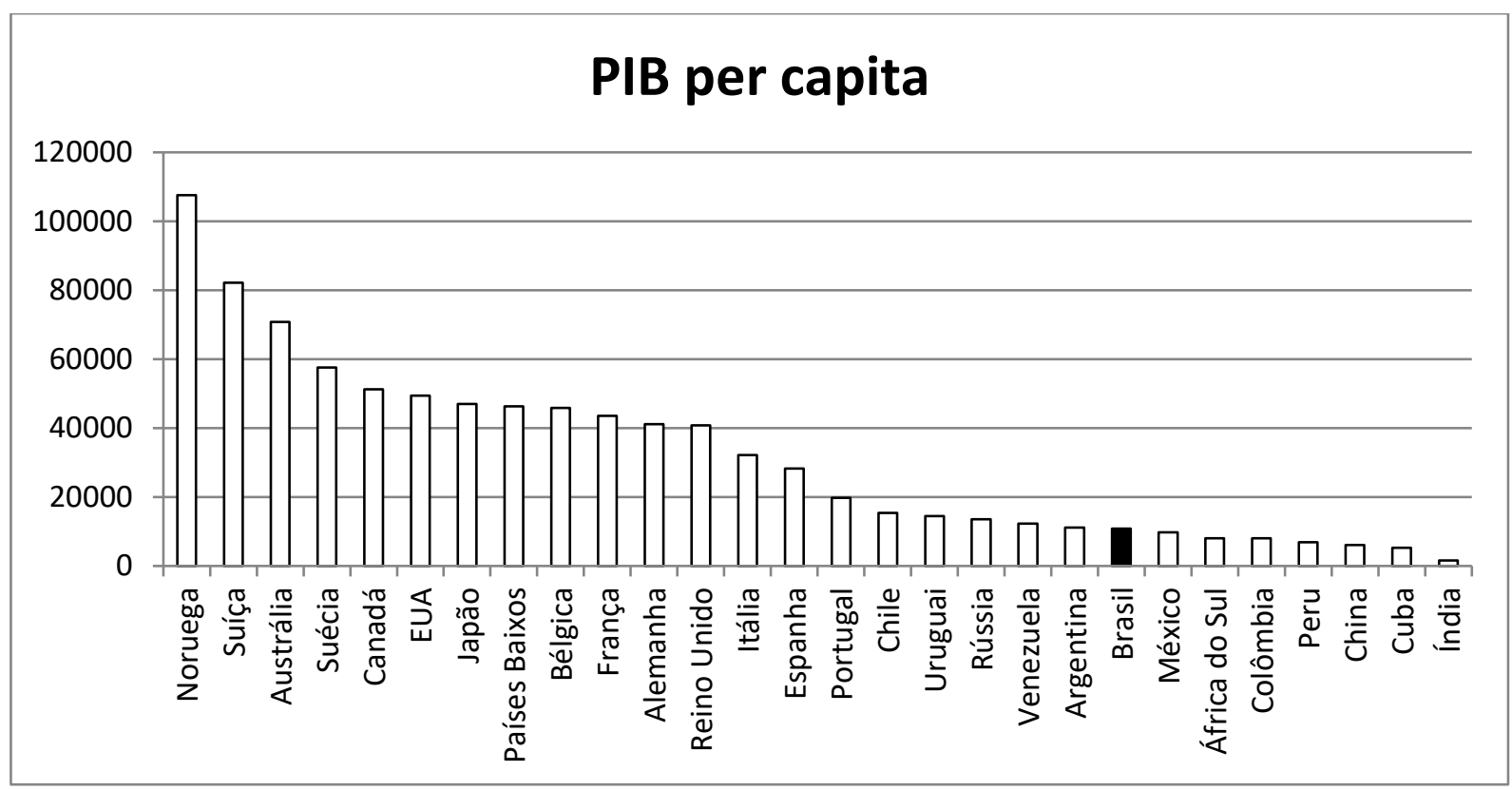

Fonte: Fundo Monetário Internacional, 2013.

Ainda analisando os dados publicados pelo Fundo Monetário Internacional em 2013, o Brasil aplicou em saúde aproximadamente 9\% de seu PIB. Esse percentual assemelha-se ao de países desenvolvidos, tais como Reino Unido, Austrália, Espanha e Itália.

Porém, é importante destacar que do montante total aplicado em saúde, cerca de $56 \%$ refere-se a gastos privados e apenas $44 \%$ é proveniente de aportes públicos.

Em outra análise, se a avaliação for em relação ao gasto de saúde por habitante, os valores anuais médios no Brasil ficam em torno de USD 964,00, conforme o gráfico 3. Porém, sabe-se que a população atendida pelo sistema público de saúde no Brasil gira em torno de 3/4 da população, enquanto $1 / 4$ é coberto pela saúde suplementar. Com isso, estima-se que o gasto anual per capita no serviço público gira em torno de aproximadamente USD 500,00, enquanto que para os beneficiários da saúde suplementar o gasto anual per capita ultrapassa USD $2.000,00$. 
Gráfico 3 - Gasto total per capita com saúde (milhões de USD)

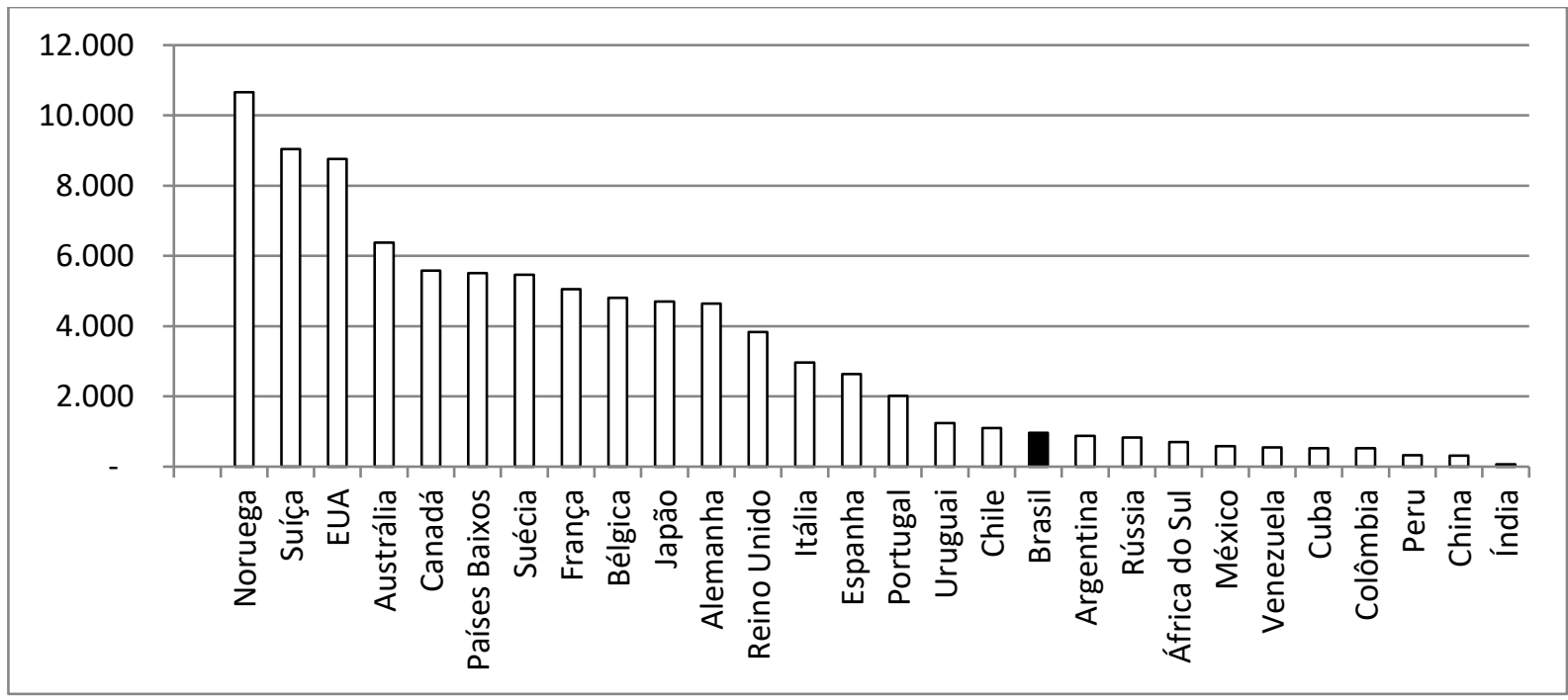

Fonte: Fundo Monetário Internacional, 2013. 


\subsection{O Universo das Operadoras de Planos de Saúde}

A Lei 9.656, de 03 de junho de 1998, define:

Operadora de Plano de Assistência à Saúde: pessoa jurídica constituída sob a modalidade de sociedade civil ou comercial, cooperativa, ou entidade de autogestão, que opere produto, serviço ou contrato de assistência à saúde (Artigo $1^{\circ}$, Inciso II).

Conforme a Resolução 39/2000 da ANS, que compõe o marco regulatório do setor, as operadoras podem ser classificadas em sete modalidades:

- Administradoras;

- Cooperativas médicas;

- Cooperativas odontológicas;

- Autogestão;

- Medicina de grupo;

- Odontologia de grupo; e

- Filantropia.

O detalhamento da classificação de cada uma das setes modalidades foi modificado alguma vezes nestes últimos 15 anos pelas resoluções 137/2006, 196/2009 e 315/2012, todas da ANS. Além disso, a Lei 10.185/2001 dispõe sobre a especialização das seguradoras na área da saúde.

Após estes ajustes, temos as seguintes definições para cada modalidade:

- Administradora de Benefícios:

Considera-se Administradora de Benefícios a pessoa jurídica que propõe a contratação de plano coletivo na condição de estipulante ou que presta serviços para pessoas jurídicas contratantes de planos privados de assistência à saúde coletivos, desenvolvendo ao menos uma das seguintes atividades: I - promover a reunião de pessoas jurídicas contratantes na forma do artigo 23 da $\underline{\mathrm{RN}} \mathrm{n}^{\circ} \mathbf{1 9 5}$, de 14 de julho de 2009; II - contratar plano privado de assistência à saúde coletivo, na condição de estipulante, a ser disponibilizado para as pessoas jurídicas legitimadas para contratar; III oferecimento de planos para associados das pessoas jurídicas contratantes; IV - apoio técnico na discussão de aspectos operacionais, tais como: a) negociação de reajuste; b) aplicação de mecanismos de regulação pela operadora de plano de saúde; e c) alteração de rede assistencial. Parágrafo único. Além das atividades constantes do caput, a Administradora de Benefícios poderá desenvolver outras atividades, tais como: I - apoio à área de recursos humanos na gestão de benefícios do plano; II - terceirização de 
serviços administrativos; III - movimentação cadastral; IV - conferência de faturas; V - cobrança ao beneficiário por delegação; e VI - consultoria para prospectar o mercado, sugerir desenho de plano, modelo de gestão. (Art $2^{\circ}$. da RN 196/2009)

- Cooperativas Médicas

Classificam-se na modalidade de cooperativa médica as sociedades de pessoas sem fins lucrativos, constituídas conforme o disposto na Lei ํㅜ 5.764 , de 16 de dezembro de 1971, que operam Planos Privados de Assistência à Saúde. (Art 12‥ Da RDC 39/2000)

- Cooperativas Odontológicas

Classificam-se na modalidade de cooperativa odontológica as sociedades de pessoas sem fins lucrativos, constituídas conforme o disposto na Lei $n^{0} 5.764$, de 16 de dezembro de 1971, que operam Planos Odontológicos. (Art 13ํ․ Da RDC 39/2000)

- Autogestão

I - A pessoa jurídica de direito privado que, por intermédio de seu departamento de recursos humanos ou órgão assemelhado, opera plano privado de assistência à saúde exclusivamente aos seguintes beneficiários: a) sócios da pessoa jurídica; b) administradores e ex-administradores da entidade de autogestão; c) empregados e ex-empregados da entidade de autogestão; d) aposentados que tenham sido vinculados anteriormente à entidade de autogestão; e) pensionistas dos beneficiários descritos nas alíneas anteriores; f) grupo familiar até o quarto grau de parentesco consangüíneo, até o segundo grau de parentesco por afinidade, criança ou adolescente sob guarda ou tutela, curatelado, cônjuge ou companheiro dos beneficiários descritos nas alíneas anteriores. II - a pessoa jurídica de direito privado de fins não econômicos que, vinculada à entidade pública ou privada patrocinadora, instituidora ou mantenedora, opera plano privado de assistência à saúde exclusivamente aos seguintes beneficiários: a) empregados e servidores públicos ativos da entidade pública patrocinadora; b) empregados e servidores públicos aposentados da entidade pública patrocinadora; c) ex-empregados e exservidores públicos da entidade pública patrocinadora; d) pensionistas dos beneficiários descritos nas alíneas anteriores; e) sócios ou associados da entidade privada patrocinadora ou mantenedora da entidade de autogestão; f) empregados e ex-empregados, administradores e ex-administradores da entidade privada patrocinadora ou mantenedora da entidade de autogestão; g) empregados, ex-empregados, administradores e ex-administradores da própria entidade de autogestão; h) aposentados que tenham sido vinculados anteriormente à própria entidade de autogestão ou a sua entidade patrocinadora ou mantenedora; i)pensionistas dos beneficiários descritos nas alíneas anteriores;j) grupo familiar até o quarto grau de parentesco consangüíneo, até o segundo grau de parentesco por afinidade, criança ou adolescente sob guarda ou tutela, curatelado, cônjuge ou companheiro dos 
beneficiários descritos nas alíneas anteriores; k) as pessoas previstas nas alíneas "e", "f", "h", "i"e "j" vinculadas ao instituidor desde que este também seja patrocinador ou mantenedor da entidade de autogestão; ou III - pessoa jurídica de direito privado de fins não econômicos, constituída sob a forma de associação ou fundação, que opera plano privado de assistência à saúde aos integrantes de determinada categoria profissional que sejam seus associados ou associados de seu instituidor, e aos seguintes beneficiários: a) empregados, ex-empregados, administradores e ex-administradores da própria entidade de autogestão; b) aposentados que tenham sido vinculados anteriormente à própria entidade de autogestão; c) pensionistas dos beneficiários descritos nas alíneas anteriores; e d) grupo familiar até o quarto grau de parentesco consangüíneo, até o segundo grau de parentesco por afinidade, criança ou adolescente sob guarda ou tutela, curatelado, cônjuge ou companheiro dos beneficiários descritos nas alíneas anteriores. (Art $2^{\circ}$. da RN 137/2006, alterada pela RN 148/2007, pela RN 272/2011 e pela RN 355/2014)

- Medicina de Grupo

Classificam-se na modalidade de medicina de grupo as empresas ou entidades que operam Planos Privados de Assistência à Saúde, excetuando-se aquelas classificadas nas modalidades contidas nas Seções I (Administradoras), II (Cooperativas Médicas), IV (autogestão) e VII (Filantropia) desta Resolução. (Art 15․ da RDC 39/2000)

- Odontologia de Grupo

Classificam-se na modalidade de odontologia de grupo as empresas ou entidades que operam exclusivamente Planos Odontológicos, excetuando-se aquelas classificadas na modalidade contida na Seção III (Cooperativa Odontológica) desta Resolução. (Art 16. da RDC 39/2000)

- Filantropia

Classificam-se na modalidade de filantropia as entidades sem fins lucrativos que operam Planos Privados de Assistência à Saúde e tenham obtido o certificado de entidade beneficente de assistência social emitido pelo Ministério competente, dentro do prazo de validade, bem como da declaração de utilidade pública federal junto ao Ministério da Justiça ou declaração de utilidade pública estadual ou municipal junto aos Órgãos dos Governos Estaduais e Municipais, na forma da regulamentação normativa específica vigente. (Art $5^{\circ}$. da RN 315/2012)

- Seguradora

As sociedades seguradoras poderão operar o seguro enquadrado no art. $1^{\circ}$, inciso I e $\S 1^{\circ}$, da Lei $n^{\circ} 9.656$, de 3 de junho de 1998 , desde que estejam constituídas como seguradoras especializadas nesse seguro, devendo seu estatuto social vedar a atuação em quaisquer outros ramos ou modalidades. (Art 1ํ. da Lei 10.185/2001) 
Segundo a ANS, nota-se no gráfico 4, que em 2015 estavam ativas 1330 operadoras de planos de saúde, sendo que destas, 1150 possuíam beneficiários. Nos últimos 10 anos, a quantidade de operadoras encolheu mais de $30 \%$ e a concentração de beneficiários se intensificou, sendo que aproximadamente $10 \%$ das operadoras detêm mais de $80 \%$ dos beneficiários.

Gráfico 4 - Número de Operadoras de Planos Médico-Hospitalares e Odontológicos

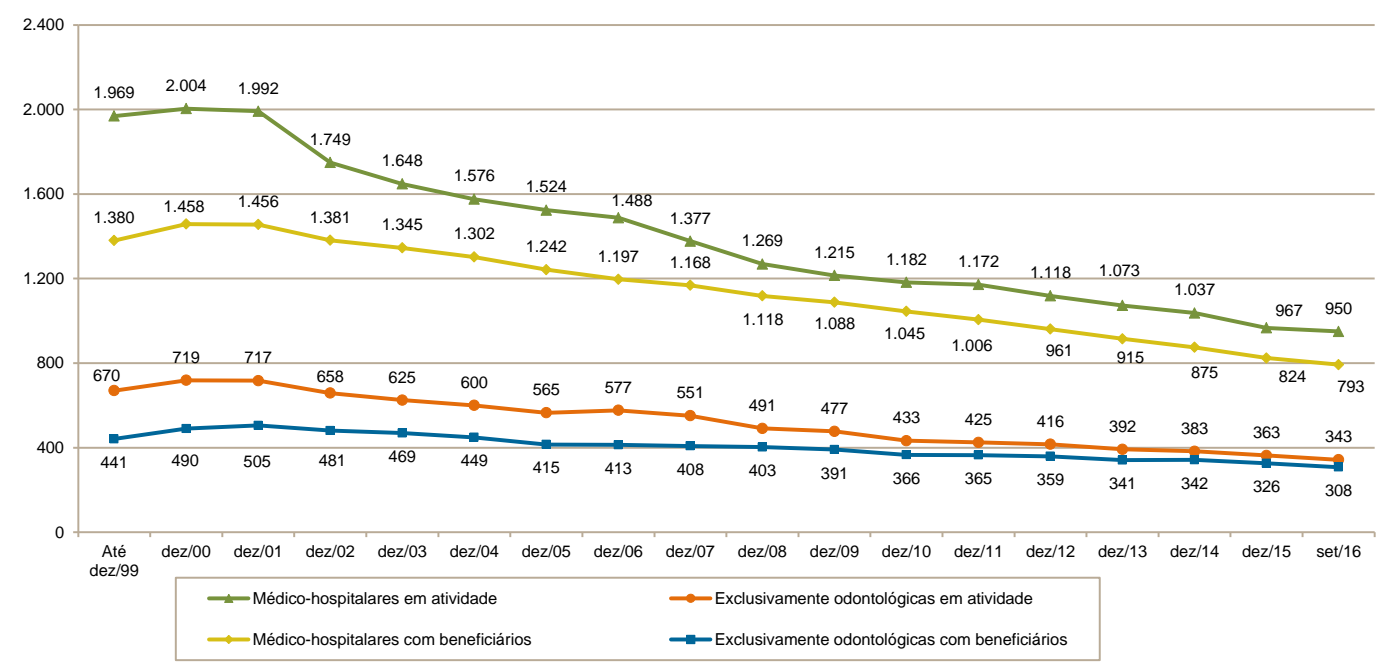

Fontes: CADOP/ANS/MS - 09/2016 e SIB/ANS/MS - 09/2016

O número de beneficiários de Planos de Assistência Médica com ou sem Odontologia, após sucessivos crescimentos durante mais de uma década (2004-2014), sofreu duas quedas consecutivas nos últimos anos, conforme gráfico 5 , colocando todo o setor de saúde em alerta.

A mídia tem feito uma relação entre a crise nos planos de saúde com a perda de beneficiários e o agravamento da superlotação nos serviços prestados pelo SUS. Essa migração está levando o Governo a estudar uma flexibilização nas regras contratuais dos produtos oferecidos pelas Operadoras de Planos de Saúde, com a possibilidade de criação de planos mais baratos que oferecem coberturas segmentadas ou parciais (ANS, 2017). 
Gráfico 5 - Número de Beneficiários de Planos Médico-Hospitalares e Odontológicos

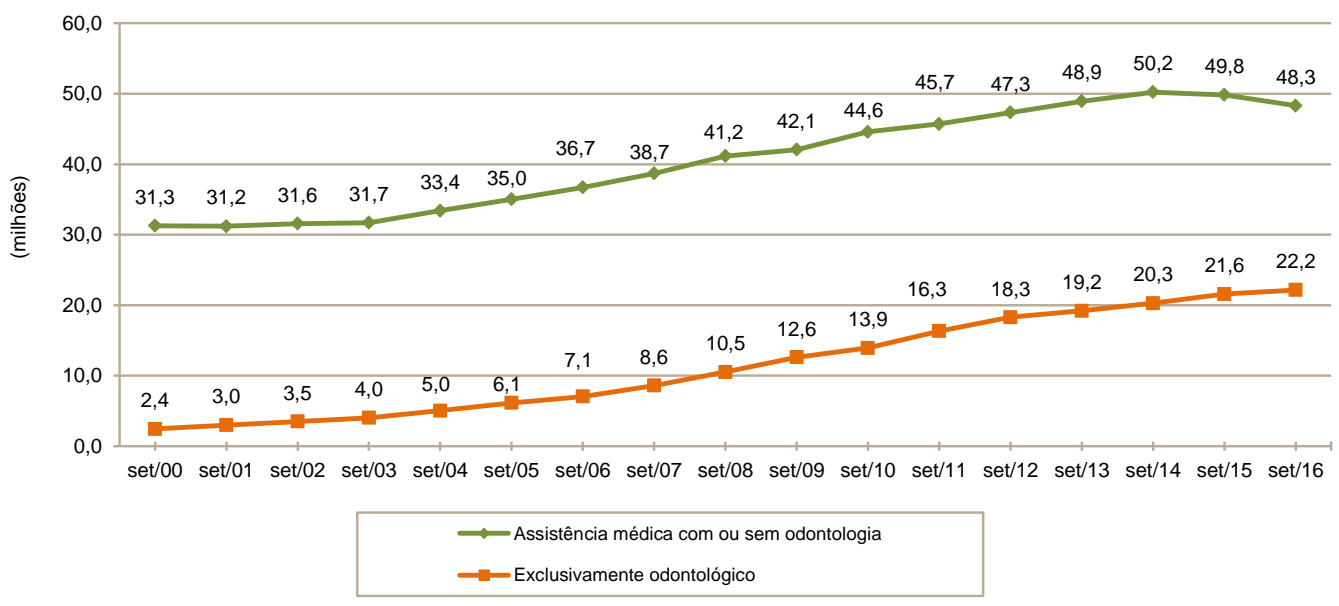

Fontes: CADOP/ANS/MS - 09/2016 e SIB/ANS/MS - 09/2016

O gráfico 6, também reflete a dificuldade enfrentada pelo setor nos últimos anos, ficando evidente o encolhimento da taxa de crescimento do setor e a inversão para taxa negativa.

Gráfico 6 - Taxa de Crescimento de Beneficiários de Planos Médico-Hospitalares e Odontológicos

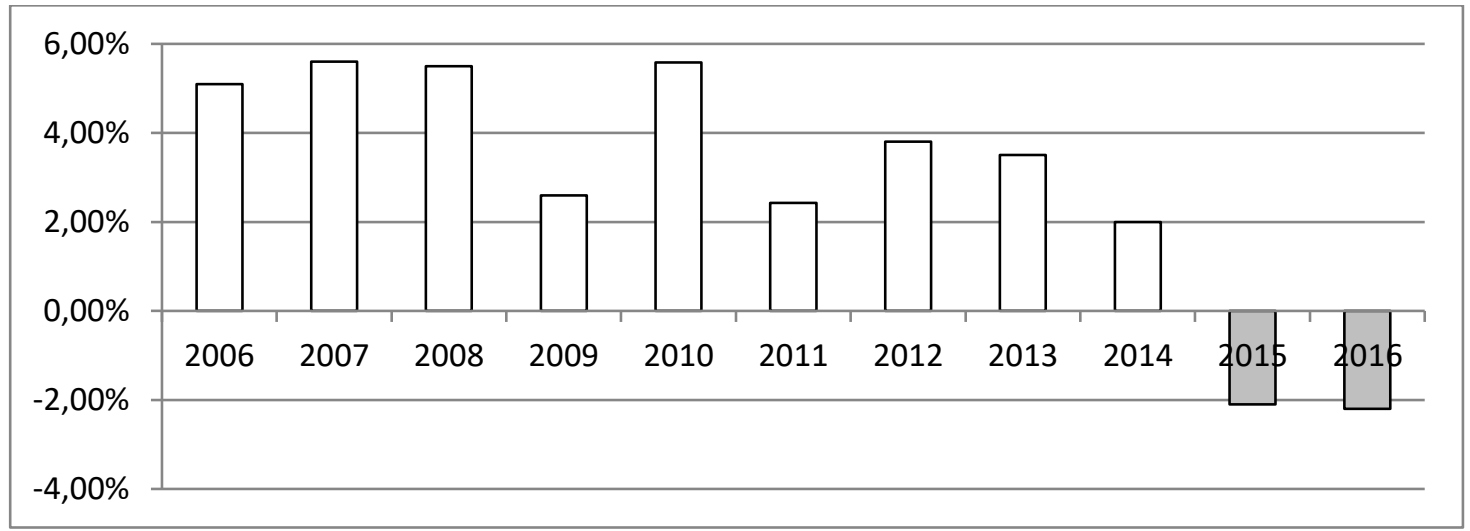

Fontes: CADOP/ANS/MS - 09/2016 e SIB/ANS/MS - 09/2016

A análise para criação de planos mais baratos com coberturas reduzidas conflita, em princípio, com a regulamentação vigente do setor que vem sendo construída desde o marco legal em 1998.

A Lei 9.656/1998, que dispõe sobre os planos e seguros privados de assistência à saúde, define em seu artigo $12^{\circ}$ as exigências mínimas de coberturas para os diferentes produtos 
(atendimento ambulatorial, internação hospitalar, atendimento obstétrico e atendimento odontológico). Apesar de sofrer diversas inclusões e modificações ao longo desses 18 anos, através de algumas medidas provisórias ou leis, o conteúdo de oferta de produtos continua praticamente inalterado, a não ser pelas diversas inclusões de coberturas obrigatórias adicionais, constantemente publicadas pela ANS.

Os diferentes produtos possíveis de comercialização são apresentados originalmente na RN 85/2004, sendo modificada posteriormente por diversas RNs e, atualmente vigentes no anexo II, da RN 356/2014:

A Operadora deverá optar por uma das segmentações:

Ambulatorial; Hospitalar com Obstetrícia; Hospitalar sem Obstetrícia;

Odontológico; Referência (Ambulatorial + Hospitalar com Obstetrícia e acomodação padrão de enfermaria); Ambulatorial + Hospitalar com Obstetrícia; Ambulatorial + Hospitalar sem Obstetrícia; Ambulatorial + Odontológico; Hospitalar com Obstetrícia + Odontológico; Hospitalar sem Obstetrícia + Odontológico; Ambulatorial + Hospitalar com Obstetrícia + Odontológico; Ambulatorial + Hospitalar sem Obstetrícia + Odontológico. 


\subsection{O Universo dos Prestadores de Serviços Privados de Assistência à Saúde}

De acordo com a Lei $\mathrm{n}^{\circ}$ 8080/90 em seu artigo 20 $0^{\circ}$, "os serviços privados de assistência à saúde caracterizam-se pela atuação, por iniciativa própria, de profissionais liberais, legalmente habilitados, e de pessoas jurídicas de direito privado na promoção, proteção e recuperação da saúde". Os serviços de saúde são estruturas organizacionais e técnicas extremamente diversificadas, incluindo desde consultórios individuais e unidades básicas até hospitais terciários e especializados, bem como serviços de apoio diagnóstico e terapêutico.

Atualmente, conforme dados do Cadastro Nacional de Estabelecimentos de Saúde (CNES) existem mais de 278 mil unidades de saúde no Brasil. Ainda de acordo com o CNES, os serviços de oncologia que realizam procedimentos de quimioterapia e/ou radioterapia totalizam 840 estabelecimentos, sendo que mais de 70\% deles ficam na região Sudeste e Sul do país (BRASIL, 2016). Conforme o anexo da Portaria 140/2014 da Secretaria de Assistência à Saúde do Ministério da Saúde, 286 serviços atendem ao SUS (BRASIL, 2014).

A quimioterapia ambulatorial realizada pelos prestadores de saúde representa uma parte significativa dos custos para as operadoras e vem sofrendo

Alguns fatores como envelhecimento da população, pesquisa e desenvolvimento de novas tecnologias e o manejo do paciente com câncer influenciam diretamente nos custos da saúde, o que afeta tanto os orçamentos públicos de saúde como o fluxo financeiro dos atores citados acima: operadoras, prestadores e usuários.

Na última década o tratamento do câncer sofreu grandes modificações tecnológicas. Neste sentido, este trabalho busca analisar os custos sob a perspectiva dos prestadores de serviços em oncologia. O surgimento de novos agentes quimioterápicos, do desenvolvimento de anticorpos monoclonais e de novas combinações de fármacos se, de um lado podem proporcionar uma nova esperança de aumento de sobrevida, qualidade de vida e até cura para os pacientes, de outro gerou pressões de custos para o sistema de saúde, particularmente para as operadoras e seguros (STEFANI, 2005).

Ainda segundo Stefani (2005), os custos com a quimioterapia podem consumir cerca de $8 \%$ da receita das operadoras de saúde suplementar. Com isso, algumas seguradoras americanas determinaram que os tratamentos prescritos por oncologistas somente poderiam ser tratados em serviços próprios da seguradora ou em serviços de outros oncologistas que não do próprio prescritor ou, de alguma forma, ele teria que compartilhar o risco do tratamento. Tudo isso, buscando evitar que os lucros pudessem induzir alguma utilização desnecessária. 
Nos EUA, assim como no Brasil, as atenções têm se voltado para o fato de que, como a remuneração dos serviços de oncologia está ancorada na diferença entre o custo de aquisição e a remuneração recebida pelos medicamentos utilizados na prestação de serviços de quimioterapia, teme-se que este modelo gere um "incentivo perverso" (STEFANI, 2005). Estudo apresentado no National Institute of Health analisou que 30\% dos pacientes que receberam quimioterapia nos últimos 6 meses de vida, apresentavam critérios objetivos que definiam a refratariedade ao tratamento, sugerindo superindicação (STEFANI, 2005, apud EMANUAL, 2001). 


\section{Sistemas e formas de remuneração: Hospitais e médicos}

Os sistemas de remuneração representam a contrapartida que os empregadores oferecem aos trabalhadores em troca de seus serviços ou de seu tempo dedicado. A remuneração médica está intrinsicamente ligada aos objetivos organizacionais voltados à eficiência e qualidade, ao equilíbrio financeiro e à equidade de acesso nos serviços de saúde (GIRARDI; CARVALHO; GIRARDI, 2007).

Este tema não segue a abordagem da teoria econômica convencional, que considera a racionalidade ilimitada das partes na tomada de decisões visando alcançar a maximização de seus objetivos. No mercado dos serviços de saúde deve-se considerar os fenômenos da assimetria de informações, a existência de externalidades com a extensão dos benefícios obtidos a outras pessoas, a presença de um terceiro pagador e a presença de inúmeras instituições sem fins lucrativos (ANDREAZZI, 2003).

Soares (2012), define quatro mecanismos que influenciam a definição da forma de pagamento: unidade de pagamento (atendimento, dia, visita, etc.), base global (per capita, por procedimento), em função do momento da realização do procedimento (prospectivo ou retrospectivo) e compartilhamento de risco entre o prestador e o pagador.

No Brasil, apresentam-se quatro formas principais de remuneração dos prestadores de serviço médico-hospitalar: pagamento por procedimento ou remuneração por procedimento (“fee for service”),“capitation”, salário e pacotes (BESSA, 2011).

Nos últimos anos, vem ganhando evidência no Brasil as discussões sobre DRG "Diagnosis Related Groups" que é um sistema de classificação de pacientes internados em hospitais que atendem casos agudos, desenvolvido no final dos anos 60 por uma equipe interdisciplinar de pesquisadores da Yale University - EUA (NORONHA et al, 1991). 


\subsection{Remuneração por Procedimento - "fee for service"}

A remuneração por procedimento ou "fee for service" pressupõe uma tabela com os preços unitários de cada ato, pré acordada entre a operadora e o prestador, e a multiplicação, pós encerramento de um período, da quantidade realizada pelo preço unitário, encontrando-se assim o valor total da remuneração.

Andreazzi (2003), destaca em um estudo realizado pelo IPEA - Instituto de Pesquisa Econômica Aplicada, fundação pública ligada ao Ministério do Planejamento, que as remunerações caracterizadas pelo pós-pagamento como o "fee for service" podem levar à uma demanda induzida pela oferta, embasada na teoria dos incentivos. Outro ponto destacado são as fraudes de superfaturamento ou serviços inexistentes cobrados.

A mesma autora aponta ainda para outros problemas como a dificuldade de refletir diferenças regionais de custos de mão-de-obra, aluguéis, importação de equipamentos, etc., numa tabela única, causando um direcionamento da oferta em certos lugares conforme condições mais atraentes economicamente ou até mesmo concentração ou escassez de especialidades conforme o incentivo financeiro ou a falta dele (ANDREAZZI, 2003).

O aumento na utilização dos serviços gera também um aumento dos custos assistenciais, o que não garante melhoria no acesso ou na qualidade dos serviços prestados (KOYAMA, 2006).

A herança desse formato de remuneração vem do sistema adotado nos EUA e que ainda predomina amplamente no Medicare que também enfrenta o fenômeno da produção excessiva. O aumento na utilização, assim como nos custos, também é percebido na saúde suplementar brasileira, inclusive agravado pela prescrição de tratamentos que sofrem questionamentos dos serviços de auditorias das operadoras de saúde suplementar, o que sistematicamente tem levado a discussões na ANS ou no judiciário. Neste segundo caso, normalmente a decisão favorece o paciente com a concessão de liminares, já que o juizado não possui suporte técnico para a tomada de decisão (SOARES, 2012).

Gomes (2010), ressalta que há uma tendência a produção excessiva no "fee for service", já que os ganhos dos profissionais estão intimamente relacionados à quantidade de serviços realizados. 


\subsection{Capitation}

O “capitation" referencia o gerenciamento da saúde de uma determinada população a um ativo assistencial. A remuneração será então calculada periodicamente de acordo com esta base referenciada e, numa variação mais avançada, também se podem levar em consideração os resultados desse gerenciamento.

Segundo Bichuetti e Mere Jr (2016), o capitation é o formato que possui maior relação com o risco. A base de informação sobre a população coberta, além de informações gerais sobre a incidência das diversas enfermidades, estratificadas por região, sexo, faixa etária, entre outros, deve oferecer subsídios para que o risco seja calculado e considerado na definição do valor a ser pago por aquela população referenciada.

Bessa (2011), enfatiza que nesse modelo o risco é compartilhado com os profissionais da saúde e com os prestadores de serviços de saúde e afirma que as atenções passam a ser redirecionadas para a promoção da saúde da população referenciada e não atuação sistemática na doença.

A controvérsia do "Capitation" em relação ao "fee for service" é que enquanto este último privilegia uma maior quantidade de serviços prestados, o primeiro se beneficia da não realização de serviços, podendo dificultar o acesso ou restringir o escopo (SOARES, 2012).

Cherchiglia (1994), afirma que enquanto o modelo de pagamento por procedimento é criticado por estimular a superprodução, o "capitation" é questionado por estimular o subtratamento.

Conforme defendido por Gomes (2010), "O processo de atendimento dessa clientela, pela teoria dos incentivos, pode gerar algumas situações que exigem a intervenção e o acompanhamento da qualidade do serviço prestado. Pode haver uma tendência à seleção, quando possível, do grupo populacional, mecanismo semelhante à seleção de risco, levando a priorização de populações mais hígidas que utilizarão menos serviços, gerando mais lucro. Essa atitude pode ser prevenida utilizando-se um limite de pacientes por profissional, assim, mesmo que o profissional disponha de tempo, não lhe é permitido ampliar a clientela”. 


\subsection{Trabalho assalariado}

Segundo Bessa (2011), o salário é a forma mais tradicional de remuneração que tem como variáveis o valor da hora e o número de horas trabalhadas. Também numa variação mais avançada, podem-se considerar alguns indicadores de desempenho para o cálculo de um fator variável nessa remuneração periódica.

Segundo Girardi; Carvalho e Girardi (2007), a remuneração possui forte relação com a jornada, as qualificações e o tempo de experiência do profissional, além da complexidade do trabalho e também segue uma relação com os salários recebidos por profissionais ocupando posições similares em outras organizações públicas ou privadas. Já a relação com o rendimento ou resultado desse profissional, apesar de existir, não fica tão explícita como no caso da remuneração por procedimento.

Gomes (2010), revela maior frequência deste modelo no setor público, ao contrário das organizações privadas. Garante maior estabilidade e previsibilidade. Estabilidade porque segue as regras trabalhistas garantindo acesso aos benefícios sociais associados. Previsibilidade porque predominantemente é utilizado de forma fixa, podendo, porém, possuir fatores varáveis, porém sempre definidos previamente. Exceto quando esses fatores variáveis premiam produtividade, qualidade, controle dos custos ou satisfação do paciente, a tendência é que haja uma acomodação em relação a estes quesitos.

Soares (2012), apresenta um caso de sucesso e outro de suporto fracasso. Sucesso citando a "Mayo Clinic", um dos serviços de saúde de referência mundial em saúde nas áreas de qualidade e custo, que implantou o modelo de assalariamento para os médicos. Fracasso, ao analisar a remuneração médica da Prefeitura de Município de São Paulo no ano de 2010, que possuía a média de salário base variando entre $\mathrm{R} \$ 883,64$ e $\mathrm{R} \$ 1.060,35$, chegando a uma média de $\mathrm{R} \$ 2.255,62$ e $\mathrm{R} \$ 2.932,35$ quando somados os adicionais e gratificações. 


\subsection{Pagamento por Pacotes}

Os pacotes de serviços, utilizados inclusive pelo SUS, preveem um valor fixo préestabelecidos para a realização completa do ato. Podem incluir materiais e medicamentos e outros gastos. Como são originados de um cálculo prévio de eventos semelhantes, em alguns casos, podem também sofrer variações de acordo com eventos que se distanciem da média pela ocorrência de exceções.

Segundo Koyama (2006), neste modelo a operadora de saúde suplementar praticamente se isenta do risco do negócio, transferindo-o aos prestadores de serviços de saúde, porém este passa a analisar e controlar o acesso e a utilização dos serviços, o que pode gerar conflitos uma vez que a oferta possui regras claras de acesso regulamentadas pela ANS. Neste caso, o conflito costuma surgir quando o prestador identifica um desequilíbrio no valor de determinado pacote e não obter a correção junto à operadora de saúde suplementar. Neste caso, poderá haver restrição ao acesso e utilização dos serviços.

Bessa (2011), aponta para outros pontos positivos para a operadora de saúde suplementar: a previsibilidade dos custos; a possibilidade de redução na despesa com os setores de auditorias de contas; e, a redução dos conflitos que surgem entre as partes com a ocorrência das glosas. Em resumo, a sistemática de produção e cobrança fica muito mais simplificada.

Por outro lado, o prestador passa a ter que aperfeiçoar seus controles, principalmente em relação a possíveis desperdícios nos processos assistenciais e administrativos para evitar que os preços negociados tenham suas margens consumidas pelos desperdícios e pela ineficiência. Uma vez controlados esses pontos, essa sistemática passa a valorizar o prestador mais eficiente, diferentemente no modelo "fee for service" que pode levar a uma acomodação do prestador.

A principal deficiência deste modelo é apontada por Takahashi (2011), que em sua pesquisa observou que os hospitais não fazem os cálculos dos pacotes baseados nos protocolos clínicos ou cirúrgicos utilizados e, sim, determinam seu valor pela média de preços de venda praticados dos eventos semelhantes ocorridos anteriormente.

Takahashi (2011), ainda aponta a participação ativa do Corpo Clínico do hospital como um importante diferencial para a definição e para o posterior cumprimento clínico/cirúrgico dos pacotes definidos. Hospitais com corpo clínico aberto podem ter maior dificuldade na adesão dos médicos aos pacotes definidos. 
Uma variação para o conceito do pagamento por pacote, que é mais utilizado para casos cirúrgicos, é a Diária Global, que é mais utilizada para casos clínicos. Neste caso, costuma-se agrupar os custos hospitalares de estrutura física e equipe, materiais de consumo, medicamentos, utilização de equipamentos, gases medicinais, exames e honorários médicos, criando uma única diária global, independentemente da patologia do paciente (SILVA, 2003). Normalmente ficam excluídos dessa diária global medicamento de alto custo e OPME's.

Também no caso das diárias globais, deve-se atentar para a possibilidade de redução nos níveis de qualidade e oferta de serviços necessários, além da possibilidade de seleção de casos (ANDREAZZI, 2003). 


\section{5 "Diagnosis Related Groups"}

Com os estudos iniciados no final da década de 60, como resposta à demanda gerada pela implantação em 1965 do programa Medicare, já que o programa americano determinava que cada hospital pertencente ao programa deveria ter um comitê de revisão de utilização, buscava-se correlacionar os tipos de pacientes atendidos pelo hospital, com os recursos consumidos durante o período da internação, criando grupos de pacientes coerentes, do ponto de vista clínico e similares ou homogêneos quanto ao consumo dos recursos hospitalares (NORONHA et al, 1991).

Ainda segundo Noronha et al (1991), o objetivo inicial que tinha foco a monitorização da qualidade assistencial e a utilização dos ativos hospitalares, passou também a ser utilizado consequentemente como base para a remuneração desses hospitais, já que com o conhecimento do perfil nosológico dos hospitais e a mensuração dos produtos utilizados obteve-se um melhor gerenciamento logístico dos insumos e melhor controle do processo de trabalho médico.

A partir da experiência americana, vários países começaram a desenvolver pesquisas sobre o tema, tais como: Grã-Bretanha, França, Holanda, Bélgica, Alemanha, Espanha, Itália, Portugal, Áustria, Suíça, Noruega, Dinamarca, Suécia, Finlândia, Austrália, Canadá, Coréia e Brasil. O escopo dos estudos deixou de ser restrito ao âmbito hospitalar e, atualmente, buscase analisar a aplicação do modelo para a saúde como um todo em diversos países (NORONHA et al, 1991).

De acordo com Soares (2012), o DRG é uma classificação de grupos de casos hospitalares que se utiliza de recursos similares para tratamento. Esse agrupamento leva em consideração características relevantes para a composição dos grupos como diagnóstico, procedimentos, idade, sexo, presença ou ausência complicações e/ou comorbidades.

Takahashi (2011) destaca a experiência do estado de Maryland - EUA, que desenvolveu um modelo de DRG na década de 70 e, desde então, possui a menor taxa de aumento dos custos hospitalares do EUA. Esse sucesso está atrelado à capacidade de se cruzar os dados dos resultados obtidos pelos hospitais, com seus respectivos custos e a avaliação de sua qualidade.

O DRG tem evoluído ao longo dos anos em diversos lugares no mundo e algumas variações e adaptações acabam sendo moldadas com a finalidade de se adequar às particularidades locais. Soares (2012), aponta algumas dessas adaptações listando-as: DRG do 
sistema de saúde Medicare, DRG refinados, DRG com gravidade, DRG para todos os pacientes, DRG refinados para todos os pacientes, entre outros. Porém, essas adaptações não serão aqui detalhadas, pois o escopo neste trabalho é apenas apresentar resumidamente os principais modelos de remuneração.

No Brasil, no final de 2012, a ANS divulgou a conclusão dos trabalhos desenvolvidos por um grupo composto de diversos órgãos representativos tanto das operadoras de planos de saúde como dos prestadores de serviços de saúde e coordenados pela própria agência, cujo objetivo era desenvolver um piloto sobre uma nova forma de remuneração, que buscasse a incorporação das boas práticas de gestão em ambos os lados da relação, resultando na redução de custos, principalmente baseado na transformação do tradicional fee for service para a remuneração de protocolos gerenciados (ANS, 2012).

O trabalho previa em sua primeira fase a implantação de 27 procedimentos cirúrgicos que atendiam aos critérios de previsibilidade dos processos assistenciais e representavam grande relevância em termos de frequência e custos. Com isso, esperava-se alcançar os seguintes benefícios: "previsibilidade de custos; racionalização de recursos; envolvimento dos fornecedores de insumos; participação e contribuição das equipes médicas; busca de qualidade e resultados nos serviços prestados; segurança assistencial do paciente; reconhecimento dos resultados e da qualidade dos prestadores de serviços; agilidade das autorizações, faturamento e cobrança pelo prestador; diminuição das divergências e dos conflitos de auditoria que passam a ser sobre a pertinência do procedimento, da análise de risco do paciente e da necessidade de saída do procedimento gerenciado ou não; a discussão prévia sobre a inclusão de novas tecnologias, medicamentos e materiais; manutenção do equilíbrio econômico-financeiro com revisões sistemáticas prévias e periódicas dos Procedimentos Gerenciados, contemplando critérios de reajustes, os quais devem ser livremente negociados entre as partes (critérios x livre negociação)"(ANS, 2012).

Conforme apresentado na figura 3, foram deixadas alternativas para os casos que estivessem compreendidos nos Procedimento Gerenciados nesta primeira etapa do projeto. 
Figura 3 - Proposta de nova sistemática de remuneração para hospitais

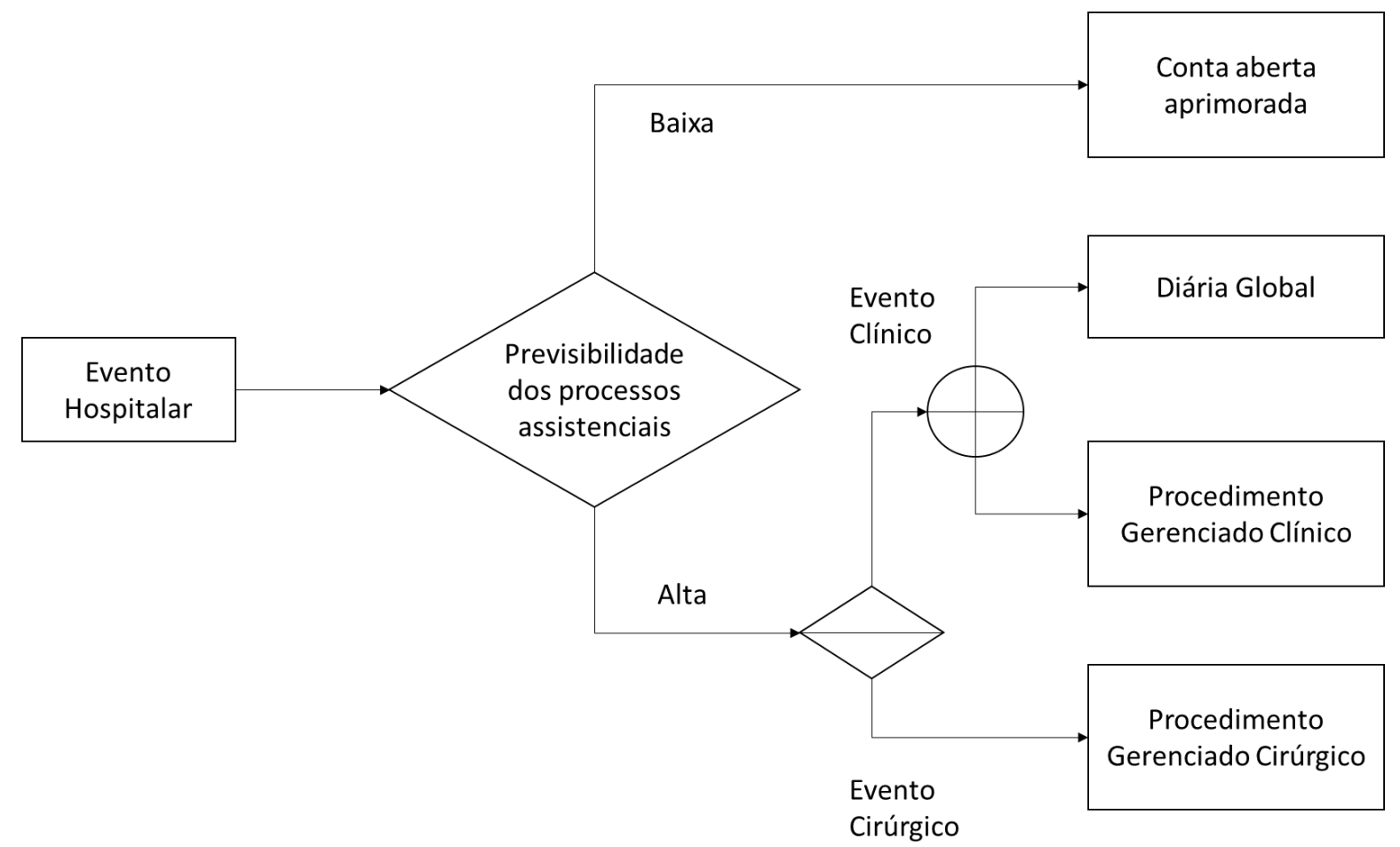

Fonte: ANS (2012)

O piloto foi colocado em prática em maio de 2013, contando com a participação de 17 hospitais de grande porte espalhados pelo Brasil e 9 operadoras e previa 2 etapas: Implementação do Modelo de Conta Aberta Aprimorada nos 3 primeiros meses e Modelo de Procedimentos Gerenciados Cirúrgicos, nos 4 meses subsequentes. Porém, em matéria divulgada pelo jornal Folha de São Paulo, em março de 2014, o presidente da Associação Nacional dos Hospitais Privados afirmou que parecia que a ANS tinha se desinteressado pelo assunto e a própria ANS reconheceu que só metade dos participantes do projeto-piloto continuava no projeto. (ANS, 2012)

Segundo Zanatta (2013), o pagamento por procedimento é o formato mais aplicado nas relações de prestação de serviço de médicos e hospitais na saúde suplementar, superando amplamente as demais formas. Ainda que algumas operadoras de saúde suplementar optem pela verticalização dos serviços, para efeito de cálculo da sinistralidade do plano, o pagamento é contabilizado através do formato "fee for service" entre as unidades de negócios de uma mesma 
operadora. Esse fenômeno é ainda mais evidente nas operadoras e ativos assistenciais de organizações prestadores de saúde "filantrópicas", por exemplo, que, numa proporção considerável, possuem um único CNPJ para a operadora e para os ativos assistenciais, mas ainda assim, contabilizam os custos assistenciais através das tabelas do "fee for service" multiplicadas pela quantidade de eventos ocorridos, ao invés de contabilizar os custos com pessoal, materiais/medicamentos e outros (ZANATTA, 2013).

A verticalização, aliás, tem sido uma saída adotada por diversas operadoras de saúde suplementar, na expectativa de reduzir os custos ou gerenciar melhor alguns serviços de grande impacto no que se refere aos custos de sinistralidade. Diversas Unimeds pelo Brasil, partiram para a construção de estruturas hospitalares próprias visando controlar melhor ou reduzir seus custos operacionais. Na prática, os gastos com os sinistros hospitalares chegam a representar mais de 50\% do total dos custos operacionais de uma operadora de saúde suplementar.

O movimento de verticalização tem sido adotado também para os serviços de oncologia, principalmente em operadoras de saúde suplementar que possui atuação mais local ou regional.

A estratégia de verticalização como tentativa de redução de custos, em diversos casos, não tem gerado a economia esperada e, por outro lado, tem levado a uma redução da qualidade dos serviços ofertados, especialmente porque esta atividade não representa o "core business" da operadora de saúde suplementar.

Considerando o fator redução de custos, um fator importante é o volume para os quais estes serviços verticalizados são montados, já que são dimensionados para uma única operadora de saúde suplementar e não para todo o mercado local.

Sob o aspecto da qualidade dos serviços prestados, o conflito pode surgir quando esta qualidade estiver atrelada a custos mais elevados. Uma vez que a estratégia de verticalização se deu com o objetivo de reduzir custos, pode-se haver uma priorização deste objetivo da operadora de saúde suplementar em detrimento da qualidade dos serviços prestados.

No caso de profissionais de saúde, a unidade de remuneração é representada pela quantidade de atos realizados (número de consultas, número de exames, visitas hospitalares diárias, ato cirúrgico, número de sessões terapêuticas, etc.). No caso da remuneração de hospitais, as unidades são representadas por diárias das acomodações, taxas de uso de salas, equipamentos, instrumentais e procedimentos de equipes especializadas como enfermagem, fisioterapia, entre outras, além das quantidades de materiais, medicamentos e outros insumos como gases medicinais e hemoderivados, por exemplo. 
Para o cálculo dos valores unitários dos atos profissionais, as tabelas mais utilizadas são as disponibilizadas pela Associação Médica Brasileira (AMB) que se dividem em 3 versões: AMB 92, LPM 96 e LPM 99, ou mais recentemente a Classificação Brasileira Hierarquizada de Procedimentos Médicos (CBHPM) criada em 2003, com apoio do Conselho Federal de Medicina (CFM) e da Federação Nacional dos Médicos (FENAM), que já coleciona quase uma dezena de versões nestes 12 anos de existência.

Para a cobrança de materiais e medicamentos, as tabelas predominantemente utilizadas são Brasíndice e SIMPRO que refletem a Lista de Preços de Medicamentos da Câmara de Regulação do Mercado de Medicamentos (CMED) da Agência Nacional de Vigilância Sanitária (ANVISA). O portal da ANVISA (2015) define:

“A lista de Preços de Medicamentos contempla o Preço Fábrica (PF) que é o preço praticado pelas empresas produtoras ou importadoras do produto e pelas empresas distribuidoras. $\mathrm{O}$ PF é o preço máximo permitido para venda a farmácias, drogarias e para entes da Administração Pública. Apresenta, também, o Preço Máximo ao Consumidor (PMC), o qual é praticado pelas farmácias e drogarias. $\mathrm{O}$ PMC é o preço máximo permitido para venda ao consumidor e inclui os impostos incidentes por estado".

Os prestadores de serviços de saúde tradicionalmente utilizam-se do PMC para cobrar os medicamentos das operadoras de saúde suplementar. Já para os materiais, que possuem apenas a referência do PF nas tabelas, convencionou-se aplicar uma margem referente aos custos com aquisição, armazenamento, controle, manipulação, entre outros, para cobrança nas contas dos serviços prestados às operadoras de saúde suplementar. Em alguns casos, os contratos tratam os medicamentos de forma similar aos materiais, fazendo referência ao Preço Fábrica e aplicando a margem referente aos custos citados acima.

O maior ponto de conflito entre operadoras e prestadores encontra-se nesta questão (SILVA, 2003). A concorrência entre as diversas marcas nacionais e importadas dos medicamentos de mesmo princípio ativo ou de materiais similares faz com que os prestadores obtenham descontos na hora da compra em relação aos valores apresentados no PF das tabelas citadas. Cientes destas práticas, as operadoras vêm, constantemente, tentando aplicar deflatores nas margens existentes nestes itens das contas cobradas pelos prestadores (STEFANI, 2005).

Por outro lado, estas margens passaram a ser o fator de sobrevivência dos prestadores, uma vez que as tabelas de remuneração dos trabalhos profissionais e as tabelas de diárias e taxas 
que remuneram os demais custos fixos acabaram ficando defasadas ao longo do tempo (STEFANI, 2005).

Os materiais e medicamentos poderiam ser utilizados de forma racional ou com menor custo se os ganhos estivessem focados no serviço hospitalar e não sobre as margens de materiais e medicamentos (BRITTO, 2011).

Vale ainda destacar iniciativa divulgada no Encontro Nacional de Recursos e Serviços Próprios do Sistema Unimed, em abril de 2015, pela Unimed Federação Santa Catarina, que possui sob sua responsabilidade 22 singulares, sendo 14 operadoras e 8 unidades de prestação de serviços. O projeto previa a migração de margens de materiais e medicamento para diárias e taxas, sem alteração dos montantes totais. Com as premissas de corrigir as distorções atuais do modelo tradicional de remuneração; definir uma metodologia de reajuste anual que pudesse corrigir o aumento real dos custos; e, sem trazer perdas para nenhum lado em termos financeiros, os trabalhos foram conduzidos por consultoria independente de renome no mercado nacional e geraram resultados impressionantes, com aumento percentuais na ordem de $28 \%$ em diárias e taxas e reduções que alcançaram até 76\% em alguns "materiais discrepantes". 


\section{Metodologia: análise da composição de remuneração versus custos num prestador da oncologia}

Este trabalho utiliza os dados de uma clínica ambulatorial de oncologia de médio porte, que realiza tratamento de quimioterapia em aproximadamente 100 pacientes/mês localizada no estado de São Paulo. A identificação da clínica é mantida em sigilo por solicitação dos proprietários. A empresa possui mais de duas décadas de existência e conta com 5 médicos, além de uma equipe composta por 15 profissionais não médicos, entre enfermeiros, farmacêuticos, equipe administrativa e de apoio.

Esta clínica oncológica possui duas atividades principais dentre seus processos de trabalho: a consulta médica para definição do diagnóstico e prescrição do tratamento quimioterápico e a realização desse tratamento através da infusão de medicamentos quimioterápicos.

Os fluxogramas nas figuras 4 e 5 apresentam graficamente o desenvolvimento dessas atividades. 
Figura 4 - Macro Fluxograma do paciente para uma consulta oncológica

\section{MACRO FLUXO - PACIENTE ONCOLÓGICO}

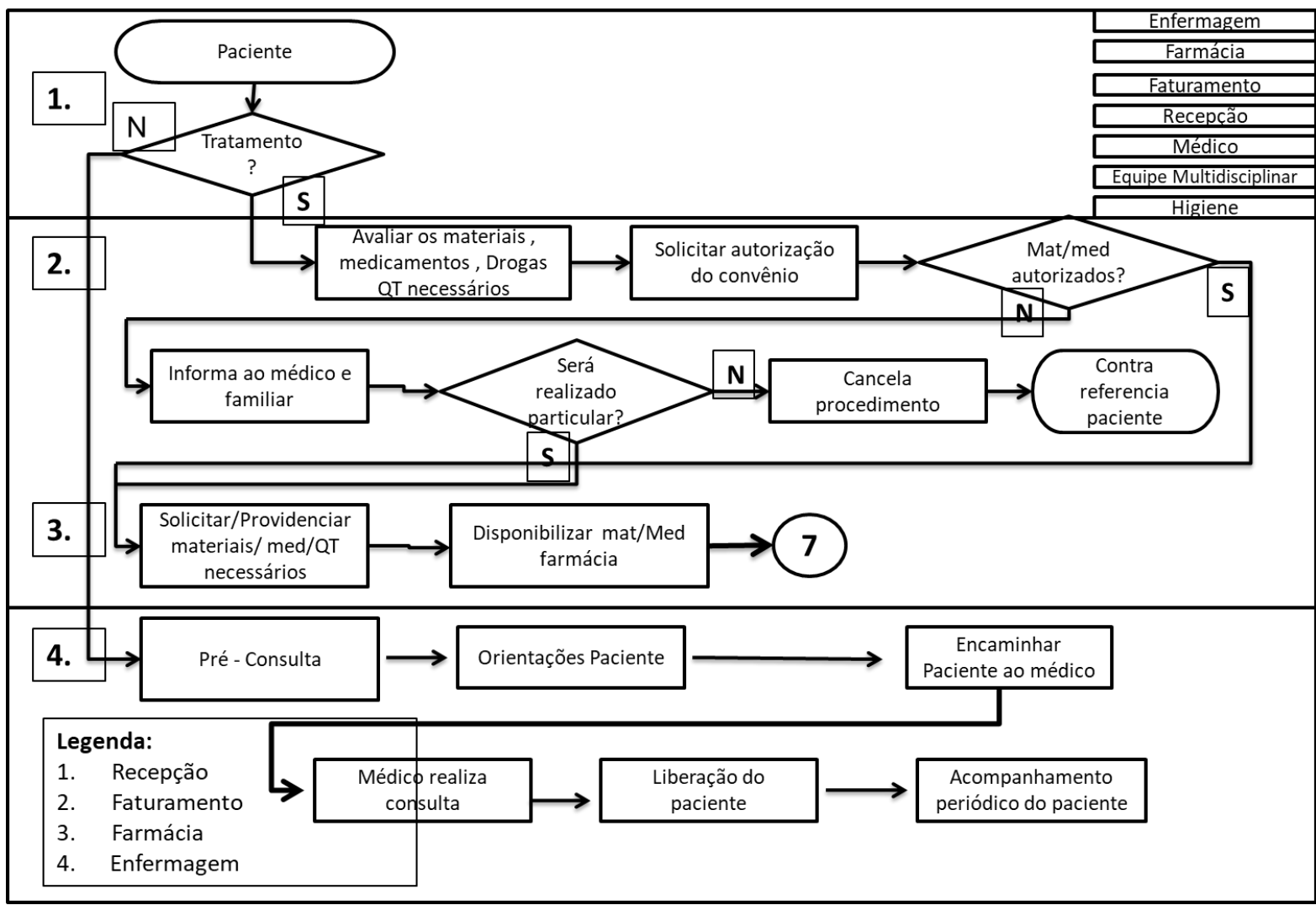

Fonte: Próprio Autor

A cancerologia (oncologia clínica e cirúrgica) é considerada uma especialidade médica que recebe encaminhamento de casos, normalmente já diagnosticados, de outras especialidades médicas, por exemplo, o urologista detecta e encaminha um paciente com câncer de próstata para o oncologista definir o tratamento mais adequado ou um ginecologista ou mastologista detecta e encaminha uma paciente com câncer de mama.

A consulta é agendada na clínica oncológica (área 1, na figura 4). No dia da consulta, o paciente passará por uma pré-consulta realizada pela equipe de enfermagem, na qual serão coletadas informações vitais do paciente, como por exemplo peso, altura, temperatura, pressão, etc. Esses dados serão utilizados pelo médico e receberão uma série de outras informações importantes identificadas durante a consulta médica que servirão de base para a definição do tratamento a ser proposto. 
Na pré-consulta, além de coletar informações, o profissional de enfermagem transfere também uma série de informações importantes para o paciente, realizando uma orientação detalhada com conteúdo previamente definido.

Concluída a pré-consulta, o paciente é encaminhado para a consulta com o oncologista que tem duração média entre 30 (seguimento) e 60 minutos (primeira consulta).

Como resultado desta consulta, o paciente poderá não precisar de nenhum tratamento, passando apenas a ser periodicamente acompanhado e orientado pela equipe composta por médico oncologista e demais profissionais de saúde, entre eles enfermeiro, farmacêutico, psicólogo, fisioterapeuta e nutricionista, ou ainda poderá ser encaminhado para outros tipos de tratamento fora da clínica de quimioterapia (radioterapia e/ou cirurgia, por exemplo).

O outro resultado possível é o encaminhamento deste paciente para o tratamento quimioterápico, o que provoca o início de algumas atividades de suporte em paralelo com a preparação do paciente para o tratamento. Essas atividades paralelas estão descritas nas áreas 2 e 3 da figura 4 e incluem a organização logística para a adequada obtenção dos materiais e medicamento a serem utilizados no dia do tratamento e a liberação das operadoras de saúde suplementar, que condiciona o início do tratamento à sua autorização.

No dia do tratamento (Figura 5), a equipe recepciona o paciente, confere as suas condições físicas para a realização do tratamento e a documentação adequada conforme as normas das operadoras de saúde suplementar. Com todas as condições satisfeitas, o tratamento é realizado pela enfermagem, sempre com a supervisão presencial de um médico no local do tratamento durante todo o período de permanência do paciente, afim de evitar possíveis intercorrências ou realizar procedimentos de emergência e suporte à vida em caso de necessidade.

Um acompanhamento minucioso também é realizado pela equipe técnica da clínica nos dias subsequentes ao tratamento, esclarecendo dúvidas, coletando informações sobre possíveis reações físicas e orientando as melhores condutas.

Todos os pacientes em tratamento devem receber acompanhamento periódico através de consultas médicas que podem ocorrer no dia do tratamento, em dias alternados ou ambos.

O detalhamento das atividades relacionadas ao tratamento quimioterápico está descrito na figura 5. 
Figura 5 - Macro Fluxograma do paciente encaminhado para tratamento de quimioterapia

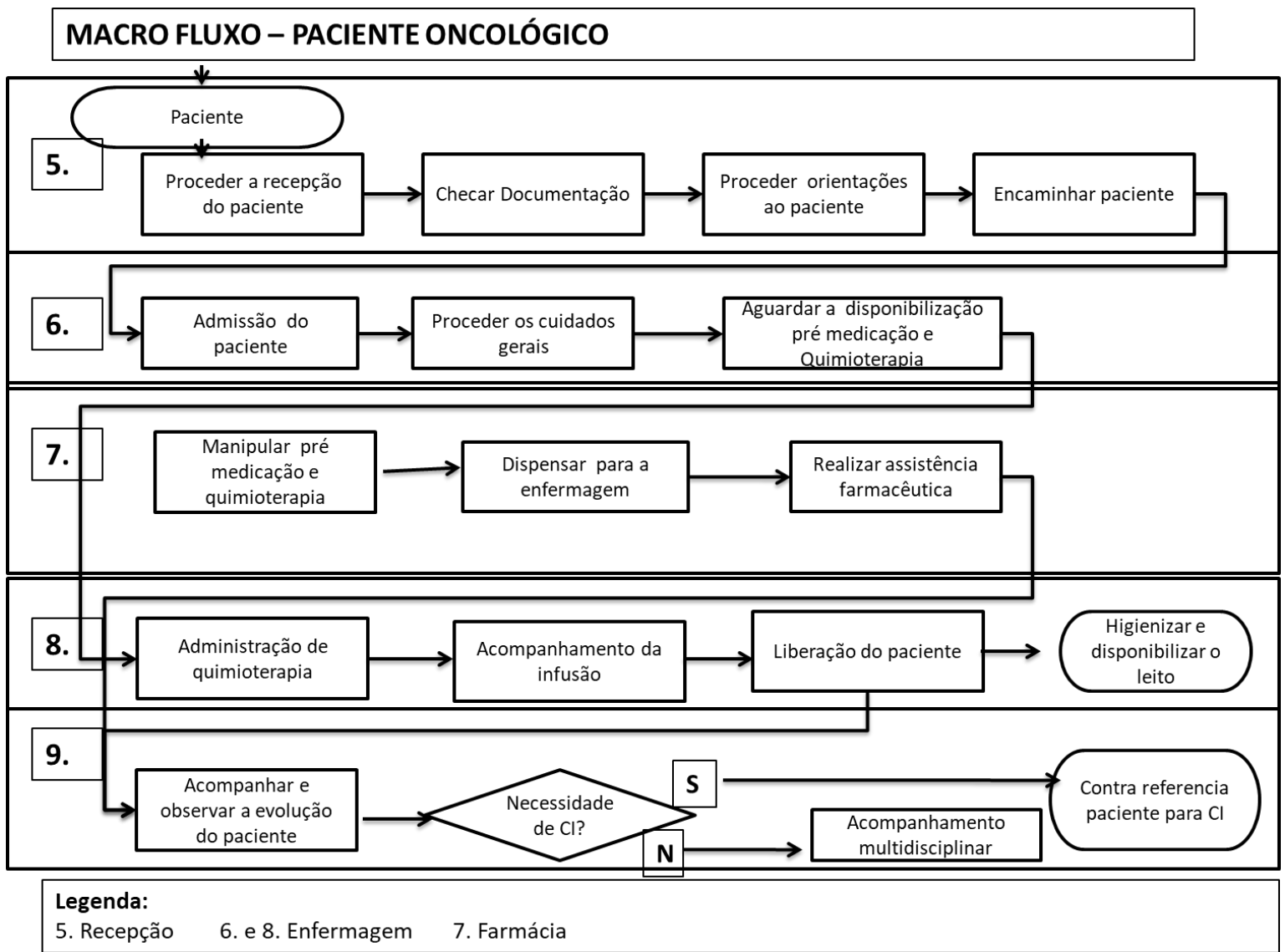

Fonte: Próprio Autor

Compreendido o fluxo de operações, passa-se a detalhar os diversos componentes de remuneração dos serviços prestados.

Os dados da remuneração foram obtidos através de relatórios consolidados de transferência de informações da unidade médica oncológica para as operadoras de saúde. Ressalte-se que o trabalho não teve acesso às informações médicas dos pacientes, apenas aos dados financeiros de transferência.

O quadro 1 demonstra o formato do relatório gerencial que recebe as informações dos relatórios mensais de transferência de informações entre a unidade médica oncológica e as operadoras de saúde. Ele está consolidado, com valores anuais. 
Quadro 1 - Relatório anual de receitas por fonte pagadora

\begin{tabular}{|c|c|c|c|c|c|c|c|c|c|c|c|}
\hline 2015 & \multicolumn{11}{|c|}{ TOTAL } \\
\hline & \multicolumn{2}{|c|}{ Internação } & \multicolumn{2}{|c|}{ Consultas } & \multicolumn{2}{|c|}{ HM quimio } & \multicolumn{2}{|c|}{ Taxa de sala } & \multicolumn{2}{|c|}{ SADT } & \multirow[t]{2}{*}{ Total faturado } \\
\hline CONVÊNIO & $\begin{array}{c}\text { VALOR } \\
\text { FATURADO } \\
\end{array}$ & $\begin{array}{c}\text { № } \\
\text { internações }\end{array}$ & $\begin{array}{c}\text { VALOR } \\
\text { FATURADO } \\
\end{array}$ & \begin{tabular}{|c} 
№ \\
consulta \\
$\mathbf{S}$
\end{tabular} & $\begin{array}{c}\text { VALOR } \\
\text { FATURADO }\end{array}$ & $\begin{array}{c}\text { № } \\
\text { proced }\end{array}$ & \begin{tabular}{|c|} 
VALOR \\
FATURADO
\end{tabular} & $\begin{array}{c}\text { № } \\
\text { proced }\end{array}$ & $\begin{array}{c}\text { VALOR } \\
\text { FATURADO }\end{array}$ & $\begin{array}{c}\text { № } \\
\text { tratamentos }\end{array}$ & \\
\hline OPERADORA A & & & & & & & & & & & \\
\hline OPERADORA B & & & & & & & & & & & \\
\hline OPERADORA C & & & & & & & & & & & \\
\hline TOTAL DE GUIAS FATURADAS - 2015 & & & & & & & & & & & \\
\hline
\end{tabular}

Nos contratos estabelecidos com as operadoras de planos de saúde suplementar, podese subdividir o faturamento de um serviço de saúde especializado na área de oncologia com oferta de tratamento de quimioterapia em 5 grupos:

- Honorários de visitas hospitalares;

- Honorários de consultas médicas;

- Honorários médicos de quimioterapia;

- Taxas (tradicionalmente taxa de sala de quimioterapia);

- Materiais/medicamentos (os contratos tradicionalmente estabelecem uma margem a ser aplicada sobre o Preço Fábrica da Lista de Preços de Medicamentos da Câmara de Regulação do Mercado de Medicamentos. Esta margem corresponde à remuneração pelos custos referentes a aquisição, separação, armazenamento, manipulação, dispensação, entre outras atividades administrativas e técnicas da área de suprimentos e farmácia).

O quadro 2 será a base de análise para as principais conclusões deste trabalho. Nele, os valores dos honorários de quimioterapia são somados aos valores de honorários de internação e de consultas. O total da remuneração dos serviços médicos estão destacados na primeira linha do Quadro 2.

As taxas recebidas para remuneração da estrutura de atendimento estão destacadas na segunda linha do quadro 2, na coluna de receitas. Na terceira linha, o valor representa a remuneração de materiais e medicamentos dos tratamentos realizados.

Vale ainda destacar que a empresa em questão realiza atendimentos privados, sendo a cobrança dos honorários médicos, das taxas e dos materiais e medicamentos realizada diretamente ao paciente. 
Neste estudo, optou-se por tratar a receita de atendimentos privados como uma linha dentro das receitas totais (operadora $\mathrm{T}$ ), na qual predomina a participação de receitas provenientes de operadoras de saúde suplementar. Dois motivos reforçaram essa decisão: o primeiro é que as receitas desses atendimentos são registradas em uma linha separada, o que permitiria facilmente a sua exclusão da análise, porém não existe a mesma separação em relação aos custos desses atendimentos. A estimativa desses custos, necessitariam, então, de uma definição por proporcionalidade, o que o iguala aos demais atendimentos. O segundo motivo relaciona-se à grande proximidade dos valores praticados para atendimentos privados em comparação com atendimentos de beneficiários das operadoras de saúde suplementar. Como tanto os valores das receitas como os custos não geram interferências significativas nos totais, optou-se por incluir os valores dos atendimentos privados no estudo.

Os dados de custos são obtidos pelos relatórios contábeis da instituição oncológica. Neste caso, também não houve acesso aos nomes dos pacientes, mas apenas a dados agregados.

O custo dos serviços médicos, assim como o custo de materiais e medicamentos foram extraídos diretamente do demonstrativo de resultados do exercício da empresa em 2015. Para a linha de custos fixos e variáveis de equipe não médica e custos fixos de estrutura, entre outros, considera-se todos os demais custos e despesas não constantes das linhas de serviços médicos e materiais e medicamentos, além do lucro ou prejuízo do exercício que, neste caso, é somado nesta linha com a intenção de criar uma proporcionalidade percentual entre as duas colunas (Receitas e Custos) e também por ser considerado a remuneração do capital investido no negócio.

Desta forma, ambas as colunas possuem totais equivalentes e são analisadas em formato percentual para apuração do possível desequilíbrio em questão.

Quadro 2 - Estrutura de Remuneração X Custos

\begin{tabular}{|l|l|}
\hline Receitas & Custos \\
\hline Remuneração dos serviços medicos & Custos dos serviços medicos \\
\hline \multirow{2}{*}{ Remuneração de taxas } & Custos fixos e variáveis de equipe não médica \\
\hline Remuneração de materiais e medicamentos & Custos fixos de estrutura e do capital investido \\
\hline
\end{tabular}


Partindo para uma segunda abordagem de análise, buscando-se encontrar o custo unitário dos dois principais serviços prestados pela empresa que são a consulta médica e o tratamento de quimioterapia, utiliza-se, para a apuração dos custos, a metodologia de custeio por absorção nos diversos departamentos da clínica, também utilizando-se para isso, os dados contábeis de 2015.

Metodologia mais tradicional de apuração de custos e aceita pela legislação fiscal brasileira, o custeio por absorção consiste em apropriar todos os custos à produção ou ao serviço prestado. Os custos diretos são diretamente alocados no serviço ou produto e os custos indiretos são alocados por meio de critérios de rateio (KUDLAWICZ, 2010).

Tradicionalmente, no custeio por absorção, é feito uma diferenciação entre o custo e a despesa. Os custos estão diretamente relacionados com a produção. Já as despesas são consideradas operacionais e estão relacionadas às atividades administrativas e gerais. Porém, o processo de operação dos custos hospitalares, compreende uma adaptação a essa versão básica e estende o cálculo dos custos para a totalidade dos insumos, independente da classificação de custos e despesas. Sob esta orientação, a expressão de custeio por absorção passa por uma adaptação e denomina-se custeio por absorção pleno (MATOS, 2005).

Para a apuração dos custos é necessária a organização da clínica em centros de custos, que são classificados da seguinte forma:

- Produtivos - são os departamentos que atendem diretamente os pacientes e realizam as atividades que geram a remuneração como, por exemplo, os consultórios e a quimioterapia (MARTINS, 2000).

- Auxiliares ou de Apoio - são os departamentos que desempenham as atividades de apoio e complementares aos centros de custos produtivos como, por exemplo, a farmácia e limpeza (MARTINS, 2000).

- Administrativos - são os departamentos que desempenham as atividades de manutenção administrativa da clínica como, por exemplo, a administração e o faturamento.

Os centros de custos produtivos utilizados estão apresentados no quadro 3. 
Quadro 3 - Centros de custos produtivos

\begin{tabular}{|l|l|l|}
\hline Cód. & Descrição & Produtos \\
\hline 101 & Oncologia & № de Atendimentos de Oncologia \\
\hline 102 & Geriatria & № de Atendimentos de Geriatria \\
\hline 103 & Hematologia & № de Atendimentos de Hematologia \\
\hline 104 & Genética & № de Atendimentos de Genética \\
\hline 105 & Psicologia & № de Atendimentos de Psicologia \\
\hline 106 & Nutrição & № de Atendimentos de Nutrição \\
\hline 107 & Fisioterapia & № de Sessões de Fisioterapia \\
\hline 108 & Clínica Integrativa & № de Atendimentos da Clínica Integrativa \\
\hline \multirow{2}{*}{109} & \multirow{2}{*}{ Quimioterapia } & Horas de Quimioterapia \\
\cline { 2 - 3 } & & № de Sessões de Quimioterapia \\
\hline 110 & Pré-Consulta & № de Atendimentos de Pré-Consulta \\
\hline 111 & Oncologia Unidade II & № de Atendimentos de Oncologia Unidade II \\
\hline 112 & Hematologia Unidade II & № de Atendimentos de Hematologia Unidade II \\
\hline \multirow{2}{*}{113} & \multirow{2}{*}{ Quimioterapia Unidade II } & Horas de Quimioterapia Unidade II \\
\cline { 3 - 4 } & № de Sessões de Quimioterapia Unidade II \\
\hline 114 & Oncologia Unidade III & № de Atendimentos de Oncologia Unidade III \\
\hline 115 & Hematologia Unidade III & № de Atendimentos de Hematologia Unidade III \\
\hline 116 & \multirow{2}{*}{ Quimioterapia Unidade III } & Horas de Quimioterapia Unidade III \\
\cline { 3 - 4 } & & № de Sessões de Quimioterapia Unidade III \\
\hline 117 & Oncologia Unidade IV & № de Atendimentos de Oncologia Unidade IV \\
\hline 118 & Hematologia Unidade IV & № de Atendimentos de Hematologia Unidade IV \\
\hline \multirow{2}{*}{119} & \multirow{2}{*}{ Quimioterapia Unidade IV } & Horas de Quimioterapia Unidade IV \\
\cline { 3 - 4 } & № de Sessões de Quimioterapia Unidade IV \\
\hline
\end{tabular}

Para extração dos valores desejados no quadro de apuração dos resultados, foram utilizados apenas os custos alocados nos seguintes centros de custo: Oncologia, denominado pelo código 101 e Quimioterapia, denominado pelo código 109, conforme quadro 4.

Quadro 4 - Centros de custos produtivos objeto do estudo

\begin{tabular}{|c|l|l|}
\hline Cód. & Descrição & Produtos \\
\hline 101 & Oncologia & $\mathrm{N}^{\mathrm{o}}$ de Atendimentos de Oncologia \\
\hline 109 & Quimioterapia & $\mathrm{N}^{\mathrm{o}}$ de Sessões de Quimioterapia \\
\hline
\end{tabular}

Os centros de custos auxiliares e os administrativos e seus respectivos critérios de rateio estão apresentados nos quadros 5 e 6 , respectivamente. 
Quadro 5 - Centros de custos auxiliares

\begin{tabular}{|l|l|l|l|l|}
\hline \multicolumn{5}{|l|}{ Centros de Custos Auxiliares } \\
\hline Cód. & Descrição & & Critério de Rateio & Observações/Abrangência \\
\hline 201 & Farmácia & Auxiliar & № de Itens Dispensados - Farmacia & Centros de Custos Produtivos \\
\hline 202 & Almoxarifado & Auxiliar & № de Itens Dispensados - Almoxarifado & Todos os Centros de Custos \\
\hline 203 & Refeitório / Copa & Auxiliar & No de Funcionários & Todos os Centros de Custos \\
\hline 204 & Higiene e Limpeza & Auxiliar & Área $\mathrm{m}^{2}$ & Todos os Centros de Custos \\
\hline 205 & Manutenção & Auxiliar & Área $\mathrm{m}^{2}$ & Todos os Centros de Custos \\
\hline 206 & Segurança & Auxiliar & Área $\mathrm{m}^{2}$ & Todos os Centros de Custos \\
\hline 207 & Resíduos Hospitalares & Auxiliar & Nível de Criticidade - Resíduos & Centros de Custos Produtivos \\
\hline 208 & Transporte & Auxiliar & Km Rodado & Todos os Centros de Custos \\
\hline
\end{tabular}

Quadro 6 - Centros de custos Administrativos

\begin{tabular}{|l|l|l|l|l|}
\hline \multicolumn{5}{|c|}{ Centros de Custos Administrativos } \\
\hline Cód. & Descrição & & Critério de Rateio & Observações/Abrangência \\
\hline 301 & Administração & Administrativo & \% Custos Diretos & Todos os Centros de Custos \\
\hline 302 & Informática & Administrativo & № de Equipamentos de Informática & Todos os Centros de Custos \\
\hline 303 & Recepção & Administrativo & № de Atendimentos/Sessões Totais & Centros de Custos Produtivos \\
\hline 304 & Áreas Comuns & Administrativo & Área m & Todos os Centros de Custos \\
\hline 305 & Recepção Matão & Administrativo & № de Atendimentos/Sessões Totais Matão & Centros de Custos Produtivos \\
\hline
\end{tabular}

Além da definição dos critérios de rateio em cada centro de custo, também é importante classificar cada item de custo como direto ou indireto. Os custos diretos são alocados diretamente em seus respectivos centros de custo. Os custos indiretos necessitam de um critério de rateio pré-definido.

A lista de custos diretos está detalhada no quadro 7 e os custos indiretos estão no quadro 8.

Quadro 7 - Lista de Custos Diretos

(continua)

\begin{tabular}{|l|l|}
\hline Custos Diretos & Classificação \\
\hline Custos com Pessoal & \\
\hline Salários & Fixo \\
\hline Benefícios & Fixo \\
\hline Encargos e Contribuições & Fixo \\
\hline Outras Despesas de Pessoal & Fixo \\
\hline Serviços de Terceiros & Fixo \\
\hline Serviços Médicos & Fixo \\
\hline Custos com Materiais e Medicamentos & \\
\hline Medicamentos & Variável \\
\hline Materiais & Variável \\
\hline Gases Medicinais & Variável \\
\hline Custos com Materiais Gerais & \\
\hline Gêneros Alimentícios & Fixo \\
\hline Material de Escritório/Papéis em Geral/Impressos & Fixo - Aux. e Adm. e Variável - Prod. \\
\hline Material de Informática & Fixo - Aux. e Adm. e Variável - Prod. \\
\hline Peças e Materiais Manutenção & Fixo \\
\hline
\end{tabular}


Quadro 7 - Lista de Custos Diretos

\begin{tabular}{|l|l|} 
Combustíveis e Lubrificantes & Fixo \\
\hline Material de Limpeza & Fixo - Aux. e Adm. e Variável - Prod. \\
\hline Livros/Jornais/Publicações em Geral & Fixo \\
\hline Vestuário e Uniformes & Fixo \\
\hline Outras Despesas de Consumo & Fixo \\
\hline Custos Gerais & \\
\hline Serviços-Manutenção Predial & Fixo \\
\hline Serviços-Manutenção Equipamentos em Geral & Fixo \\
\hline Serviços-Manutenção Equipamentos de Informática & Fixo \\
\hline Serviços-Manutenção de Veículos & Fixo \\
\hline Locação Predial & Fixo \\
\hline Locação Cilindros Gases Medicinais & Fixo \\
\hline Serviços de Limpeza e Higienização & Fixo \\
\hline Serviços de Coleta de Resíduos Hospitalares & Variável \\
\hline Segurança e Vigilância & Fixo \\
\hline TV a Cabo & Fixo \\
\hline Internet a Cabo & Fixo \\
\hline Outros Serviços de Internet & Fixo \\
\hline Cursos & Fixo \\
\hline Serviços de Lavanderia & Variável \\
\hline Licenças de Software & Fixo \\
\hline Honorários Advocatícios & Fixo \\
\hline Despesas com Locomoção e Transporte & Fixo \\
\hline Despesas com Hospedagem e Alimentação & Fixo \\
\hline Despesas com Propaganda e Publicidade & Fixo \\
\hline Fornecimento de Alimentação & Fixo \\
\hline Outros Serviços de Terceiros & Fixo \\
\hline Taxas/Impostos/Contribuiçães & Fixo \\
\hline Gás & Fixo \\
\hline Telefone & Fixo \\
\hline Correio & Fixo \\
\hline Material para Distribuição Gratuita & Fixo \\
\hline Outras & Fixo \\
\hline & \\
\hline
\end{tabular}


Quadro 8 - Lista de custos indiretos

\begin{tabular}{|l|l|l|l|}
\hline Custos Indiretos & Classificação & Base de Rateio & Observações/Abrangência \\
\hline Água Ind. & Variável (Prod.) Fixo (Aux. e Adm.) & \% Consumo de Água & Todos os Centros de Custos \\
\hline Aluguel do Prédio Ind. & Fixo & Área m ${ }^{2}$ & Todos os Centros de Custos \\
\hline Despesas com Propaganda e Publicidade Ind. & Fixo & Linear & Todos os Centros de Custos \\
\hline Energia Elétrica Ind. & Variável (Prod.) Fixo (Aux. e Adm.) & \% Consumo de E. Elétrica & Todos os Centros de Custos \\
\hline Internet Ind. & Fixo & No de Equipamentos de Informática & Todos os Centros de Custos \\
\hline Seguros Predial Ind. & Fixo & Área m ${ }^{2}$ & Todos os Centros de Custos \\
\hline Taxas/Impostos/Contribuições Ind. & Fixo & Área m ${ }^{2}$ & Todos os Centros de Custos \\
\hline Telefone Ind. & Fixo & No de Ramais & Todos os Centros de Custos \\
\hline
\end{tabular}

Após a apuração de todos os custos, conforme apresentado nos quadros 5 a 8, parte-se para o preenchimento final consolidado de cada centro de custo.

O quadro 9 é utilizado pela empresa para o cálculo de cada centro de custo, segundo a metodologia do custeio por absorção. Todos os centros de custo produtivos possuem este modelo preenchido, encontrando-se assim o custo final do respectivo centro de custo e permitindo também a divisão do valor final daquele centro de custo pela quantidade total das unidades produzidas por aquele centro de custo, encontrando-se assim o custo unitário daquele serviço. 
Quadro 9 - Centro de Custo Oncologia

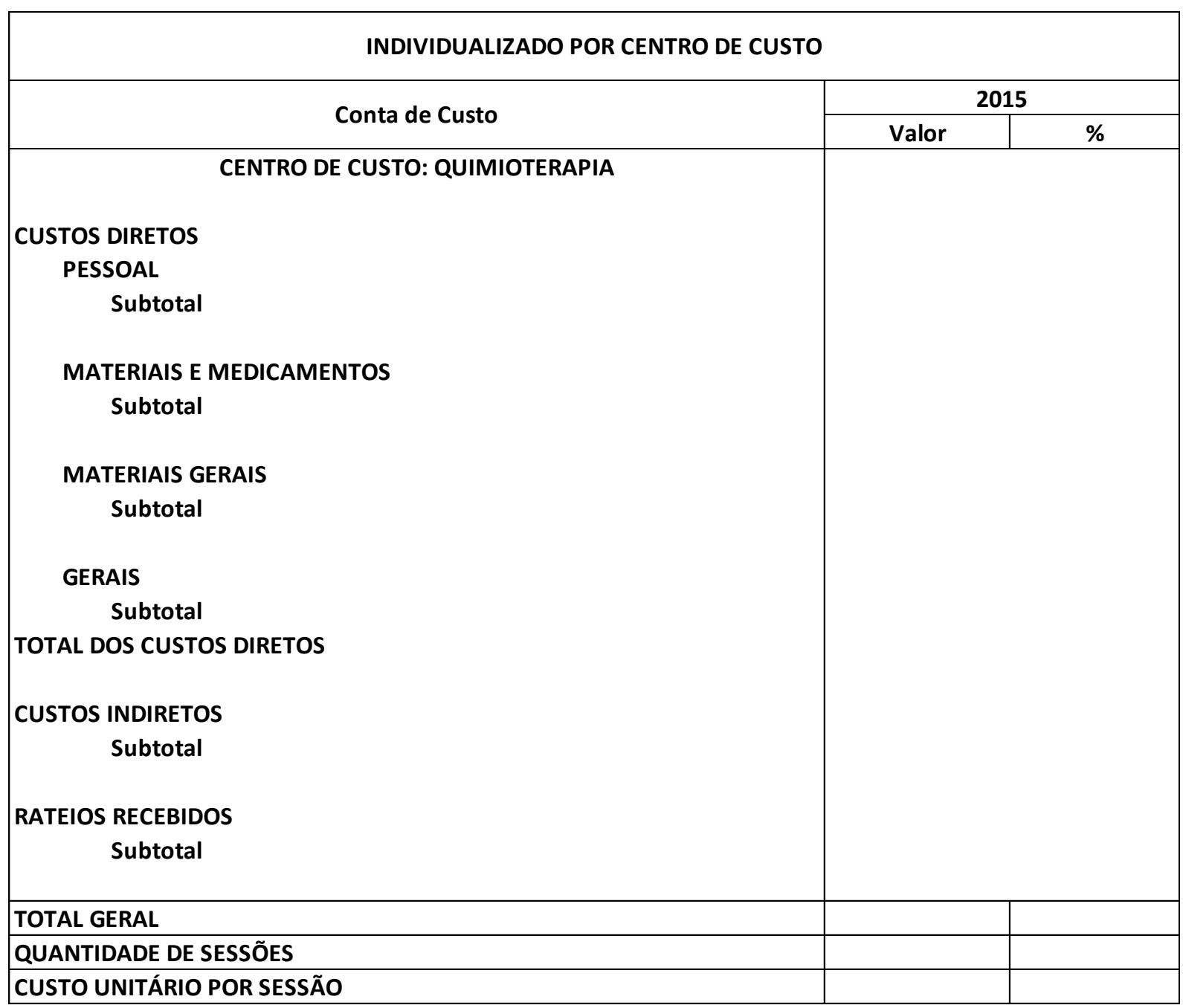

O quadro 10 consolida as informações de todos os centros de custo produtivos com as colunas individualizadas dos custos diretos, indiretos e rateios recebidos, consolidando no custo total. Através da divisão do custo total de cada centro de custo pelas unidades de serviços prestados, encontra-se o custo unitário dos serviços correspondentes a cada centro de custo.

Após a apuração de cada centro de custo produtivo, os valores finais dos centros de custos objeto do estudo serão resumidos no quadro 11, contendo a divisão pelas unidades produzidas durante o exercício de 2015, encontrando-se o custo unitário dessas unidades de produção. 
Quadro 10 - Centros de Custo produtivos

\begin{tabular}{|l|l|l|l|l|l|l|l|}
\hline Cód. & Centro de Custo & $\begin{array}{c}\text { Custos } \\
\text { Diretos }\end{array}$ & $\begin{array}{c}\text { Custos } \\
\text { Indiretos }\end{array}$ & $\begin{array}{c}\text { Rateios } \\
\text { Recebidos }\end{array}$ & $\begin{array}{c}\text { Custo } \\
\text { Total }\end{array}$ & $\begin{array}{c}\text { Unid. de } \\
\text { Produção }\end{array}$ & $\begin{array}{c}\text { Custo } \\
\text { Unitário }\end{array}$ \\
\hline 101 & Oncologia & & & & & & \\
\hline 102 & Geriatria & & & & & & \\
\hline 103 & Hematologia & & & & & & \\
\hline 104 & Genética & & & & & & \\
\hline 105 & Psicologia & & & & & & \\
\hline 106 & Nutrição & & & & & & \\
\hline 107 & Fisioterapia & & & & & & \\
\hline 108 & Clínica Integrativa & & & & & & \\
\hline 109 & Quimioterapia & & & & & & \\
\hline 110 & Pré-Consulta - Hormonioterapia & & & & & & \\
\hline & Pré-Consulta & & & & & \\
\hline 111 & Oncologia Filial 1 & & & & & \\
\hline 112 & Hematologia Filial 1 & & & & & & \\
\hline 113 & Quimioterapia Filial 1 & & & & & & \\
\hline 114 & Oncologia Filial 2 & & & & & & \\
\hline 115 & Hematologia Filial 2 & & & & & & \\
\hline 116 & Quimioterapia Filial 2 & & & & & & \\
\hline 117 & Oncologia Filial 3 & & & & & & \\
\hline 118 & Hematologia Filial 3 & & & & & & \\
\hline 119 & Quimioterapia Filial 3 & & & & & & \\
\hline
\end{tabular}

Quadro 11 - Resumo dos centros de custo objeto do estudo

\begin{tabular}{|c|l|c|c|c|c|c|c|}
\hline Cód. & Centro de Custo & $\begin{array}{c}\text { Custos } \\
\text { Diretos }\end{array}$ & $\begin{array}{c}\text { Custos } \\
\text { Indiretos }\end{array}$ & $\begin{array}{c}\text { Rateios } \\
\text { Recebidos }\end{array}$ & $\begin{array}{c}\text { Custo } \\
\text { Total }\end{array}$ & $\begin{array}{c}\text { Unid. de } \\
\text { Produção }\end{array}$ & $\begin{array}{c}\text { Custo } \\
\text { Unitário }\end{array}$ \\
\hline 101 & Oncologia & & & & & & \\
\hline 109 & Quimioterapia & & & & & & \\
\hline \multicolumn{1}{|c|}{ Total Geral } & & & & & & \\
\hline
\end{tabular}

O quadro 12 apresenta um comparativo entre a remuneração dos serviços destacados, expresso através da média encontrada na remuneração paga pelas operadoras credenciadas e o custo unitário destes serviços.

Quadro 12 - Comparativo entre a remuneração (média) e o respectivo custo do procedimento selecionado

\begin{tabular}{|c|c|c|}
\hline & Remuneração (média) & Custo do procedimento \\
\hline Consulta Médica & & \\
\hline Sala de infusão (sem mat/med) & & \\
\hline
\end{tabular}




\section{Resultados}

Iniciando-se a análise dos resultados, apresenta-se a tabela 1, com os resultados das receitas do ano de 2015 da empresa em estudo. O valor total expresso está de acordo com o total das receitas apresentadas na DRE de 2015.

Tabela 1 - Apuração anual das receitas em 2015

\begin{tabular}{|c|c|c|c|c|c|c|c|c|c|c|c|}
\hline 2015 & \multicolumn{11}{|c|}{ TOTAL } \\
\hline & \multicolumn{2}{|c|}{ Internação } & \multicolumn{2}{|c|}{ Consultas } & \multicolumn{2}{|c|}{ HM quimio } & \multicolumn{2}{|c|}{ Taxa de sala } & \multicolumn{2}{|c|}{ SADT } & \multirow[t]{2}{*}{ Total faturado } \\
\hline CONVÊNIO & $\begin{array}{c}\text { VALOR } \\
\text { FATURADO }\end{array}$ & $\begin{array}{c}\text { № } \\
\text { internações }\end{array}$ & $\begin{array}{c}\text { VALOR } \\
\text { FATURADO }\end{array}$ & \begin{tabular}{|c|} 
№ \\
consulta \\
$\mathrm{s}$
\end{tabular} & $\begin{array}{c}\text { VALOR } \\
\text { FATURADO }\end{array}$ & $\begin{array}{c}\text { № } \\
\text { proced }\end{array}$ & \begin{tabular}{|c|} 
VALOR \\
FATURAD \\
0 \\
\end{tabular} & $\begin{array}{c}\text { № } \\
\text { proced }\end{array}$ & $\begin{array}{c}\text { VALOR } \\
\text { FATURADO }\end{array}$ & $\begin{array}{c}\text { № } \\
\text { tratamentos }\end{array}$ & \\
\hline OPERADORA A & 0 & 0 & 0 & 0 & 0 & 0 & 0 & 0 & 0 & 0 & 0 \\
\hline OPERADORA B & 51 & 1 & 1.876 & 22 & 330 & 21 & 1.985 & 21 & 135.156 & 21 & 139.398 \\
\hline OPERADORA C & 998 & 10 & 4.352 & 69 & 1.824 & 116 & 18.444 & 116 & 789.596 & 116 & 815.215 \\
\hline OPERADORA D & 356 & 2 & 1.064 & 13 & 157 & 10 & 200 & 10 & 66.241 & 10 & 68.018 \\
\hline OPERADORA E & 0 & 0 & 450 & 8 & 79 & 5 & 480 & 5 & 84.166 & 5 & 85.175 \\
\hline OPERADORA F & 2.363 & 6 & 6.935 & 87 & 2.674 & 170 & 16.065 & 170 & 979.692 & 170 & 1.007 .729 \\
\hline OPERADORA G & 1.417 & 4 & 11.098 & 125 & 1.683 & 107 & 4.280 & 107 & 1.055 .804 & 107 & 1.074 .282 \\
\hline OPERADORA H & 109 & 1 & 2.594 & 36 & 739 & 47 & 8.362 & 47 & 180.523 & 47 & 192.328 \\
\hline OPERADORA I & 1.193 & 8 & 15.343 & 229 & 4.231 & 269 & 55.952 & 269 & 1.969 .008 & 269 & 2.045.727 \\
\hline OPERADORA J & 164 & 1 & 6.954 & 103 & 2.910 & 185 & 8.991 & 185 & 1.176 .358 & 185 & 1.195 .376 \\
\hline OPERADORA K & 0 & 0 & 600 & 10 & 189 & 12 & 720 & 12 & 8.967 & 12 & 10.476 \\
\hline OPERADORA L & 69 & 1 & 3.804 & 41 & 1.180 & 75 & 5.070 & 75 & 700.835 & 75 & 710.957 \\
\hline OPERADORA M & 0 & 0 & 168 & 4 & 0 & 0 & 0 & 0 & 0 & 0 & 168 \\
\hline OPERADORA N & 2.200 & 4 & 3.720 & 63 & 1.494 & 95 & 5.700 & 95 & 509.540 & 95 & 522.654 \\
\hline OPERADORA O & 0 & 0 & 615 & 7 & 204 & 13 & 1.040 & 13 & 103.300 & 13 & 105.159 \\
\hline OPERADORA P & 0 & 0 & 1.580 & 20 & 362 & 23 & 3.795 & 23 & 208.335 & 23 & 214.072 \\
\hline OPERADORA Q & 552 & 3 & 7.165 & 139 & 3.728 & 237 & 5.084 & 237 & 654.677 & 237 & 671.206 \\
\hline OPERADORA R & 0 & 0 & 270 & 6 & 47 & 3 & 330 & 3 & 18.946 & 3 & 19.593 \\
\hline OPERADORAS & 0 & 0 & 3.316 & 48 & 220 & 14 & 700 & 14 & 40.291 & 14 & 44.527 \\
\hline OPERADORA T & 19.245 & 9 & 166.810 & 341 & 3.539 & 225 & 85.500 & 225 & 1.396 .795 & 225 & 1.671 .890 \\
\hline OPERADORA U & 0 & 0 & 22.403 & 498 & 6.323 & 402 & 18.090 & 402 & 2.221 .350 & 402 & 2.268.166 \\
\hline OPERADORA V & 0 & 0 & 13.457 & 293 & 3.948 & 251 & 11.295 & 251 & 1.282 .552 & 251 & 1.311 .252 \\
\hline TOTAL DE GUIAS FATURADAS - 2015 & 28.717 & 50 & 274.574 & 2.162 & 35.860 & 2.280 & 252.082 & 2.280 & 13.582.132 & 2.280 & 14.173.366 \\
\hline
\end{tabular}

$\mathrm{Na}$ tabela 1, portanto, conclui-se que a clínica realizou durante o ano de 2015, 50 internações que geraram honorários médicos de $\mathrm{R} \$ 28.717,00 ; 2162$ consultas que geraram honorários médicos de $\mathrm{R} \$ 274.574,00$ e 2280 tratamentos de quimioterapia que geraram honorários de $\mathrm{R} \$ 35.860,00$, totalizando um valor de honorários médicos de $\mathrm{R}$ \$339.151,00. 
A remuneração das taxas totaliza $\mathrm{R} \$ 252.082,00$ para os 2280 procedimentos realizados. Já a remuneração dos materiais e medicamentos totaliza $\mathrm{R} \$ 13.582 .132,00$ para os mesmos 2280 procedimentos realizados em 2015.

A partir da tabela 1, consolida-se os dados de honorários para o preenchimento da tabela 2 que reunirá todos as informações de receitas consolidadas para a tabela 3.

Tabela 2 - Total das receitas, segmentada de acordo com os critérios desejados no estudo.

\begin{tabular}{|l|c|c|c|c|c|c|c|}
\hline \multicolumn{1}{|c|}{2015} & \multicolumn{2}{|c|}{ Honorários } & \multicolumn{2}{c|}{ Taxas } & \multicolumn{2}{c|}{$\begin{array}{c}\text { Materiais e } \\
\text { Medicamentos }\end{array}$} & $\begin{array}{c}\text { Total } \\
\text { faturado }\end{array}$ \\
\hline CONVÊNIO & $\begin{array}{c}\text { Valor } \\
\text { Faturado }\end{array}$ & $\begin{array}{c}\text { № } \\
\text { Atend }\end{array}$ & $\begin{array}{c}\text { Valor } \\
\text { Faturado }\end{array}$ & $\begin{array}{c}\text { № } \\
\text { Atend }\end{array}$ & $\begin{array}{c}\text { Valor } \\
\text { Faturado }\end{array}$ & $\begin{array}{c}\text { № } \\
\text { Atend }\end{array}$ & \\
\hline TOTAL & 339.151 & 2212 & 252.082 & 2280 & 13.582 .132 & 2280 & 14.173 .366 \\
\hline
\end{tabular}

Como dito anteriormente, a partir dos dados obtidos na tabela 2, compõe-se a coluna de receitas da tabela 3 , onde também teremos a avaliação percentual de cada componente em relação ao total das receitas.

Tabela 3 - Comparativo com valores e percentuais confrontando as receitas com seus respectivos componentes de custos

\begin{tabular}{|c|c|c|c|c|c|}
\hline Receitas & 14.173.366 & $100 \%$ & Custos & 14.173 .366 & $100 \%$ \\
\hline $\begin{array}{l}\text { Remuneração dos serviços } \\
\text { médicos }\end{array}$ & 339.151 & $2 \%$ & Custos dos serviços médicos & 2.039 .055 & $14 \%$ \\
\hline Remuneração de taxas & 252.082 & $2 \%$ & $\begin{array}{l}\text { Custos fixos e variáveis de } \\
\text { equipes, estrutura, entre } \\
\text { outros }\end{array}$ & 6.176 .809 & $44 \%$ \\
\hline $\begin{array}{l}\text { Remuneração de } \\
\text { materiais e medicamentos }\end{array}$ & 13.582 .132 & $96 \%$ & $\begin{array}{l}\text { Custos de materiais e } \\
\text { medicamentos }\end{array}$ & 5.957 .502 & $42 \%$ \\
\hline
\end{tabular}

Para o preenchimento da coluna de custos deve-se considerar os seguintes ajustes:

- Aos custos médicos explícitos no DRE da empresa (R \$ 743.055,00), deve-se somar a remuneração médica que era paga via distribuição de dividendos aos sócios médicos da empresa ( $\mathrm{R} \$ 1.296 .000,00)$ e que, portanto, estaria incluída na linha custos fixos e variáveis de equipes, estrutura entre outros. 
- Aos materiais e medicamentos, deve-se somar outros insumos que são dispensados diretamente ao paciente, como dietas e outros insumos afins. Esses valores não são representativos no montante total $(0,1 \%)$ e tampouco possuem remuneração junto às operadoras de saúde suplementar.

A linha de custos dos serviços médicos totaliza $\mathrm{R} \$ 2.039 .055,00$, representando $14 \%$ do total dos custos. Os custos com materiais e medicamentos totalizam R $\$$ 5.957.502,00 representando $42 \%$ do total dos custos. A linha de custos fixos e variáveis de equipes não médicas, estrutura, entre outros, totaliza R \$ 6.176.809,00, representando 44\% do total dos custos.

Partindo para a construção dos resultados visando a definição do custo unitário de uma consulta e de um procedimento de quimioterapia, confrontando-o com a remuneração média da consulta médica e dos honorários médicos de quimioterapia, tem-se na tabela 4, a alocação dos custos com pessoal próprio, terceirizado e equipe médica em cada centro produtivo. 
Tabela 4 - Cálculo do custo de pessoal próprio, terceirizado e equipe médica

\begin{tabular}{|c|c|c|c|c|c|c|c|c|c|}
\hline \multirow[b]{2}{*}{ Cód. } & \multirow[b]{2}{*}{ Descrição } & \multirow{2}{*}{$\begin{array}{l}\text { Critério de Rateio } \\
\text { № de Funcionários }\end{array}$} & \multicolumn{7}{|c|}{ Custo Direto } \\
\hline & & & Salários* & Benefícios** & $\begin{array}{c}\text { Encargos e } \\
\text { Contribuições*** }\end{array}$ & $\begin{array}{c}\text { Outras Despesas de } \\
\text { Pessoal }\end{array}$ & $\begin{array}{c}\text { Serviços de } \\
\text { Terceiros }\end{array}$ & $\begin{array}{l}\text { Serviços } \\
\text { Médicos }\end{array}$ & TOTAL \\
\hline \multicolumn{10}{|c|}{ Centros de Custos Produtivos } \\
\hline 101 & Oncologia & 1 & - & - & - & - & - & 286.718 & $349.604,69$ \\
\hline 102 & Geriatria & - & - & - & - & - & - & - & - \\
\hline 103 & Hematologia & - & - & - & - & - & - & 31.515 & $38.427,28$ \\
\hline 104 & Genética & - & - & - & - & - & - & - & - \\
\hline 105 & Psicologia & - & - & - & - & - & - & - & - \\
\hline 106 & Nutrição & - & - & - & - & - & - & - & - \\
\hline 107 & Fisioterapia & - & - & - & - & - & - & - & - \\
\hline 108 & Clínica Integrativa & - & - & - & - & - & - & 24.417 & $29.772,79$ \\
\hline 109 & Quimioterapia & 5 & 143.485 & 15.849 & 49.601 & - & 17.024 & 362.125 & $564.558,81$ \\
\hline 110 & Pré-Consulta & - & 22.075 & 2.438 & 7.631 & - & 2.619 & - & $18.924,26$ \\
\hline 111 & Oncologia Filial 1 & - & - & - & - & - & - & 40.596 & $49.499,51$ \\
\hline 112 & Hematologia Filial 1 & - & - & - & - & - & - & 63.030 & $76.854,56$ \\
\hline 113 & Quimioterapia Filial 1 & - & 44.149 & 4.877 & 15.262 & - & 5.238 & 68.511 & $121.386,07$ \\
\hline 114 & Oncologia Filial 2 & - & - & - & - & - & - & 27.747 & $33.832,71$ \\
\hline 115 & Hematologia Filial 2 & - & - & - & - & - & - & - & - \\
\hline 116 & Quimioterapia Filial 2 & - & 11.037 & 1.219 & 3.815 & - & 1.310 & - & $9.462,13$ \\
\hline 117 & Oncologia Filial 3 & - & - & - & - & - & - & - & - \\
\hline 118 & Hematologia Filial 3 & - & - & - & - & - & - & - & - \\
\hline 119 & Quimioterapia Filial 3 & - & - & - & - & - & - & - & - \\
\hline \multicolumn{10}{|c|}{ Centros de Custos Auxiliares } \\
\hline 201 & Farmácia & 3 & 119.787 & 22.706 & 41.409 & - & 27.212 & - & $126.268,90$ \\
\hline 202 & Almoxarifado & - & - & - & - & - & - & - & - \\
\hline 203 & Refeitório / Copa & 1 & 28.596 & 8.765 & 9.885 & - & - & - & $20.328,38$ \\
\hline 204 & Higiene e Limpeza & 2 & 55.724 & 7.372 & 19.263 & - & - & - & $37.250,30$ \\
\hline 205 & Manutenção & 1 & 10.479 & 2.542 & 3.623 & - & - & - & $7.286,42$ \\
\hline 206 & Segurança & 2 & 38.341 & 6.063 & 13.254 & - & - & - & $25.871,28$ \\
\hline 207 & Resíduos Hospitalares & - & - & - & - & - & - & - & - \\
\hline 208 & Transporte & - & - & - & - & - & - & - & - \\
\hline \multicolumn{10}{|c|}{ Centros de Custos Administrativos } \\
\hline 301 & Administração & 5 & 75.718 & 13.832 & 26.175 & - & 164.568 & - & $320.813,26$ \\
\hline 302 & Informática & - & - & - & - & - & - & - & - \\
\hline 303 & Recepção & 2 & 43.128 & 17.900 & 14.909 & - & - & - & $31.797,96$ \\
\hline 304 & Áreas Comuns & - & - & - & - & - & - & - & - \\
\hline 305 & Recepção Filial 1 & - & - & - & - & - & - & - & - \\
\hline \multicolumn{2}{|r|}{ Total } & 20 & 592.520 & 103.565 & 204.827 & - & 217.971 & 743.055 & $1.861 .939,31$ \\
\hline
\end{tabular}

Em seguida, nas tabelas 5 a 13, realiza-se o rateio de diversos outros custos como aluguel, impostos, gastos com transporte, telefonia, energia, água, internet, materiais/ medicamentos, resíduos e publicidade e propaganda. 
Tabela 5 - Rateio de aluguel e impostos, proporcional por área ocupada

\begin{tabular}{|c|c|c|c|c|}
\hline \multirow{2}{*}{ Cód. } & \multirow{2}{*}{ Descrição } & Critério de Rateio & \multirow{2}{*}{ Aluguel Ind. } & \multirow{2}{*}{$\begin{array}{l}\text { Taxas/Impostos/C } \\
\text { ontribuições Ind. }\end{array}$} \\
\hline & & Área $\mathrm{m}^{2}$ & & \\
\hline \multicolumn{5}{|c|}{ Centros de Custos Produtivos } \\
\hline 101 & Oncologia & 57 & $\mathrm{R} \$ 22.248,64$ & $\mathrm{R} \$ 426,99$ \\
\hline 102 & Geriatria & 7 & $\mathrm{R} \$ 2.311,55$ & $\mathrm{R} \$ 44,36$ \\
\hline 103 & Hematologia & 6 & $\mathrm{R} \$ 2.167,08$ & $\mathrm{R} \$ 41,59$ \\
\hline 104 & Genética & 16 & $\mathrm{R} \$ 6.501,23$ & $\mathrm{R} \$ 124,77$ \\
\hline 105 & Psicologia & 7 & $\mathrm{R} \$ 866,83$ & $R \$ 16,64$ \\
\hline 106 & Nutrição & 3 & $\mathrm{R} \$ 1.589,19$ & $\mathrm{R} \$ 30,50$ \\
\hline 107 & Fisioterapia & 4 & $\mathrm{R} \$ 144,47$ & $\mathrm{R} \$ 2,77$ \\
\hline 108 & Clínica Integrativa & 2 & $\mathrm{R} \$ 722,36$ & $R \$ 13,86$ \\
\hline 109 & Quimioterapia & 145 & $\mathrm{R} \$ 52.794,29$ & $\mathrm{R} \$ 1.013,22$ \\
\hline 110 & Pré-Consulta & 9 & $R \$ 3.289,53$ & $\mathrm{R} \$ 63,13$ \\
\hline 111 & Oncologia Filial 1 & - & $\mathrm{R} \$ 0,00$ & $\mathrm{R} \$ 0,00$ \\
\hline 112 & Hematologia Filial 1 & - & $\mathrm{R} \$ 0,00$ & $\mathrm{R} \$ 0,00$ \\
\hline 113 & Quimioterapia Filial 1 & - & $\mathrm{R} \$ 0,00$ & $\mathrm{R} \$ 0,00$ \\
\hline 114 & Oncologia Filial 2 & - & $\mathrm{R} \$ 0,00$ & $\mathrm{R} \$ 0,00$ \\
\hline 115 & Hematologia Filial 2 & - & $\mathrm{R} \$ 0,00$ & $\mathrm{R} \$ 0,00$ \\
\hline 116 & Quimioterapia Filial 2 & - & $\mathrm{R} \$ 0,00$ & $\mathrm{R} \$ 0,00$ \\
\hline 117 & Oncologia Filial 3 & - & $R \$ 0,00$ & $\mathrm{R} \$ 0,00$ \\
\hline 118 & Hematologia Filial 3 & - & $\mathrm{R} \$ 0,00$ & $\mathrm{R} \$ 0,00$ \\
\hline 119 & Quimioterapia Filial 3 & - & $R \$ 0,00$ & $\mathrm{R} \$ 0,00$ \\
\hline \multicolumn{5}{|c|}{ Centros de Custos Auxiliares } \\
\hline 201 & Farmácia & 49 & $\mathrm{R} \$ 18.009,44$ & $\mathrm{R} \$ 345,64$ \\
\hline 202 & Almoxarifado & - & $\mathrm{R} \$ 0,00$ & $\mathrm{R} \$ 0,00$ \\
\hline 203 & Refeitório / Copa & 46 & $\mathrm{R} \$ 16.954,57$ & $\mathrm{R} \$ 325,39$ \\
\hline 204 & Higiene e Limpeza & 23 & $\mathrm{R} \$ 8.556,60$ & $\mathrm{R} \$ 164,22$ \\
\hline 205 & Manutenção & - & $R \$ 0,00$ & $\mathrm{R} \$ 0,00$ \\
\hline 206 & Segurança & - & $\mathrm{R} \$ 0,00$ & $\mathrm{R} \$ 0,00$ \\
\hline 207 & Resíduos Hospitalares & 1 & $\mathrm{R} \$ 499,17$ & $\mathrm{R} \$ 9,58$ \\
\hline 208 & Transporte & 17 & $\mathrm{R} \$ 6.190,66$ & $\mathrm{R} \$ 118,81$ \\
\hline \multicolumn{5}{|c|}{ Centros de Custos Administrativos } \\
\hline 301 & Administração & 33 & $\mathrm{R} \$ 11.969,22$ & $\mathrm{R} \$ 229,71$ \\
\hline 302 & Informática & - & $\mathrm{R} \$ 0,00$ & $\mathrm{R} \$ 0,00$ \\
\hline 303 & Recepção & 10 & $R \$ 3.464,58$ & $\mathrm{R} \$ 66,49$ \\
\hline 304 & Áreas Comuns & 906 & $\mathrm{R} \$ 330.580,13$ & $\mathrm{R} \$ 6.344,47$ \\
\hline 305 & Recepção Filial 1 & - & $R \$ 0,00$ & $\mathrm{R} \$ 0,00$ \\
\hline & Total & 1.340 & $\mathrm{R} \$ \mathbf{4 8 8 . 8 5 9 , 5 2}$ & $\mathrm{R} \$ \mathbf{9 . 3 8 2 , 1 5}$ \\
\hline
\end{tabular}

O rateio dos valores pagos de aluguéis e IPTU foram rateados considerando-se a área ocupada por cada centro de custo, inclusive os centros de custos auxiliares e administrativos que, na sequência serão também rateados para os centos de custos produtivos. 
Tabela 6 - Rateio dos custos com transportes

\begin{tabular}{|c|c|c|c|c|c|}
\hline \multirow{2}{*}{ Cód. } & \multirow{2}{*}{ Descrição } & Critério de Rateio & \multirow{2}{*}{$\begin{array}{c}\text { Combustíveis e } \\
\text { Lubrificantes }\end{array}$} & \multirow{2}{*}{$\begin{array}{c}\text { Despesas com Locomoção } \\
\text { e Transporte }\end{array}$} & \multirow{2}{*}{ TOTAL } \\
\hline & & Km Rodado & & & \\
\hline \multicolumn{6}{|c|}{ Centros de Custos Produtivos } \\
\hline 101 & Oncologia & - & $\mathrm{R} \$ 0,00$ & $\mathrm{R} \$ 0,00$ & $\mathrm{R} \$ 0,00$ \\
\hline 102 & Geriatria & - & $R \$ 0,00$ & $R \$ 0,00$ & $R \$ 0,00$ \\
\hline 103 & Hematologia & - & $R \$ 0,00$ & $R \$ 0,00$ & $\mathrm{R} \$ 0,00$ \\
\hline 104 & Genética & - & $\mathrm{R} \$ 0,00$ & $R \$ 0,00$ & $\mathrm{R} \$ 0,00$ \\
\hline 105 & Psicologia & - & $R \$ 0,00$ & $R \$ 0,00$ & $\mathrm{R} \$ 0,00$ \\
\hline 106 & Nutrição & - & $R \$ 0,00$ & $R \$ 0,00$ & $\mathrm{R} \$ 0,00$ \\
\hline 107 & Fisioterapia & - & $R \$ 0,00$ & $R \$ 0,00$ & $\mathrm{R} \$ 0,00$ \\
\hline 108 & Clínica Integrativa & - & $R \$ 0,00$ & $\mathrm{R} \$ 0,00$ & $\mathrm{R} \$ 0,00$ \\
\hline 109 & Quimioterapia & - & $R \$ 0,00$ & $R \$ 0,00$ & $\mathrm{R} \$ 0,00$ \\
\hline 110 & Pré-Consulta & - & $R \$ 0,00$ & $R \$ 0,00$ & $\mathrm{R} \$ 0,00$ \\
\hline 111 & Oncologia Filial 1 & - & $R \$ 0,00$ & $\mathrm{R} \$ 0,00$ & $\mathrm{R} \$ 0,00$ \\
\hline 112 & Hematologia Filial 1 & - & $\mathrm{R} \$ 0,00$ & $R \$ 0,00$ & $\mathrm{R} \$ 0,00$ \\
\hline 113 & Quimioterapia Filial 1 & 2.405 & $\mathrm{R} \$ 13.578,01$ & $R \$ 2.400,52$ & $\mathrm{R} \$ 15.952,90$ \\
\hline 114 & Oncologia Filial 2 & - & $\mathrm{R} \$ 0,00$ & $R \$ 0,00$ & \\
\hline 115 & Hematologia Filial 2 & - & $R \$ 0,00$ & $R \$ 0,00$ & \\
\hline 116 & Quimioterapia Filial 2 & 429 & $\mathrm{R} \$ 2.414,89$ & $\mathrm{R} \$ 428,20$ & $\mathrm{R} \$ 2.828,72$ \\
\hline 117 & Oncologia Filial 3 & - & $\mathrm{R} \$ 0,00$ & $R \$ 0,00$ & $R \$ 0,00$ \\
\hline 118 & Hematologia Filial 3 & - & $\mathrm{R} \$ 0,00$ & $R \$ 0,00$ & $\mathrm{R} \$ 0,00$ \\
\hline 119 & Quimioterapia Filial 3 & - & $R \$ 0,00$ & $R \$ 0,00$ & $\mathrm{R} \$ 0,00$ \\
\hline \multicolumn{2}{|r|}{ Total } & 2.834 & $\mathrm{R} \$ 15.992,90$ & $\mathrm{R} \$ 2.828,72$ & $\mathrm{R} \$ 18.781,62$ \\
\hline
\end{tabular}

A empresa possui um veículo próprio que é utlizado exclusivamente para deslocamento dos profissionais e dos materiais e medicamentos para a realização de tratamentos de quimioterapia nas filiais. Portanto, as despesas foram rateadas de acordo com o número de procedimentos realizados nas filiais. 
Tabela 7 - Rateio dos gastos com telefonia

\begin{tabular}{|c|c|c|c|}
\hline \multirow{2}{*}{ Cód. } & \multirow{2}{*}{ Descrição } & \multirow{2}{*}{$\begin{array}{c}\text { Critério de Rateio } \\
\text { № de Ramais }\end{array}$} & \multirow{2}{*}{ Telefone Ind. } \\
\hline & & & \\
\hline \multicolumn{4}{|c|}{ Centros de Custos Produtivos } \\
\hline 101 & Oncologia & 3 & $\mathrm{R} \$ 2.880,05$ \\
\hline 102 & Geriatria & 0 & $\mathrm{R} \$ 299,23$ \\
\hline 103 & Hematologia & 0 & $R \$ 280,52$ \\
\hline 104 & Genética & 1 & $\mathrm{R} \$ 841,57$ \\
\hline 105 & Psicologia & 0 & $\mathrm{R} \$ 112,21$ \\
\hline 106 & Nutrição & 0 & $\mathrm{R} \$ 205,72$ \\
\hline 107 & Fisioterapia & 0 & $\mathrm{R} \$ 18,70$ \\
\hline 108 & Clínica Integrativa & 0 & $R \$ 93,51$ \\
\hline 109 & Quimioterapia & 4 & $R \$ 3.785,20$ \\
\hline 110 & Pré-Consulta & - & $\mathrm{R} \$ 0,00$ \\
\hline 111 & Oncologia Filial 1 & - & $\mathrm{R} \$ 0,00$ \\
\hline 112 & Hematologia Filial 1 & - & $\mathrm{R} \$ 0,00$ \\
\hline 113 & Quimioterapia Filial 1 & - & $R \$ 0,00$ \\
\hline 114 & Oncologia Filial 2 & - & $R \$ 0,00$ \\
\hline 115 & Hematologia Filial 2 & - & $R \$ 0,00$ \\
\hline 116 & Quimioterapia Filial 2 & - & $\mathrm{R} \$ 0,00$ \\
\hline 117 & Oncologia Filial 3 & - & $R \$ 0,00$ \\
\hline 118 & Hematologia Filial 3 & - & $R \$ 0,00$ \\
\hline 119 & Quimioterapia Filial 3 & - & $R \$ 0,00$ \\
\hline \multicolumn{4}{|c|}{ Centros de Custos Auxiliares } \\
\hline 201 & Farmácia & 3 & $\mathrm{R} \$ 2.838,90$ \\
\hline 202 & Almoxarifado & - & $\mathrm{R} \$ 0,00$ \\
\hline 203 & Refeitório / Copa & 1 & $\mathrm{R} \$ 946,30$ \\
\hline 204 & Higiene e Limpeza & - & $\mathrm{R} \$ 0,00$ \\
\hline 205 & Manutenção & - & $\mathrm{R} \$ 0,00$ \\
\hline 206 & Segurança & - & $\mathrm{R} \$ 0,00$ \\
\hline 207 & Resíduos Hospitalares & - & $R \$ 0,00$ \\
\hline 208 & Transporte & - & $R \$ 0,00$ \\
\hline \multicolumn{4}{|c|}{ Centros de Custos Administrativos } \\
\hline 301 & Administração & 7 & $R \$ 6.624,11$ \\
\hline 302 & Informática & - & $\mathrm{R} \$ 0,00$ \\
\hline 303 & Recepção & 2 & $\mathrm{R} \$ 1.892,60$ \\
\hline 304 & Áreas Comuns & - & $R \$ 0,00$ \\
\hline 305 & Recepção Filial 1 & - & $R \$ 0,00$ \\
\hline \multicolumn{2}{|r|}{ Total } & 22 & $\mathrm{R} \$ 20.818,62$ \\
\hline
\end{tabular}

Os gastos com telefonia foram rateados de acordo com quantidade de ramais instalados em cada setor. 
Tabela 8 - Gastos com energia elétrica

\begin{tabular}{|c|c|c|c|c|c|c|}
\hline \multirow{2}{*}{ Cód. } & \multirow{2}{*}{ Descrição } & \multirow{2}{*}{$\begin{array}{c}\text { Potência } \\
\text { Instalada (Kw) }\end{array}$} & \multirow{2}{*}{$\begin{array}{c}\text { Horas de } \\
\text { "Funcionamento" }\end{array}$} & \multirow{2}{*}{ Total Kw/h } & Critério de Rateio & \multirow{2}{*}{$\begin{array}{l}\text { Energia Elétrica } \\
\text { Ind. }\end{array}$} \\
\hline & & & & & $\begin{array}{c}\text { \% Consumo de } \\
\text { E. Elétrica }\end{array}$ & \\
\hline \multicolumn{7}{|c|}{ Centros de Custos Produtivos } \\
\hline 101 & Oncologia & 8.599 & 9 & 1.702 .599 & $6 \%$ & $R \$ 3.086,08$ \\
\hline 102 & Geriatria & 980 & 9 & 194.135 & $1 \%$ & $\mathrm{R} \$ 320,63$ \\
\hline 103 & Hematologia & 850 & 9 & 168.303 & $1 \%$ & $\mathrm{R} \$ 300,59$ \\
\hline 104 & Genética & 2.333 & 9 & 461.854 & $2 \%$ & $\mathrm{R} \$ 901,78$ \\
\hline 105 & Psicologia & 1.016 & 9 & 201.181 & $1 \%$ & $\mathrm{R} \$ 120,24$ \\
\hline 106 & Nutrição & 455 & 9 & 90.022 & $0 \%$ & $\mathrm{R} \$ 220,43$ \\
\hline 107 & Fisioterapia & 546 & 9 & 108.027 & $0 \%$ & $R \$ 20,04$ \\
\hline 108 & Clínica Integrativa & 289 & 9 & 57.145 & $0 \%$ & $\mathrm{R} \$ 100,20$ \\
\hline 109 & Quimioterapia & 21.919 & 9 & 4.339 .962 & $16 \%$ & $R \$ 7.375,65$ \\
\hline 110 & Pré-Consulta & 3.050 & 9 & 603.900 & $2 \%$ & $\mathrm{R} \$ 1.026,31$ \\
\hline 111 & Oncologia Filial 1 & - & - & - & $0 \%$ & $R \$ 0,00$ \\
\hline 112 & Hematologia Filial 1 & - & - & - & $0 \%$ & $R \$ 0,00$ \\
\hline 113 & Quimioterapia Filial 1 & - & - & - & $0 \%$ & $R \$ 0,00$ \\
\hline 114 & Oncologia Filial 2 & - & - & - & $0 \%$ & $R \$ 0,00$ \\
\hline 115 & Hematologia Filial 2 & - & - & - & $0 \%$ & $R \$ 0,00$ \\
\hline 116 & Quimioterapia Filial 2 & - & - & - & $0 \%$ & $R \$ 0,00$ \\
\hline 117 & Oncologia Filial 3 & - & - & - & $0 \%$ & $R \$ 0,00$ \\
\hline 118 & Hematologia Filial 3 & - & - & - & $0 \%$ & $R \$ 0,00$ \\
\hline 119 & Quimioterapia Filial 3 & - & - & - & $0 \%$ & $R \$ 0,00$ \\
\hline \multicolumn{7}{|c|}{ Centros de Custos Auxiliares } \\
\hline 201 & Farmácia & 13.409 & 9 & 2.654 .982 & $10 \%$ & $\mathrm{R} \$ 4.512,07$ \\
\hline 202 & Almoxarifado & - & 9 & - & $0 \%$ & $R \$ 0,00$ \\
\hline 203 & Refeitório / Copa & 6.591 & 9 & 1.305 .018 & $5 \%$ & $R \$ 2.217,84$ \\
\hline 204 & Higiene e Limpeza & 276 & 9 & 54.648 & $0 \%$ & $\mathrm{R} \$ 92,87$ \\
\hline 205 & Manutenção & - & 9 & - & $0 \%$ & $R \$ 0,00$ \\
\hline 206 & Segurança & - & 9 & - & $0 \%$ & $R \$ 0,00$ \\
\hline 207 & Resíduos Hospitalares & - & 9 & - & $0 \%$ & $R \$ 0,00$ \\
\hline 208 & Transporte & 72 & 9 & 14.256 & $0 \%$ & $R \$ 24,23$ \\
\hline \multicolumn{7}{|c|}{ Centros de Custos Administrativos } \\
\hline 301 & Administração & 10.341 & 9 & 2.047 .419 & $8 \%$ & $\mathrm{R} \$ 3.479,54$ \\
\hline 302 & Informática & 9.491 & 24 & 5.010 .984 & $18 \%$ & $\mathrm{R} \$ 8.516,04$ \\
\hline 303 & Recepção & 2.047 & 9 & 405.306 & $1 \%$ & $\mathrm{R} \$ 688,81$ \\
\hline 304 & Áreas Comuns & 38.800 & 9 & 7.682 .400 & $28 \%$ & $\mathrm{R} \$ 13.056,04$ \\
\hline 305 & Recepção Filial 1 & - & - & - & $0 \%$ & $R \$ 0,00$ \\
\hline & Total & 121.062 & - & 27.102.141 & $100 \%$ & $R \$ 46.059,38$ \\
\hline
\end{tabular}

O rateio dos gastos com energia elétrica é um dos itens mais complexos de se calcular, pois leva em consideração a potência instalada em cada centro de custo, tanto no que se refere a iluminação artificial, como equipamentos que utilizam a eletricidade para o funcionamento.

Com base nesta potência instalada, estimou-se a quantidade de horas diárias em que esses equipamentos e que a iluminação artificial é utilizada para calcular a quantidade de Kilowatts/hora consumida por centro de custo e criar a base de rateio dos gastos com energia elétrica.

Importante ressaltar que as filiais estão instaladas dentro de unidades hospitalares parceiras da clínica analisada e todos os gastos com infraestrutura são de responsabilidade dos parceiros nessas operações. 
Tabela 9 - Gastos com água

\begin{tabular}{|c|c|c|c|c|c|c|c|c|c|c|}
\hline \multirow{3}{*}{ Cód. } & \multirow{3}{*}{ Descrição } & \multirow{3}{*}{\begin{tabular}{c|c}
$\begin{array}{c}\text { № de } \\
\text { Funcionários }\end{array}$ \\
$\begin{array}{c}\text { Litros por dia } \\
\text { por func. }\end{array}$ \\
\end{tabular}} & \multirow{2}{*}{ Consumo } & \multirow{3}{*}{\begin{tabular}{|c|}
$\begin{array}{c}\text { No de Atendimentos e } \\
\text { Sessões Totais (exceto } \\
\text { pré-consulta) }\end{array}$ \\
$\begin{array}{c}\text { Litros por } \\
\text { Atendimento }\end{array}$ \\
\end{tabular}} & \multirow{2}{*}{ Consumo } & \multirow{2}{*}{$\begin{array}{c}\text { Área m² } \\
\text { (Limpeza) }\end{array}$} & \multirow{2}{*}{ Consumo } & \multirow{3}{*}{ Consumo Total } & \multirow{3}{*}{\begin{tabular}{|l|} 
Critério de Rateio \\
\% Consumo de Água \\
\end{tabular}} & \multirow{3}{*}{ Água Ind. } \\
\hline & & & & & & & & & & \\
\hline & & & 55 & & $\Rightarrow \quad 10$ & Litros por $\mathrm{m}^{2}$ & 12 & & & \\
\hline \multicolumn{11}{|c|}{ Centros de Custos Produtivos } \\
\hline 101 & Oncologia & 1 & 1.210 & 2.175 & 478.500 & 57 & 15.101 & 494.811 & $16 \%$ & $R \$ 258,09$ \\
\hline 102 & Geriatria & - & - & 248 & 54.560 & 7 & 1.722 & 56.282 & $2 \%$ & $R \$ 26,18$ \\
\hline 103 & Hematologia & - & - & 215 & 47.300 & 6 & 1.493 & 48.793 & $2 \%$ & $R \$ 24,54$ \\
\hline 104 & Genética & - & - & 590 & 129.800 & 16 & 4.096 & 133.896 & $4 \%$ & $R \$ 73,63$ \\
\hline 105 & Psicologia & - & - & 257 & 56.540 & 7 & 1.784 & 58.324 & $2 \%$ & $R \$ 9,82$ \\
\hline 106 & Nutrição & - & - & 115 & 25.300 & 3 & 798 & 26.098 & $1 \%$ & $\mathrm{R} \$ 18,00$ \\
\hline 107 & Fisioterapia & - & - & 138 & 30.360 & 4 & 958 & 31.318 & $1 \%$ & $\mathrm{R} \$ 1,64$ \\
\hline 108 & Clínica Integrativa & - & - & 73 & 16.060 & 2 & 507 & 16.567 & $1 \%$ & $\mathrm{R} \$ 8,18$ \\
\hline 109 & Quimioterapia & 5 & 5.445 & 8.743 & 1.923 .471 & 145 & 38.218 & 1.967 .134 & $63 \%$ & $\mathrm{R} \$ 1.127,31$ \\
\hline 110 & Pré-Consulta & - & - & & - & 9 & 2.381 & 2.381 & $0 \%$ & $R \$ 12,00$ \\
\hline 111 & Oncologia Filial 1 & - & - & & - & - & - & - & $0 \%$ & $R \$ 0,00$ \\
\hline 112 & Hematologia Filial 1 & - & - & & - & - & - & - & $0 \%$ & $R \$ 0,00$ \\
\hline 113 & Quimioterapia Filial 1 & - & - & & - & - & - & - & $0 \%$ & $R \$ 0,00$ \\
\hline 114 & Oncologia Filial 2 & - & - & & - & - & - & - & $0 \%$ & $R \$ 0,00$ \\
\hline 115 & Hematologia Filial 2 & - & - & & - & - & - & - & $0 \%$ & $R \$ 0,00$ \\
\hline 116 & Quimioterapia Filial 2 & - & - & & - & - & - & - & $0 \%$ & $R \$ 0,00$ \\
\hline 117 & Oncologia Filial 3 & - & - & & - & - & - & - & $0 \%$ & $R \$ 0,00$ \\
\hline 118 & Hematologia Filial 3 & - & - & & - & - & - & - & $0 \%$ & $R \$ 0,00$ \\
\hline 119 & Quimioterapia Filial 3 & - & - & & - & - & - & - & $0 \%$ & $R \$ 0,00$ \\
\hline \multicolumn{11}{|c|}{ Centros de Custos Auxiliares } \\
\hline 201 & Farmácia & 3 & 3.630 & & - & 49 & 13.037 & 16.667 & $1 \%$ & $\mathrm{R} \$ 84,02$ \\
\hline 202 & Almoxarifado & - & - & & - & - & - & - & $0 \%$ & $R \$ 0,00$ \\
\hline 203 & Refeitório / Copa & 1 & 1.210 & & - & 46 & 12.273 & 13.483 & $0 \%$ & $R \$ 67,97$ \\
\hline 204 & Higiene e Limpeza & 2 & 2.420 & & - & 23 & 6.194 & 8.614 & $0 \%$ & $R \$ 43,42$ \\
\hline 205 & Manutenção & 1 & 605 & & - & - & - & 605 & $0 \%$ & $R \$ 3,05$ \\
\hline 206 & Segurança & 2 & 1.815 & & - & - & - & 1.815 & $0 \%$ & $R \$ 9,15$ \\
\hline 207 & Resíduos Hospitalares & - & - & & - & 1 & 361 & 361 & $0 \%$ & $R \$ 1,82$ \\
\hline 208 & Transporte & - & - & & - & 17 & 4.481 & 4.481 & $0 \%$ & $R \$ 22,59$ \\
\hline \multicolumn{2}{|c|}{ Centros de Custos Administrativos } & & & & & & & & & 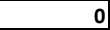 \\
\hline 301 & Administração & 5 & 6.050 & & - & 33 & 8.664 & 14.714 & $0 \%$ & $R \$ 74,18$ \\
\hline 302 & Informática & - & - & & - & - & - & - & $0 \%$ & $R \$ 0,00$ \\
\hline 303 & Recepção & 2 & 1.815 & & - & 10 & 2.508 & 4.323 & $0 \%$ & $\mathrm{R} \$ 21,79$ \\
\hline 304 & Áreas Comuns & - & - & & - & 906 & 239.306 & 239.306 & $8 \%$ & $\mathrm{R} \$ 1.206,38$ \\
\hline 305 & Recepção Filial 1 & - & - & & - & - & - & - & $0 \%$ & $R \$ 0,00$ \\
\hline \multicolumn{2}{|r|}{ Total } & 20 & 24.200 & 12.554 & \begin{tabular}{|l|l|}
2.761 .891 \\
\end{tabular} & 1.340 & 353.884 & 3.139 .975 & $100 \%$ & $\mathrm{R} \$ 3.093,77$ \\
\hline
\end{tabular}

O critério de rateio para os gastos com água levou em consideração 3 diferentes níveis de consumo: pessoas trabalhando por centro de custo, considerando que cada uma consome 55 litros de água por dia; número de atendimentos, considerando que cada pessoa atendida consome 10 litros de água por dia; e, uma quantidade de água utilizada para a limpeza do local, que foi estimada em 12 litros de água por metro quadrado ocupado.

Dessa forma, o critério de rateio considerou a quantidade proporcional de consumo de água por centro de custo. 
Tabela 10 - Gastos com internet

\begin{tabular}{|c|c|c|c|}
\hline \multirow[b]{2}{*}{ Cód. } & \multirow[b]{2}{*}{ Descrição } & \multirow{2}{*}{$\begin{array}{c}\text { Critério de Rateio } \\
\text { № de } \\
\begin{array}{c}\text { Equipamentos de } \\
\text { Informática }\end{array} \\
\end{array}$} & \multirow[b]{2}{*}{ Internet Ind. } \\
\hline & & & \\
\hline \multicolumn{4}{|c|}{ Centros de Custos Produtivos } \\
\hline 101 & Oncologia & 4 & $\mathrm{R} \$ 335,71$ \\
\hline 102 & Geriatria & 0 & $R \$ 34,88$ \\
\hline 103 & Hematologia & 0 & $R \$ 32,70$ \\
\hline 104 & Genética & 1 & $\mathrm{R} \$ 98,10$ \\
\hline 105 & Psicologia & 0 & $\mathrm{R} \$ 13,08$ \\
\hline 106 & Nutrição & 0 & $\mathrm{R} \$ 23,98$ \\
\hline 107 & Fisioterapia & 0 & $\mathrm{R} \$ 2,18$ \\
\hline 108 & Clínica Integrativa & 0 & $\mathrm{R} \$ 10,90$ \\
\hline 109 & Quimioterapia & 3 & $\mathrm{R} \$ 275,76$ \\
\hline 110 & Pré-Consulta & 1 & $\mathrm{R} \$ 91,92$ \\
\hline 111 & Oncologia Filial 1 & - & $\mathrm{R} \$ 0,00$ \\
\hline 112 & Hematologia Filial 1 & - & $\mathrm{R} \$ 0,00$ \\
\hline 113 & Quimioterapia Filial 1 & - & $\mathrm{R} \$ 0,00$ \\
\hline 114 & Oncologia Filial 2 & - & $\mathrm{R} \$ 0,00$ \\
\hline 115 & Hematologia Filial 2 & - & $\mathrm{R} \$ 0,00$ \\
\hline 116 & Quimioterapia Filial 2 & - & $\mathrm{R} \$ 0,00$ \\
\hline 117 & Oncologia Filial 3 & - & $\mathrm{R} \$ 0,00$ \\
\hline 118 & Hematologia Filial 3 & - & $\mathrm{R} \$ 0,00$ \\
\hline 119 & Quimioterapia Filial 3 & - & $\mathrm{R} \$ 0,00$ \\
\hline \multicolumn{2}{|c|}{ Centros de Custos Auxiliares } & & 0 \\
\hline 201 & Farmácia & 4 & $\mathrm{R} \$ 367,69$ \\
\hline 202 & Almoxarifado & - & $R \$ 0,00$ \\
\hline 203 & Refeitório / Copa & - & $\mathrm{R} \$ 0,00$ \\
\hline 204 & Higiene e Limpeza & - & $\mathrm{R} \$ 0,00$ \\
\hline 205 & Manutenção & - & $\mathrm{R} \$ 0,00$ \\
\hline 206 & Segurança & - & $\mathrm{R} \$ 0,00$ \\
\hline 207 & Resíduos Hospitalares & - & $\mathrm{R} \$ 0,00$ \\
\hline 208 & Transporte & - & $\mathrm{R} \$ 0,00$ \\
\hline \multicolumn{2}{|c|}{ Centros de Custos Administrativos } & & 0 \\
\hline 301 & Administração & 8 & $\mathrm{R} \$ 735,37$ \\
\hline 302 & Informática & - & $\mathrm{R} \$ 0,00$ \\
\hline 303 & Recepção & 2 & $\mathrm{R} \$ 183,84$ \\
\hline 304 & Áreas Comuns & - & $\mathrm{R} \$ 0,00$ \\
\hline 305 & Recepção Filial 1 & - & $\mathrm{R} \$ 0,00$ \\
\hline \multicolumn{2}{|r|}{ Total } & 24 & $\mathrm{R} \$ 2.206,11$ \\
\hline
\end{tabular}

O critério de rateio para os gastos com internet considerou a quantidade de desktops ou notebooks instalados em cada centro de custo. 
Tabela 11 - Gastos com materiais e medicamentos

\begin{tabular}{|c|c|c|c|}
\hline Cód. & Descrição & Medicamentos & Materiais \\
\hline \multicolumn{4}{|c|}{ Centros de Custos Produtivos } \\
\hline 101 & Oncologia & & \\
\hline 102 & Geriatria & & \\
\hline 103 & Hematologia & & \\
\hline 104 & Genética & & \\
\hline 105 & Psicologia & & \\
\hline 106 & Nutrição & & \\
\hline 107 & Fisioterapia & & \\
\hline 108 & Clínica Integrativa & & \\
\hline 109 & Quimioterapia & $\mathrm{R} \$ 4.321 .431,98$ & $R \$ 240.426,78$ \\
\hline 110 & Pré-Consulta & $\mathrm{R} \$ 192.709,70$ & $\mathrm{R} \$ 353,19$ \\
\hline 111 & Oncologia Filial 1 & & \\
\hline 112 & Hematologia Filial 1 & & \\
\hline 113 & Quimioterapia Filial 1 & $\mathrm{R} \$ 1.186 .890,19$ & $\mathrm{R} \$ 15.690,16$ \\
\hline 114 & Oncologia Filial 2 & & \\
\hline 115 & Hematologia Filial 2 & & \\
\hline 116 & Quimioterapia Filial 2 & & \\
\hline 117 & Oncologia Filial 3 & & \\
\hline 118 & Hematologia Filial 3 & & \\
\hline 119 & Quimioterapia Filial 3 & & \\
\hline & Total & $\mathrm{R} \$ 5.701 .031,88$ & $R \$ 256.470,13$ \\
\hline
\end{tabular}

Os custos dos materiais e medicamentos utilizados foram alocados diretamente no centro de custo identificado de sua utilização.

Vale ressaltar neste caso, que a filial 2 e a filial 3 ainda estavam bem no início de suas operações e, para efeito de dispensação de materiais e medicamentos, bem como para mensuração do número de procedimentos realizados, a empresa ainda não possuía apuração separada da filial 1. No caso de consumo de materiais e medicamentos, por exemplo, a dispensação era realizada em conjunto com os itens dispensados para a filial 1 e, de lá, partiam para a filial 2 que iniciava o seu funcionamento em 2015. 
Tabela 12 - Gastos com resíduos

\begin{tabular}{|c|c|c|c|c|}
\hline \multirow{2}{*}{ Cód. } & \multirow{2}{*}{ Descrição } & \multirow{2}{*}{ Peso * } & Critério de Rateio & \multirow{2}{*}{$\begin{array}{l}\text { Serviços de Coleta de } \\
\text { Resíduos Hospitalares }\end{array}$} \\
\hline & & & $\%$ & \\
\hline \multicolumn{5}{|c|}{ Centros de Custos Produtivos } \\
\hline 101 & Oncologia & 1 & $8 \%$ & $\mathrm{R} \$ 1.053,48$ \\
\hline 102 & Geriatria & 1 & $8 \%$ & $\mathrm{R} \$ 1.053,48$ \\
\hline 103 & Hematologia & 1 & $8 \%$ & $\mathrm{R} \$ 1.053,48$ \\
\hline 104 & Genética & 1 & $8 \%$ & $\mathrm{R} \$ 1.053,48$ \\
\hline 105 & Psicologia & 1 & $8 \%$ & $\mathrm{R} \$ 1.053,48$ \\
\hline 106 & Nutrição & 1 & $8 \%$ & $\mathrm{R} \$ 1.053,48$ \\
\hline 107 & Fisioterapia & 1 & $8 \%$ & $\mathrm{R} \$ 1.053,48$ \\
\hline 108 & Clínica Integrativa & 1 & $8 \%$ & $\mathrm{R} \$ 1.053,48$ \\
\hline 109 & Quimioterapia & 3 & $23 \%$ & $\mathrm{R} \$ 3.160,44$ \\
\hline 110 & Pré-Consulta & 2 & $15 \%$ & $\mathrm{R} \$ 2.106,96$ \\
\hline 111 & Oncologia Filial 1 & - & $0 \%$ & $\mathrm{R} \$ 0,00$ \\
\hline 112 & Hematologia Filial 1 & - & $0 \%$ & $\mathrm{R} \$ 0,00$ \\
\hline 113 & Quimioterapia Filial 1 & - & $0 \%$ & $\mathrm{R} \$ 0,00$ \\
\hline 114 & Oncologia Filial 2 & - & $0 \%$ & $\mathrm{R} \$ 0,00$ \\
\hline 115 & Hematologia Filial 2 & - & $0 \%$ & $\mathrm{R} \$ 0,00$ \\
\hline 116 & Quimioterapia Filial 2 & - & $0 \%$ & $\mathrm{R} \$ 0,00$ \\
\hline 117 & Oncologia Filial 3 & - & $0 \%$ & $\mathrm{R} \$ 0,00$ \\
\hline 118 & Hematologia Filial 3 & - & $0 \%$ & $\mathrm{R} \$ 0,00$ \\
\hline 119 & Quimioterapia Filial 3 & - & $0 \%$ & $\mathrm{R} \$ 0,00$ \\
\hline & Total & 13 & $100 \%$ & $\mathrm{R} \$ 13.695,22$ \\
\hline
\end{tabular}

Os gastos com a coleta de resíduos infectados foram rateados de acordo com um ranking estimado de geração e referem-se apenas à matriz, uma vez que nas filiais estes gastos também ficaram sob responsabilidade dos hospitais parceiros locais. 
Os gastos com propaganda e publicidade foram distribuídos igualmente entre todos os setores da unidade matriz, pois considerou-se que beneficiaria igualmente a empresa como um todo.

Tabela 13 - Gastos com publicidade e propaganda

\begin{tabular}{|c|c|c|c|}
\hline \multirow{2}{*}{ Cód. } & \multirow{2}{*}{ Descrição } & \multirow{2}{*}{$\begin{array}{c}\text { Critério de Rateio } \\
\text { Área } \mathrm{m}^{2} \\
\end{array}$} & \multirow{2}{*}{$\begin{array}{c}\text { Despesas com Propaganda e } \\
\text { Publicidade Ind. }\end{array}$} \\
\hline & & & \\
\hline \multicolumn{4}{|c|}{ Centros de Custos Produtivos } \\
\hline 101 & Oncologia & 1 & $\mathrm{R} \$ 5.772,08$ \\
\hline 102 & Geriatria & 1 & $\mathrm{R} \$ 5.772,08$ \\
\hline 103 & Hematologia & 1 & $\mathrm{R} \$ 5.772,08$ \\
\hline 104 & Genética & 1 & $\mathrm{R} \$ 5.772,08$ \\
\hline 105 & Psicologia & 1 & $\mathrm{R} \$ 5.772,08$ \\
\hline 106 & Nutrição & 1 & $\mathrm{R} \$ 5.772,08$ \\
\hline 107 & Fisioterapia & 1 & $\mathrm{R} \$ 5.772,08$ \\
\hline 108 & Clínica Integrativa & 1 & $\mathrm{R} \$ 5.772,08$ \\
\hline 109 & Quimioterapia & 1 & $\mathrm{R} \$ 5.772,08$ \\
\hline 110 & Pré-Consulta & 1 & $\mathrm{R} \$ 5.772,08$ \\
\hline 111 & Oncologia Filial 1 & - & $\mathrm{R} \$ 0,00$ \\
\hline 112 & Hematologia Filial 1 & - & $\mathrm{R} \$ 0,00$ \\
\hline 113 & Quimioterapia Filial 1 & - & $\mathrm{R} \$ 0,00$ \\
\hline 114 & Oncologia Filial 2 & - & $\mathrm{R} \$ 0,00$ \\
\hline 115 & Hematologia Filial 2 & - & $\mathrm{R} \$ 0,00$ \\
\hline 116 & Quimioterapia Filial 2 & - & $\mathrm{R} \$ 0,00$ \\
\hline 117 & Oncologia Filial 3 & - & $\mathrm{R} \$ 0,00$ \\
\hline 118 & Hematologia Filial 3 & - & $\mathrm{R} \$ 0,00$ \\
\hline 119 & Quimioterapia Filial 3 & - & $\mathrm{R} \$ 0,00$ \\
\hline \multicolumn{2}{|c|}{ Centros de Custos Auxiliares } & & $\mathbf{0}$ \\
\hline 201 & Farmácia & 1 & $\mathrm{R} \$ 5.772,08$ \\
\hline 202 & Almoxarifado & - & $\mathrm{R} \$ 0,00$ \\
\hline 203 & Refeitório / Copa & 1 & $\mathrm{R} \$ 5.772,08$ \\
\hline 204 & Higiene e Limpeza & 1 & $\mathrm{R} \$ 5.772,08$ \\
\hline 205 & Manutenção & 1 & $\mathrm{R} \$ 5.772,08$ \\
\hline 206 & Segurança & 1 & $\mathrm{R} \$ 5.772,08$ \\
\hline 207 & Resíduos Hospitalares & 1 & $\mathrm{R} \$ 5.772,08$ \\
\hline 208 & Transporte & 1 & $\mathrm{R} \$ 5.772,08$ \\
\hline \multicolumn{2}{|c|}{ Centros de Custos Administrativos } & & $\mathbf{0}$ \\
\hline 301 & Administração & 1 & $\mathrm{R} \$ 5.772,08$ \\
\hline 302 & Informática & 1 & $\mathrm{R} \$ 5.772,08$ \\
\hline 303 & Recepção & 1 & $\mathrm{R} \$ 5.772,08$ \\
\hline 304 & Áreas Comuns & 1 & $\mathrm{R} \$ 5.772,08$ \\
\hline 305 & Recepção Filial 1 & - & $\mathrm{R} \$ 0,00$ \\
\hline & Total & 21 & $\mathrm{R} \$ 121.213,62$ \\
\hline
\end{tabular}


Após a apuração dos custos diretos e rateio dos custos indiretos em cada centro de custo produtivo, é realizado o rateio dos centros de custos auxiliares e administrativos também nos centro de custos produtivos.

A tabela 14 apresenta a lista de todos os centros de custo produtivos com as colunas individualizadas dos custos diretos, indiretos e rateios recebidos, consolidando no custo total. Através da divisão do custo total de cada centro de custo pelas unidades de serviços prestados, encontra-se o custo unitário dos serviços correspondentes a cada centro de custo.

Tabela 14 - Custo total e unitário dos centros de custo produtivos

\begin{tabular}{|c|c|c|c|c|c|c|c|}
\hline Cód. & Centro de Custo & $\begin{array}{l}\text { Custos } \\
\text { Diretos }\end{array}$ & $\begin{array}{c}\text { Custos } \\
\text { Indiretos }\end{array}$ & \begin{tabular}{|c|} 
Rateios \\
Recebidos
\end{tabular} & $\begin{array}{l}\text { Custo } \\
\text { Total }\end{array}$ & $\begin{array}{l}\text { Unid. de } \\
\text { Produção }\end{array}$ & $\begin{array}{c}\text { Custo } \\
\text { Unitário }\end{array}$ \\
\hline 101 & Oncologia & 286.718 & 35.008 & 159.842 & 481.568 & 1.371 & 351,25 \\
\hline 102 & Geriatria & 0 & 8.809 & 21.472 & 30.281 & 248 & 122,10 \\
\hline 103 & Hematologia & 31.515 & 8.619 & 18.980 & 59.114 & 215 & 274,95 \\
\hline 104 & Genética & 0 & 14.313 & 40.459 & 54.772 & 590 & 92,83 \\
\hline 105 & Psicologia & 0 & 6.911 & 18.922 & 25.832 & 257 & 100,52 \\
\hline 106 & Nutrição & 0 & 7.860 & 10.898 & 18.758 & 115 & 163,12 \\
\hline 107 & Fisioterapia & 0 & 5.962 & 11.705 & 17.667 & 138 & 128,02 \\
\hline 108 & Clínica Integrativa & 24.417 & 6.721 & 9.701 & 40.840 & 73 & 559,45 \\
\hline 109 & Quimioterapia & 5.152 .416 & 72.144 & 661.419 & 5.885 .978 & 1.627 & $3.617,69$ \\
\hline \multirow{2}{*}{110} & Pré-Consulta - Hormonioterapia & 210.444 & 5.127 & 15.053 & 230.625 & 0 & - \\
\hline & Pré-Consulta & 17.381 & 5.127 & 15.053 & 37.562 & 0 & - \\
\hline 111 & Oncologia Filial 1 & 40.741 & 0 & 2.619 & 43.360 & 0 & - \\
\hline 112 & Hematologia Filial 1 & 63.064 & 1.260 & 6.355 & 70.679 & 498 & 141,93 \\
\hline 113 & Quimioterapia Filial 1 & 1.347 .573 & 0 & 124.532 & 1.472 .106 & 402 & $3.661,95$ \\
\hline 114 & Oncologia Filial 2 & 27.747 & 0 & 1.785 & 29.532 & 0 & - \\
\hline 115 & Hematologia Filial 2 & 0 & 0 & 0 & 0 & 0 & - \\
\hline 116 & Quimioterapia Filial 2 & 17.381 & 0 & 3.328 & 20.709 & 0 & - \\
\hline 117 & Oncologia Filial 3 & 0 & 0 & 0 & 0 & 0 & - \\
\hline 118 & Hematologia Filial 3 & 0 & 0 & 0 & 0 & 293 & 0,00 \\
\hline 119 & Quimioterapia Filial 3 & 0 & 0 & 24.169 & 24.169 & 0 & - \\
\hline & Total Geral & 7.219.398 & 177.861 & 1.146 .293 & 8.543 .552 & - & - \\
\hline
\end{tabular}

A tabela 15 apresenta o extrato do centro de custo oncologia, que refere-se ao ambulatório de consultas oncológicas e a tabela 16 apresenta o extrato do centro de custo quimioterapia. 
Tabela 15 - Extrato individualizado do centro de custo oncologia (101)

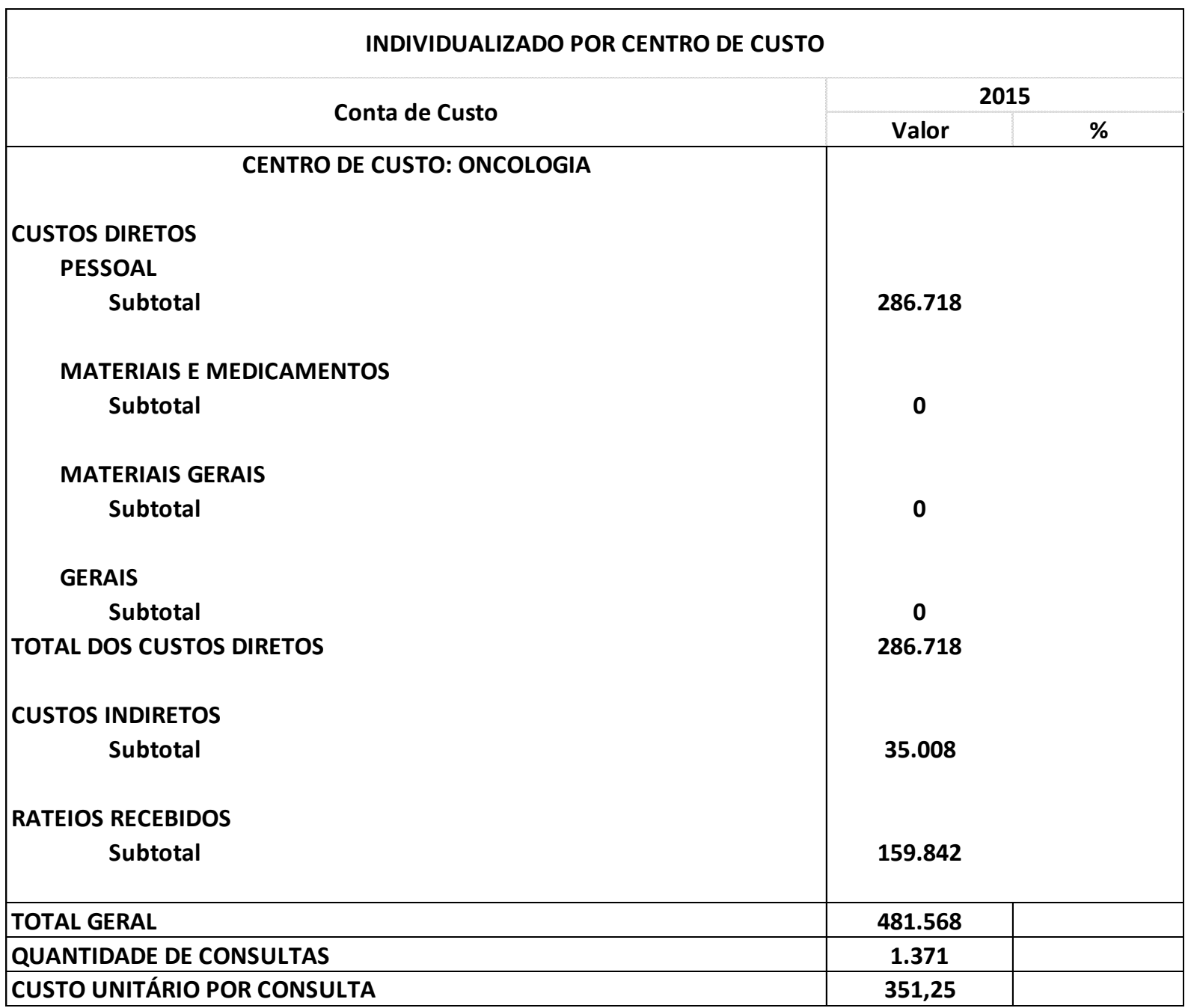

Os extratos dos centros de custo 101 e 109 estão apresentados de forma sintética, ou seja, as diversas contas que compõem os custos diretos (exibidas analiticamente no quadro 7), como os custos indiretos (exibidas analiticamente no quadro 8), bem como os rateios recebidos dos centros de custos auxiliares e administrativos (exibidos analiticamente nos quadros 5 e 6), estão todas consolidadas para exibição nestas tabelas. 
Tabela 16 - Extrato individualizado do centro de custo quimioterapia (109)

\begin{tabular}{|c|c|c|}
\hline \multicolumn{3}{|c|}{ INDIVIDUALIZADO POR CENTRO DE CUSTO } \\
\hline \multirow{2}{*}{ Conta de Custo } & \multicolumn{2}{|c|}{2015} \\
\hline & Valor & $\%$ \\
\hline CENTRO DE CUSTO: QUIMI & & \\
\hline \multicolumn{3}{|l|}{ CUSTOS DIRETOS } \\
\hline \multicolumn{3}{|l|}{ PESSOAL } \\
\hline Salários & 143.485 & \\
\hline Benefícios & 15.849 & \\
\hline Encargos e Contribuições & 49.601 & \\
\hline Outras Despesas de Pessoal & 0 & \\
\hline Serviços de Terceiros & 17.024 & \\
\hline Serviços Médicos & 362.125 & \\
\hline Subtotal & 588.084 & \\
\hline \multicolumn{3}{|l|}{ MATERIAIS E MEDICAMENTOS } \\
\hline Subtotal & 4.561.859 & \\
\hline \multicolumn{3}{|l|}{ MATERIAIS GERAIS } \\
\hline Subtotal & 302 & \\
\hline \multicolumn{3}{|l|}{ GERAIS } \\
\hline Subtotal & 2.171 & \\
\hline TOTAL DOS CUSTOS DIRETOS & 5.152 .416 & \\
\hline \multicolumn{3}{|l|}{ CUSTOS INDIRETOS } \\
\hline Subtotal & 72.144 & \\
\hline \multicolumn{3}{|l|}{ RATEIOS RECEBIDOS } \\
\hline Subtotal & 661.419 & \\
\hline TOTAL GERAL & 5.885 .978 & \\
\hline QUANTIDADE DE SESSÕES & 1.627 & \\
\hline CUSTO UNITÁRIO POR SESSÃO & $3.617,69$ & \\
\hline
\end{tabular}

No caso da apuração do custo unitário da sessão de quimioterapia, é importante que se isole a influência dos medicamentos e materiais neste custo unitário, já que os medicamentos e materiais são remunerados à parte. Portanto, excluindo do total geral $(\mathrm{R} \$ 5.885 .978,00)$ o valor de materiais e medicamentos ( $\mathrm{R} \$ 4.561 .859,00)$, obtem-se um novo total geral no valor de $\mathrm{R} \$$ 1.324.119,00.

Também é necessário ajustar o número de procedimentos realizados apenas na matriz, pois o número apresentado nas tabelas 1 e 2 está somando procedimentos realizados na matriz da empresa, que se refere ao centro de custo número 109, com procedimentos realizados em 
outras unidades, que não devem se misturar aos realizados no centro de custo 109 para a apuração do custo unitário do procedimento no centro de custo escolhido.

Portanto, dividindo-se o valor dos custos obtidos no centro de custo 109 (R\$ 5.885.978,00 - $\mathrm{R} \$ 4.561 .859,00=\mathrm{R} \$ 1.324 .119,00)$ pelos procedimentos realizados neste centro de custo (1627 sessões), tem-se o custo unitário por sessão de $\mathrm{R} \$ 813,84$.

Na tabela 18, realiza-se um comparativo entre os valores médios pagos pelas operadoras de saúde suplementar e o custo unitário de dois importantes serviços prestados, a consulta médica e a sessão de quimioterapia. A lista dos valores praticados por cada Operadora de Saúde Suplementar para os serviços em análise está apresentada na tabela 17.

Tabela 17 - Valores da consulta médica e da taxa de sala de infusão por Operadora de Plano de Saúde

\begin{tabular}{|l|r|r|}
\hline CONVÊNIO & $\begin{array}{l}\text { VALOR DA TAXA } \\
\text { DE APLICAÇÃO }\end{array}$ & $\begin{array}{l}\text { CONSULTA } \\
\text { MÉDICA }\end{array}$ \\
\hline OPERADORA A & 60,00 & 80,00 \\
\hline OPERADORA B & 94,50 & 77,00 \\
\hline OPERADORA C & 159,00 & 50,00 \\
\hline OPERADORA D & 20,00 & 85,00 \\
\hline OPERADORA E & 96,00 & 92,00 \\
\hline OPERADORA F & 94,50 & 67,00 \\
\hline OPERADORA G & 40,00 & 50,00 \\
\hline OPERADORA H & 177,92 & 71,86 \\
\hline OPERADORA I & 208,00 & 64,00 \\
\hline OPERADORA J & 48,60 & 60,00 \\
\hline OPERADORA K & 60,00 & 112,00 \\
\hline OPERADORA L & 67,60 & 42,00 \\
\hline OPERADORA M & 40,00 & 60,00 \\
\hline OPERADORA N & 60,00 & 85,00 \\
\hline OPERADORA O & 80,00 & 50,00 \\
\hline OPERADORA P & 165,00 & 72,00 \\
\hline OPERADORA Q & 21,45 & 45,00 \\
\hline OPERADORA R & 110,00 & 66,00 \\
\hline OPERADORA S & 50,00 & 120,00 \\
\hline OPERADORA U & 45,00 & 35,00 \\
\hline OPERADORA V & 45,00 & 42,00 \\
\hline MÉDIA & $\mathbf{8 2 , 9 8}$ & $\mathbf{6 7 , 9 0}$ \\
\hline
\end{tabular}


Tabela 18 - Comparativo entre a remuneração e o custo unitário dos procedimentos

\begin{tabular}{|c|c|c|}
\hline & Remuneração (média) & Custo do procedimento \\
\hline Consulta Médica & $\mathrm{R} \$ 67,90$ & $\mathrm{R} \$ 351,25$ \\
\hline Sala de infusão (sem mat/med) & $\mathrm{R} \$ 82,98$ & $\mathrm{R} \$ 813,84$ \\
\hline
\end{tabular}

Enquanto as operadoras de saúde suplementar remuneram entre $\mathrm{R} \$ 35,00$ e $\mathrm{R} \$ 120,00$ uma consulta médica, com duração média de 40 minutos com médico oncologista, com média de $\mathrm{R} \$ 67,90$ por consulta, o custo deste procedimento para a clínica em questão é de $\mathrm{R} \$ 351,25$.

$\mathrm{Da}$ mesma forma, analisando a remuneração do procedimento de infusão da quimioterapia, excluindo-se a remuneração e o custo com materiais/medicamentos tem-se que, em média, as operadoras de saúde suplementar remuneram o procedimento entre $R \$ 20,00$ e $\mathrm{R} \$ 208,00$, com média de $\mathrm{R} \$ 82,98$, enquanto o custo na clínica em questão está em $\mathrm{R} \$ 813,84$. 


\section{Conclusões}

As organizações precisam apresentar sustentabilidade financeira para realizarem seus objetivos operacionais.

A sustentabilidade financeira é obtida quando a remuneração de seus serviços/produtos é maior que os custos incorridos, inclusive os referentes ao custo de capital.

No caso específico das organizações de saúde, em que a remuneração é composta normalmente por 3 diferentes grupos (honorários dos serviços profissionais médicos; taxas que remuneram a estrutura e o capital; e, materiais e medicamentos utilizados) surge a expectativa de que a remuneração seja suficiente para cobrir os diferentes custos, notadamente quando estas condições estão definidas contratualmente.

O objetivo deste trabalho foi analisar os componentes da remuneração de uma clínica oncológica e a participação de cada um desses componentes em relação ao total da remuneração traçando um comparativo com a estrutura de custos desses mesmos itens, que também foram analisados em relação ao total dos custos.

A análise comparativa da participação de cada componente dentro dos componentes remuneração x custos está representada no gráfico 7.

Gráfico 7 - Análise comparativa da participação de cada componente em relação ao total da remuneração e dos custos

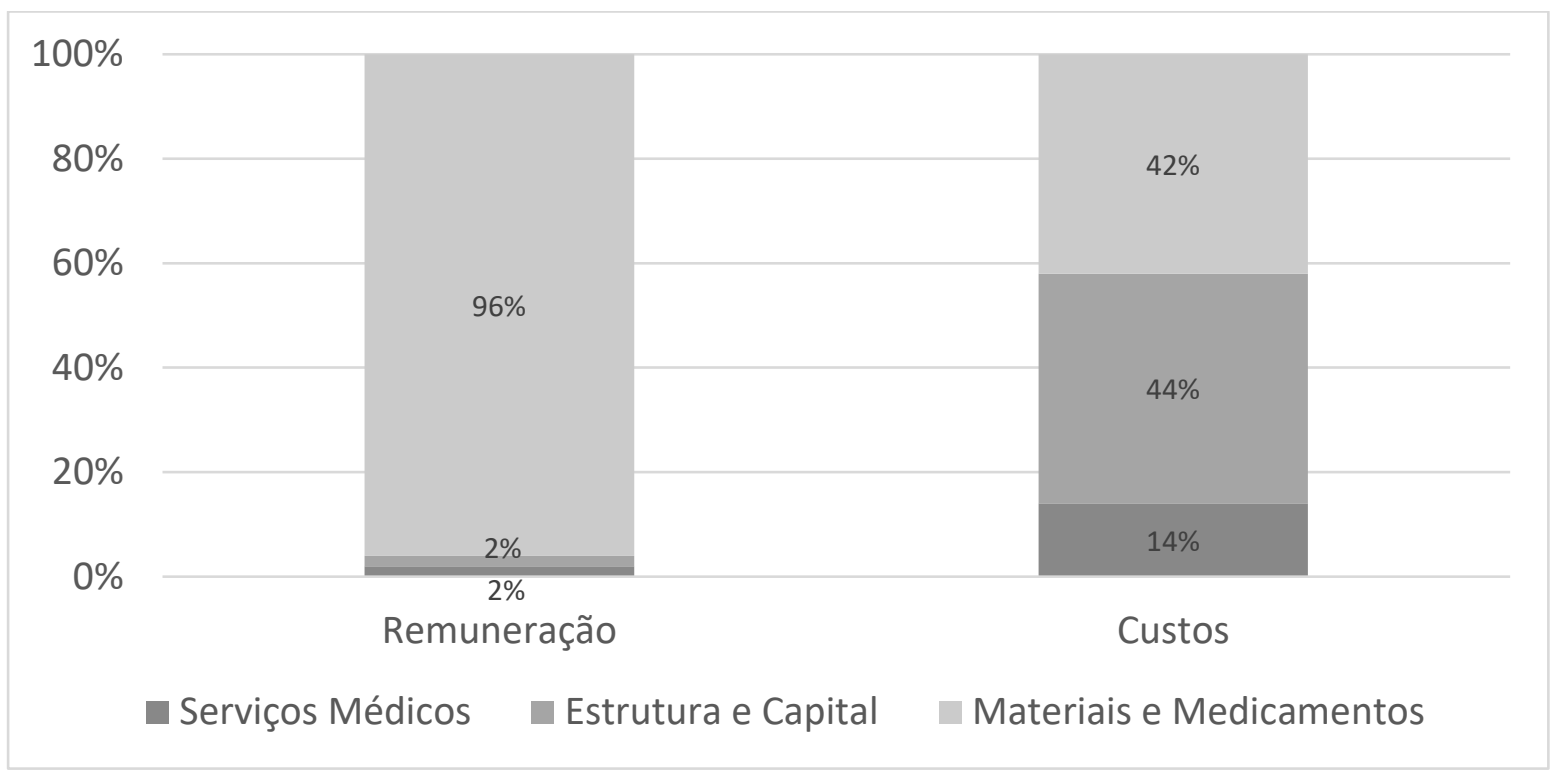


Os resultados deste trabalho demonstraram que há uma distorção clara entre a remuneração dos honorários e taxas e seus respectivos custos, podendo-se concluir que a remuneração é deficitária para estes itens, pois enquanto os custos médicos representam $14 \%$ dos custos totais da empresa, a respectiva remuneração com os serviços médicos prestados às Operadoras de Saúde Suplementar representa apenas 2\% das remunerações recebidas.

A remuneração da estrutura e do capital investido fica ainda mais prejudicada nos resultados obtidos, pois enquanto os custos com estrutura e capital representam $44 \%$ dos custos totais da empresa, a respectiva remuneração com as taxas de infusão às Operadoras de Saúde Suplementar representa apenas $2 \%$ das remunerações recebidas.

Por outro lado, o componente que vem sustentando a operação, apresentando resultado superavitário, é a relação entre os custos dos materiais e medicamentos e os valores pagos por esses itens pelas Operadoras de Saúde Suplementar. Enquanto o custo com os materiais e medicamentos representou $42 \%$ do total dos custos, a remuneração paga pelas Operadoras de Saúde Suplementar representou 96\% do total das receitas.

Ou seja, para a sustentabilidade do negócio e avaliando de maneira global o resultado que está demonstrado, entende-se que o sub-financiamento em dois componentes da remuneração é compensado pelo terceiro, mantendo-se o equilíbrio da relação comercial.

Este modelo de remuneração da área da saúde, construído há décadas e ancorado na remuneração superavitária no componente materiais e medicamentos em detrimento da remuneração dos serviços médicos, da estrutura física, do capital e dos profissionais não médicos, passa por seu momento bastante delicado, pois vem sendo amplamente questionado pelas Operadoras de Saúde Suplementar que desejam impor uma redução na remuneração dos prestadores sobre os materiais e medicamentos, porém sem a devida análise visando a compensação dos déficits nos outros componentes.

O próprio setor da saúde, como um todo, sabe e entende que este formato está com os dias contados. Porém, a inércia ainda é grande por parte de todos os atores e a promoção de ajustes dependem de estudos como este para que sejam feitos, visando a manutenção do equilíbrio do setor.

A segunda análise, que foi baseada na comparação entre a média das remunerações de dois dos serviços prestados (consulta médica de oncologia e taxa de sala dos procedimentos quimioterápicos) e suas respectivas remunerações unitárias, deixou visível o déficit existente 
nesses serviços e a inviabilidade econômica se a questão remuneração não for tratada globalmente, em conjunto com a remuneração dos materiais e medicamentos.

Nesta análise, encontrou-se que enquanto a média da remuneração de uma consulta médica de oncologia está em torno de $\mathrm{R} \$ 68,00$, o seu custo é de $\mathrm{R} \$ 351,25$, ou seja, representa um prejuízo acima de 500\%. Aplicando-se a mesma análise para a taxa de sala dos procedimentos quimioterápico na qual a remuneração média é de $\mathrm{R} \$ 83,00$, o seu custo é de $\mathrm{R} \$ 813,84$, ou seja, um prejuízo de quase $1000 \%$. Os resultados encontrados estão representados no Gráfico 8.

Gráfico 8 - Comparativo entre a remuneração unitária e o custo unitário

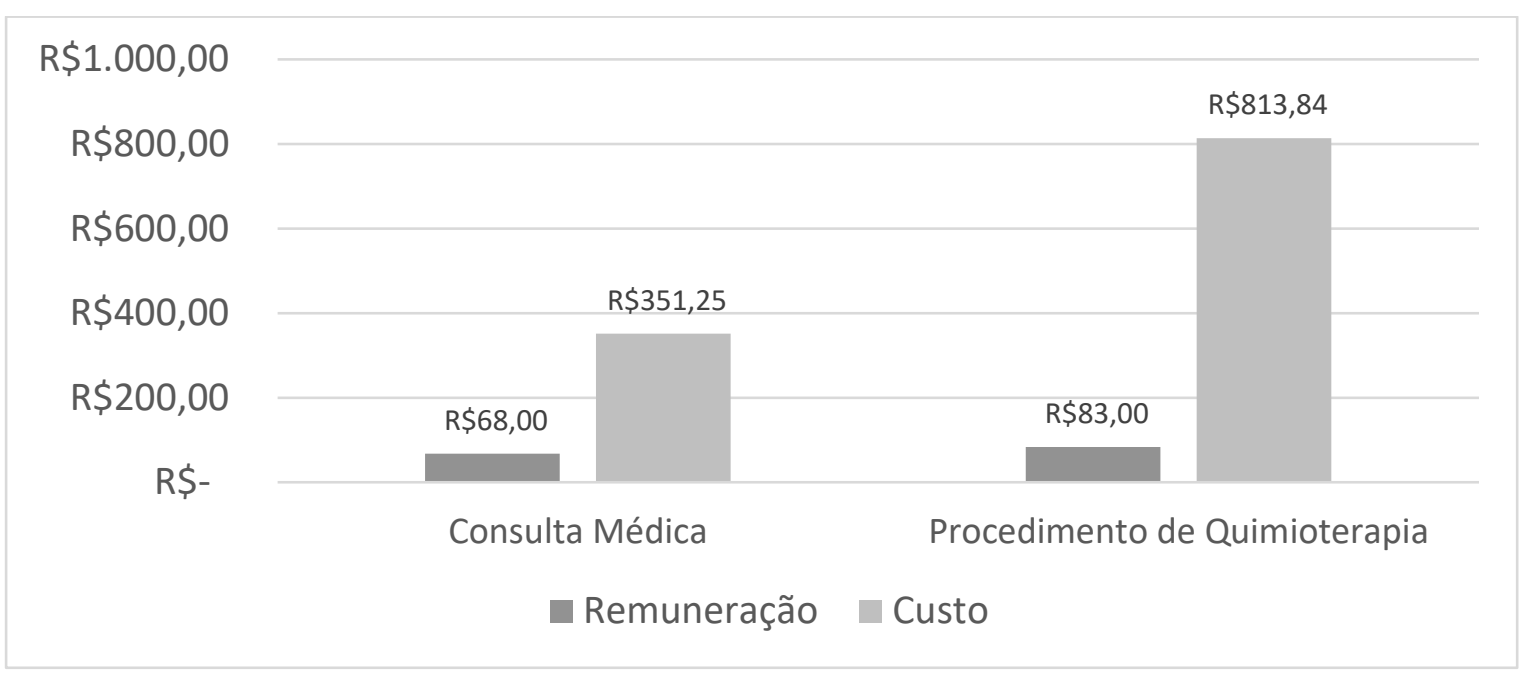

Com um gasto anual de aproximadamente $\mathrm{R} \$ 450$ bi e representando quase $10 \%$ do seu PIB, o Brasil apresenta uma singularidade entre as 10 maiores economias do mundo: é o único país em que os gastos privados com saúde superam os gastos públicos, numa proporção de aproximadamente $56 \%$ relativos aos gastos privados e $44 \%$ de gastos públicos (Revista Forbes Brasil, 2015). O desequilíbrio se acentua levando-se em conta que apenas $25 \%$ da população se beneficia desses $56 \%$ dos gastos, enquanto que o restante dos gastos tenta cobrir todas as necessidades de $75 \%$ da população e, em diversos casos, acaba servindo, pelo conceito da universalidade do SUS, a 100\% da população como nos casos de programas de imunização, serviços de vigilância sanitária, alguns tratamentos de altíssima complexidade e o fenômeno da judicialização, entre outros. 
A principal sugestão que deriva da conclusão deste trabalho é que se aplique o redimensionamento da remuneração de acordo com cada componente de custo dos serviços prestados. Esse redimensionamento traria equilíbrio, transparência e valorização adequada para cada recurso empregado.

Idealmente, imagina-se que a equipe médica seja devidamente remunerada pela sua dedicação ao paciente, experiência acumulada, educação continuada, adequação aos critérios de qualidade definidos e aos protocolos clínicos reconhecidos mundialmente e aprovados nos órgãos nacionais. Na outra ponta, a estrutura seja adequadamente remunerada para sua devida manutenção, acompanhamento às inovações tecnológicas, desenvolvimento e reconhecimento das equipes não médicas, cumprimento com todos os demais custos de funcionamento e remuneração adequada do capital investido. E, ainda, que a transação realizada com os insumos necessários (materiais e medicamentos), tenha, única e exclusivamente, a função de cobrir os seus custos de aquisição, armazenamento adequado, cobertura de seguros e eventuais perdas, manipulação, unitarização, dispensação, controle e acompanhamento farmacêutico, sem a aplicação de margens sobre este componente, uma vez que ele é considerado apenas um insumo para a prestação dos serviços que são as atividades fins do negócio.

Confirmando esta argumentação, é importante destacar novamente neste contexto a iniciativa, citada anteriormente, da Unimed Federação Santa Catarina, em 2015, que buscou o reequilíbrio dos componentes remuneração, mantendo o equilíbrio das relações vigentes.

Importante ressaltar também, as buscas, em todos os cantos do mundo, na tentativa de se estabelecer um modelo mais adequado de remuneração no setor da saúde, baseado no valor entregue ao paciente. Mesmo que as margens sejam readequadas e reequilibradas como propõe este trabalho, essa iniciativa é apenas uma ação imediata de ajuste, porém apenas intermediária, até que se implante mudanças mais radicais no modelo de remuneração, deixando o enfoque atual que está centrado na produção ( "fee for service”), passando para um enfoque centrado no valor ("fee for value").

O setor da saúde deve, neste processo de reestruturação de um novo modelo de remuneração, repensar o conceito de competição. Os bancos de dados das operadoras de saúde suplementar possuem todas as informações necessárias no que se refere ao fator custo. Por outro lado, os prestadores podem fornecer informações relevantes sobre qualidade, melhores práticas, tratamento global, experiência do paciente, entre outras. O cruzamento destas informações, 
certamente poderão revelar estratégias otimizadas, custo-efetivas, que realmente entreguem valor ao paciente, com custos gerenciados.

Algumas iniciativas começam a surgir no país, buscando abordar de forma mais profunda este assunto. Estudos como este, precisam ser intensificados para servirem como base de informação para que a negociação e a tomada de decisão sejam adequadas nestes fóruns e para que o equilíbrio do setor e a sustentabilidade econômica estejam no centro dos objetivos. 


\section{Referências}

ABELHA, Marli Câmara; GONÇALVES, A. A.; PITASSI, C. Estratégia de Operações em Serviços de Saúde: Estudo de Caso das Operadoras de Planos de Saúde Suplementar. Revista Metropolitana de Sustentabilidade, v. 4, n. 1, p. 107, 2014.

AGÊNCIA NACIONAL DE SAÚDE SUPLEMENTAR (ANS). Disponibilização de dados gerais atualizados do setor, 2005 a 2015. Disponível na internet: http://www.ans.gov.br/perfil-do-setor/dados-gerais. Acesso em: 25 de abril de 2016.

AGÊNCIA NACIONAL DE SAÚDE SUPLEMENTAR (ANS). Novo Modelo de Remuneração para Hospitais, 2012. Disponível na internet: http://www.ans.gov.br/aans/noticias-ans/sobre-a-ans/1860--novo-modelo-para-remuneracaode-hospitais. Acesso em: 26 de abril de 2016.

AGÊNCIA NACIONAL DE SAÚDE SUPLEMENTAR (ANS). Grupo de Trabalho sobre Planos Acessíveis, 2017. Disponível na internet: http://www.ans.gov.br/participacao-dasociedade/camaras-e-grupos-tecnicos/grupo-de-trabalho-sobre-planos-acessiveis. Acesso em: 29 de julho de 2017.

ANDREAZZI, Maria de Fátima Saliansky de. Formas de Remuneração de Serviços de Saúde. Texto para discussão no 1066, Instituto de Pesquisa Econômica Aplicada - IPEA, Brasília, 2003. Disponível em <http://www.ipea.gov.br>. Acesso em 03 de novembro de 2011.

BESSA, Ricardo de Oliveira. Análise dos modelos de remuneração médica no setor de saúde suplementar brasileiro. 2011.

BICHUETTI, José Luiz; MERE JR, YUSSIF A. Modelos de remuneração na saúde. Harvard Business Review. 2016. Disponível em: http://hbrbr.uol.com.br/modelos-de-remuneracao-nasaude. Acesso em 29/07/2017. 
BRASIL. Constituição da República Federativa do Brasil, de 05 de outubro de 1988. Disponível em: http://www.planalto.gov.br/ccivil_03/Constituicao/Constituicao.htm. Acesso em 25 de abril de 2016.

Ministério da Saúde. Cadastro Nacional de Estabelecimento de Saúde (CNES), 2016. Disponível em: http://cnes2.datasus.gov.br/Lista_Tot_Es_Estado.asp. Acesso em 25 de abril de 2016.

Portaria $n^{\circ}$ 140, de 27 de fevereiro de 2014. Redefine os critérios e parâmetros para organização, planejamento, monitoramento, controle e avaliação dos estabelecimentos de saúde habilitados na atenção especializada em oncologia e define as condições estruturais, de funcionamento e de recursos humanos para a habilitação destes estabelecimentos no âmbito do Sistema Único de Saúde (SUS). Diário Oficial da República Federativa do Brasil, Brasília, DF, 28 de fevereiro de 2014. Disponível em: http://bvsms.saude.gov.br/bvs/saudelegis/sas/2014/prt0140_27_02_2014.html. Acessado em 25 de abril de 2016.

BRITTO, Marcelo Moncôrvo et al. O desequilíbrio económico do sistema de saúde suplementar brasileiro com o desvio do foco da remuneração do serviço hospitalar para venda mercantil de material e medicamento: estudo de um hospital. 2011.

CAMPOS, Carla da Costa. Um estudo das relações entre operadoras de plano de assistência à saúde e prestadores de serviço. 2004.

CHERCHIGLIA, Mariangela L. Remuneração do trabalho médico: um estudo sobre seus sistemas e formas em hospitais gerais de Belo Horizonte. Cad Saude Publica, v. 10, n. 1, p. 67-79, 1994.

DA SILVA PINTO, Luiz Felipe. O Setor de Saúde Suplementar: acesso e cobertura populacional. Documentos técnicos de apoio ao Fórum, 2004. 
GIRARDI, Sábado Nicolau; CARVALHO, C. L.; GIRARDI, L. G. Modalidades de contratação e remuneração do trabalho médico: os conceitos e evidências internacionais. Organização Pan-Americana da Saúde, PWR-Brasil, Belo Horizonte, 2007.

GOMES, Cármen Lúcia Soares. Remuneração médica: uso de incentivos financeiros explícitos como indutor da mudança do cuidado na saúde suplementar. 2010.

HEALTHCARE FINANCIAL MANAGEMENT ASSOCIATION. Value in health care: Current state and future directions. 2011.

INSTITUTO BRASILEIRO DE GEOGRAFIA E ESTATÍSTICA (IBGE). Projeção da População Brasileira, 2016. Disponível na internet: http://www.ibge.gov.br/home/. Acesso em 25 de abril de 2016.

KOS, Sonia Raifur; SANTOS, N.P.; KLEIN, L.; SCARPIN, J.E. Repasse do SUS vs custo dos procedimentos hospitalares: É possível cobrir os custos com o repasse do SUS?. Anais do Congresso Brasileiro de Custos-ABC. 2015.

KOYAMA, Marcos Fumio. Auditoria e qualidade dos planos de saúde: percepções de gestores de operadoras da cidade de São Paulo a respeito do programa de qualificação da saúde suplementar da ANS. 2006. Tese de Doutorado.

KUDLAWICZ, Claudineia. Gestão de Custos Hospitalar: um Estudo de Caso. São Paulo, 2010 .

MARTINS, Domingos. Custos e Orçamentos Hospitalares. São Paulo: Atlas, 2000.

MATOS, Afonso José de. Gestão de Custos Hospitalares: técnicas, análises e tomada de decisão. 3. ed. São Paulo: STS, 2005.

MEDICI, André Cezar. Aspectos teóricos e conceituais do financiamento das políticas de saúde. Economia da saúde: conceitos e contribuição para a gestão em saúde, v. 3, p. 23-68, 2002. 
NORONHA, Marina F., VERAS, C.T., LEITE I.C., MARTINS M.S., BRAGA NETO F., SILVER L. O desenvolvimento dos "Diagnosis Related Groups" - DRGs. Metodologia de classificação de pacientes hospitalares. Revista Saúde Pública, São Paulo, 25: 198-208, 1991.

PORTER, Michael E.; TEISBERG, Elizabeth Olmsted. Repensando a saúde: estratégias para melhorar a qualidade e reduzir os custos. Bookman Editora, 2007.

RIBEIRO, José Mendes; MONTONE, J.; CASTRO, A. J. W. Restrições de informações, custos de transação e ambiente regulatório em saúde suplementar. Ministério da Saúde, ANS; Montone J, Castro AJW, organizadores. Documentos técnicos de apoio ao fórum de saúde suplementar de, 2003.

SILVA, Alceu Alves da. Relação entre operadoras de planos de saúde e prestadores de serviços: um novo relacionamento estratégico. Porto Alegre, 2003.

SOARES, Adriano Leite. Pressupostos e proposta de modelo para a remuneração do trabalho do médico cirurgião nas operadoras de planos de saúde. São Paulo, 2012.

STEFANI, Stephen Doral. O Tumultuado Cenário das Relações de Prestadores e Fontes Pagadoras. Rev. Bras. Oncologia Clínica, v. 1, n. 4, p. 19-24, 2005.

U.S. CONGRESS. Diagnosis Related Groups (DRG) and the Medicare Program: Implications for Medical Technology - a Technical Memorandum. Washington, D.C.: U.S. Congress, Office and Technology Assessment, OTA-TM-H-17, Jul. 1983.

ZANATTA, Carolina Lopes. Principais efeitos da regulamentação dos contratos entre operadoras e prestadores de serviços no mercado de saúde suplementar. 2013.

ZUCCHI, Paola; DEL NERO, C.; MALIK, A. M. Gastos em saúde: os fatores que agem na demanda e na oferta dos serviços de saúde. Saúde e Sociedade 9.1-2 (2000): 127-150. 
Anexos 


\section{Anexo A - Demonstração do Resultado do Exercício da empresa analisada (2015)}

\section{DEMONSTRAÇÃO DO RESULTADO DO EXERCÍCIO}

Dezembro/2015 Folha:0001

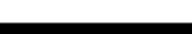

\section{DEMONSTRAČÃO DO RESULTADO DO EXERCÍCIO}

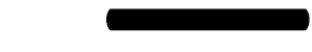

300.002-8 RECEITAS OPERACIONAIS E DEDUÇÕES

300.003-6 RECEITA BRUTA REVENDAS/VENDAS E SERVIÇOS

302.004-5 RECEITA BRUTA DA PRESTAÇÃO DE SERVIÇOS

302.005-3 SERVICOS PRESTADOS

14.173.366,48

Soma do grupo

OUTRAS RECEITAS..

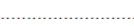

$14.173 .366,48$

$311.004-4$

soma do grupo

0,08

total dos grupos.

0,08

$14.173 .366,56$

$100,00 \%$

320.003-5 (-)DEDUÇÕES DE VENDAS/REVENDAS/SERVIÇOS

(-)TRIBUTOS/CONTRIB/S/VENDAS/REVISERV
(-)PIS SNVENDAS/REVENDAS/SERVICOS

$327.006-8$

$327.007-6$

(-)PIS SINENDAS/REVENDAS/SERVICOS
(-)COFINS SINENDAS/REVENDAS/SERVICOS

$(-)$ COFINS S/VENDAS/REVENDAS
$(-)$ ISS S/SERVICOS PRESTADOS

$-425.200,8$

$-283.467,28$

soma do grupo

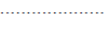

$-800.796,09$

total dos grupos.

RECEITA LIQUIDA

$-800.796,09$

$-5,65 \%$

$13.372 .570,47$

$94,35 \%$

410.002-6 CUSTOS DE MERCADORIAS, PRODUTOS/SERVIÇOS

420.003-9 CUSTOS DOS SERVIÇOS PRESTADOS

420.004-7 CUSTO DE PESSOAL APLICADO E ENCARGOS...

420.006-3 SALARIOS E ORDENADOS EN

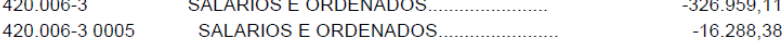

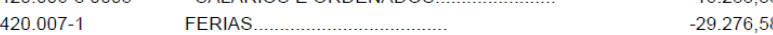

420.009-8 ABONO DE FERIAS ............................

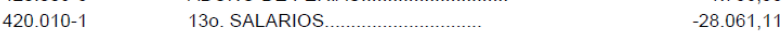

420.010-1 0005 130. SALARIOS ………………......

420.015-2 INSS.

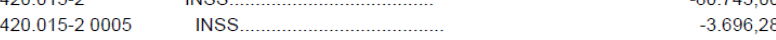

420.017-9 FGTS ..................................

420.017-9 0005 FGTS ......................................

420.022-5 VALE TRANSPORTE .........................

420.025-0 UNIFORMES ................................

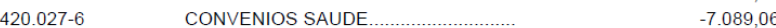

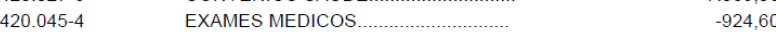

$\begin{array}{ll}420.052-7 & -22.300,37\end{array}$

$420.052-70005 \quad$ INSS - TERCEIROS ...

420.058-6 EDUCACAO E FORMACAO PROFISSIONAL ….... $-270,00$

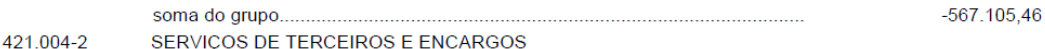

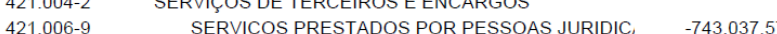

421.006-9 0005 SERVICOS PRESTADOS POR PESSOAS JURIDIC $\quad-17,80$

424.004-9 SOMa do grupo $\quad$ DEMAIS CUSTOS DE SERVIÇOS PRESTADOS

$424.005-7$

ALUGUEIS $\quad-298.471,65$

CONSERV/REPAR/MANUTENCAO MAQUINAS EQ $\quad-5.484,78$

ENERGIA ELETRICA ....................... $-46.059,38$

FRETES E CARRETOS …………................. $-3.579,15$

$-20.818,62$

MATERIAIS MEDICOS E HOSPITALARES........... - - $\quad-5.928 .386,34$

DESPESAS C/ CAFE DA MANHA .................

GENEROS ALIMENTICIOS …..................

REFEICOES E LANCHES .................................... $-33.811,83$

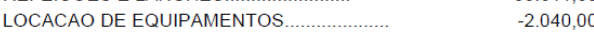

TREINAMENTO... $\quad-4.000,00$

ASSINATURA... $\quad-629,10$

DEPRECIACOES E AMORTIZACOES $\quad-64.776,60$

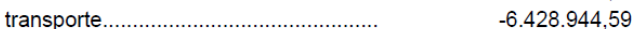


DEMONSTRAÇÃO DO RESULTADO DO EXERCÍCIO

DEMONSTRAC̨ÃO DO RESULTADO DO EXERCÍCIO

\begin{tabular}{|c|c|}
\hline & $-6.428 .944,59$ \\
\hline DESP. DE VIAGENS E ESTADIA PEDAGIOS... & $-6.784,23$ \\
\hline SEGURANÇA DO TRABALHO... & $-2.050,00$ \\
\hline ASSESSORIA EMPRESARIAL... & $-10.649,14$ \\
\hline DESPESAS C/ LAVANDERIA... & $-6.609,38$ \\
\hline
\end{tabular}

soma do grupo.

total dos grupos
Dezembro/2015 Folha:0002

$13.372 .570,47$

$-7.765 .198,17$

$-54,79 \%$

$5.607 .372,30$

$39,56 \%$

450.002-4 DESPESAS

460.003-7 DESPESAS OPERACIONAIS ADMINISTRATIVAS

460.004-5 DESPESAS TRABALHISTAS E ENCARGOS SOCIAIS

$460.006-1$

$460.007-1-2000$

$460.010-0$

$460.012-6$

$460.015-0$

$460.017-7$

$460.034-7$

$460.056-8$

$460.064-9$

SALARIOS E ORDENADOS

SALARIOS

$-110.416,57$

ABONO DE FERIAS

$-8.421,42$

ABONO DE FERIAS ………….... $\quad-1,709,20$

130. SALARIO ...........................

GRATIFICACOES .......................... $\quad-310,00$

INSS …......................... $\quad-27.249,61$

IORAS EXTRAS

INSS - TERCEIROS ........................

CONVENIO ACADEMIA ... $\quad-130,00$

461.004-0 SERVIÇOS DE TERCEIROS E ENCARGOS SOCIAIS

461.006-7

SERVICOS PRESTADOS POR PESSOAS JURIDIC,

$462.004-6$

$462.006-2$

$462.008-9$

Soma do grupo

$-95.279,99$

$-177.468,22$

AGUA E ESGOTO.

$-3.093,77$

ASSOCIACOES DE CLASSE....................... $\quad-5.319,60$

ASSOCIACOES DE CLASSE.............................

ASSOCIACOES DE CLASSE..................... $\quad-704,00$

COMBUSTIVEIS E LUBRIFICANTES................

CONTRIBUICOES E DOACOES .....................

CONSERV/REPAR/MANUTENCAO INSTALACOES $\quad-41.467,92$

CONSERV/REPAR/MANUTENCAO VEICULOS........ - $-7.273,08$

DESPESAS POSTAIS/CORREIOS E TELEGRAFOS $\quad-8.586,40$

DESPESAS DE VIAGENS E ESTADIAS............ - $-25.864,30$

IMPRESSOS E MATERIAL P/ESCRITORIO ........... $\quad-30.384,96$

MATERIAIS DE CONSUMO $\quad-7.279,56$

PRO LABORE $\quad-56736,00$

DESPESAS GERAIS ........................

MATERIAIS DE LIMPEZA …………...............

IMOBILIZ.ART. 3§ LEI 8383.................. $\quad-7.425,70$

DESPESAS LEGAIS E JUDICIAIS ................ - $\quad-1.631,97$

FOTOCOPIAS ...........................

INTERNET $\quad-2.206,11$

PROPAGANDAS E PUBLICIDADES _.............. $\quad-72.037,03$

SEGUROS DIVERSOS

INSS S/PRO LABORE ........................................... $-11.347,20$

LICENCIAMENTOS.....................

HONORARIOS ADVOCATICIOS ....................

DESPESAS C/INFORMATICA $\quad-91738,19$

CONFRATERNIZACAO

CONFRATERNIZACAO....................... $\quad-6.155,49$

REFEIÇÖES E LANCHES...

ESTACIONAMENTOS...

DESPESAS DIVERSAS ... $\quad-5.316,00$

DESPESAS DIVERSAS... $\quad-75,00$

DESPESAS DIVERSAS...

$\begin{array}{rr}\text { CONSERV. MOVEIS E UTENSILIOS... } & -760,00 \\ \end{array}$

$-272.748,21$

$5.607 .372,30$

$-95.279,99$ 


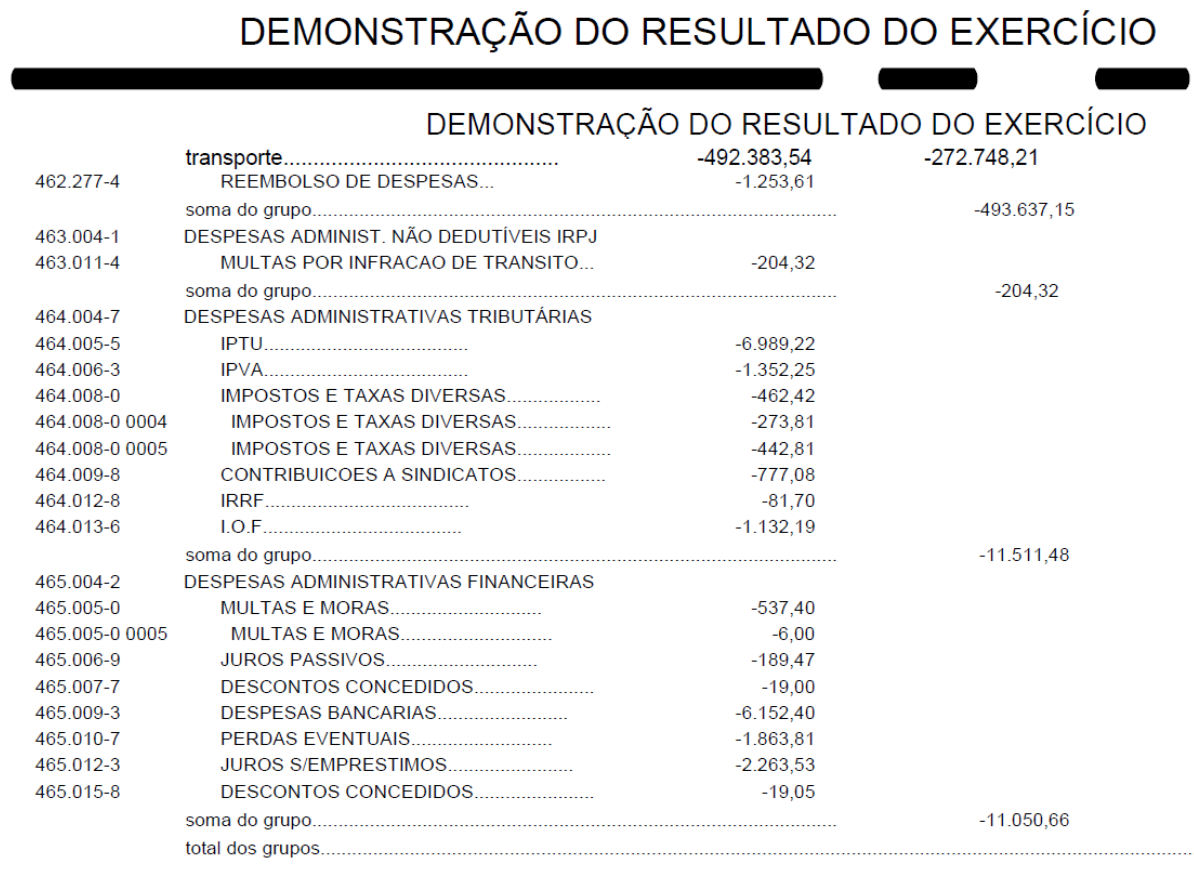

LUCRO OPERACIONAL

LUCRO OPERACIONAL II...

PROVISÕES P/MPOSTOS E CONTRIB. S/LUCROS

PROVISÕES P/ CONTRIBUIÇÕES S/ LUCRO

PROVISAO P/CONTR.SOCIAL -PRESUM/ESTIMAD

$-181.124,10$

soma do grupo.

$-181.124,10$

492.104-6

PROVISÕES PARA IMPOSTOS S/LUCRO

PROVISAO P/IRPJ - PRESUMIDO/ESTIMADO ....... $\quad-340.026,15$

soma do grupo. 